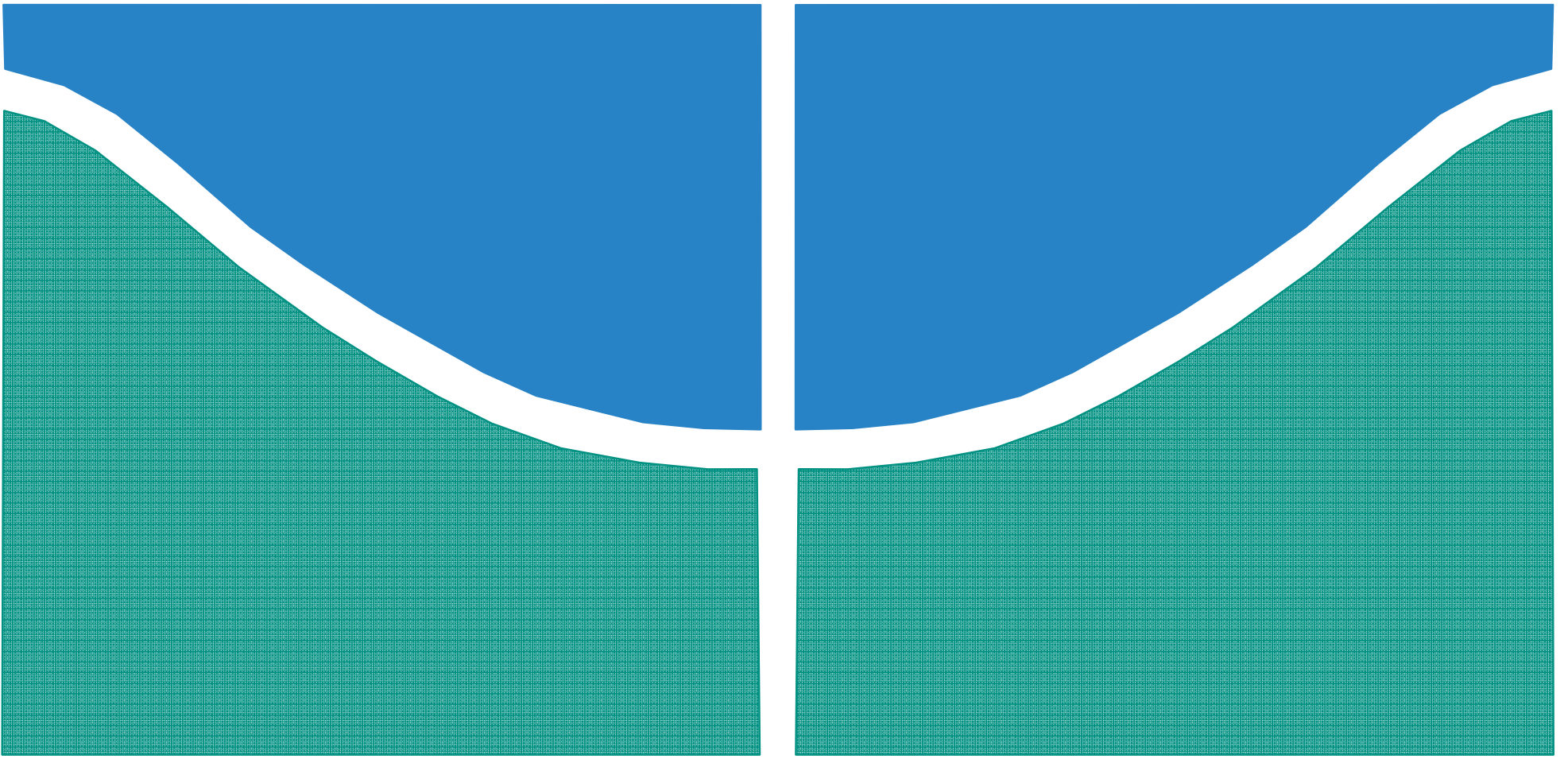

TRABALHO DE GRADUAÇÃO

\title{
UMA CONTRIBUIÇÃO PARA ANÁLISE DE VARIACÕES MOMENTÂNEAS DE TENSÃO
}

\author{
ARTHUR ASSUMPÇÃO \\ CLAUDIO ALEXANDRE FAUSTINO MATOS
}

Brasília, fevereiro de 2007

\section{UNIVERSIDADE DE BRASÍLIA}

\author{
FACULDADE DE TECNOLOGIA \\ Departamento de Engenharia Elétrica
}


UNIVERSIDADE DE BRASÍLIA

FACULDADE DE TECNOLOGIA

DEPARTAMENTO DE ENGENHARIA ELETRICA

\begin{abstract}
UMA CONTRIBUIÇÃO PARA ANÁLISE DE VARIAÇÕES
MOMENTÂNEAS DE TENSÃO.
\end{abstract}

\author{
ARTHUR ASSUMPÇÃO \\ CLAUDIO ALEXANDRE FAUSTINO MATOS
}

RELATÓRIO DE PROJETO FINAL SUBMETIDO AO DEPARTAMENTO DE ENGENHARIA ELÉTRICA DA FACULDADE DE TECNOLOGIA DA UNIVERSIDADE DE BRASÍLIA COMO PARTE DOS REQUISÍTOS NECESSÁRIOS PARA A OBTENÇÃO DO GRAU DE ENGENHEIRO ELETRICISTA.

APROVADO POR:

Prof. Anésio de Leles Ferreira Filho,(ENE-UnB) (Orientador)

Prof. Mauro Moura Severino,(ENE-UnB)

(Examinador Interno)

Prof. Marco Aurélio G. de Oliveira,(ENE-UnB)

(Examinador Interno)

BRASÍLIA/DF, 22 DE FEVEREIRO DE 2007 


\section{FICHA CATALOGRÁFICA}

ASSUMPÇÃO, ARTHUR; MATOS, CLAUDIO ALEXANDRE FAUSTINO.

Uma Contribuição para a Análise de Variações Momentâneas de Tensão [Distrito Federal] 2007.

xi, 88p., 210x297 mm (ENE/FT/UnB, Engenheiro, Engenharia Elétrica, 2007)

Projeto Final de Graduação - Universidade de Brasília. Faculdade de Tecnologia.

Departamento de Engenharia Elétrica.

1. Variações Momentâneas de Tensão $\quad$ 2. Caracterização

3. Classificação 4. Eletronorte

I. ENE/FT/UnB II. Título(série)

\section{REFERENCIA BIBLIOGRÁFICA}

ASSUMPÇÃO, A., MATOS, C. A. F. (2007). Uma Contribuição para Análise de Variações Momentâneas de Tensão. Projeto Final de Graduação em Engenharia Elétrica, Publicação ENE-0/07, Departamento de Engenharia Elétrica, Universidade de Brasília, Brasília, DF, 90p.

\section{CESSÃO DE DIREITOS}

AUTORES: Arthur Assumpção, Claudio Alexandre Faustino Matos.

ORIENTADOR: Anésio de Leles Ferreira Filho

TÍTULO: Uma Contribuição para a Análise de Variações Momentâneas de Tensão

GRAU: Engenheiro

ANO: 2007

É concedida à Universidade de Brasília permissão para reproduzir cópias deste relatório de projeto final de graduação e para emprestar ou vender tais cópias somente para propósitos acadêmicos e científicos. Os autores e o orientador reservam outros direitos de publicação e nenhuma parte desse relatório de projeto final de graduação pode ser reproduzida sem autorização por escrito do autor e do orientador.

Arthur Assumpção (AUTOR)

Claudio Alexandre Faustino Matos (AUTOR)

Anésio de Leles Ferreira Filho (ORIENTADOR) 


\title{
DEDICATÓRIA(S)
}

\author{
À minha família. \\ Aos meus pais, irmãos e avós. \\ Arthur Assumpção \\ Cláudio A. F. Matos
}




\section{AGRADECIMENTOS}

A Deus.

Aos meus pais, Antonio C. C. Assumpção e Rosangela B. F. Assumpção, pelo amor e auxílio durante toda minha vida.

Ao meu irmão, Diego Assumpção, pela alegria e otimismo nos momentos importantes.

Aos amigos Cláudio e Samuel, companheiros de trabalho, pelo entusiasmo e dedicação ao longo deste desafio.

Ao professor Anésio, pelo incentivo, paciência, apoio e dedicação.

Aos professores Damasceno, Ivan e Mauro pelas matérias ministradas que contribuíram para a base dos estudos dos sistemas de potência.

Aos amigos conquistados no decorrer do curso de graduação.

Ao amigo, Igor F. Cardoso, companheiro de muitas batalhas.

Arthur Assumpção

\section{A Deus,}

Aos meus pais, Antônio Alexandre e Dulce, pela confiança, amizade, apoio e amor em todos os momentos da vida.

Aos meus avós, Antônio e Ayda, por todo o apoio, carinho e credibilidade.

Aos meus irmãos Denise, Waleska, Sérgio e Patrícia pela paciência e pelos momentos de descontração.

Aos meus familiares, em especial Bianca, Lídia, Márcia, Celso, Zezinho e Yolanda, pelo eterno otimismo.

À Tuta por todo o incentivo, motivação, apoio e presteza ao longo deste trabalho.

Aos amigos Arthur e Samuel pelo companheirismo e dedicação para a concretização deste projeto.

Ao professor Anésio, pela dedicação e incentivo.

Aos velhos amigos e às novas amizades conquistadas na universidade.

Aos engenheiros Mauro Moura e Fritz. Mohn pela confiança depositada e pelo conhecimento compartilhado.

A todas as pessoas que colaboraram de alguma maneira com a minha formação.

Claudio Alexandre 


\section{S UMÁRIO}

Capítulo 1 .

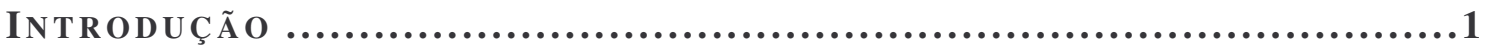

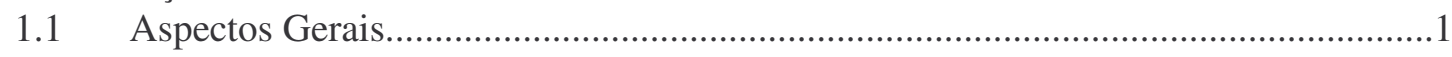

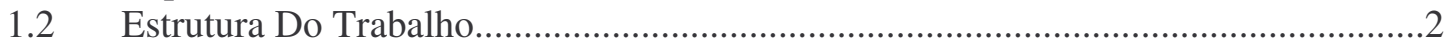

Capítulo 2 ....................................................................4

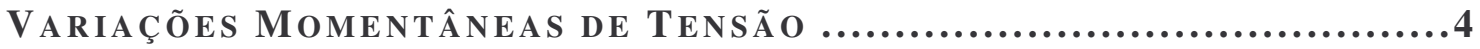

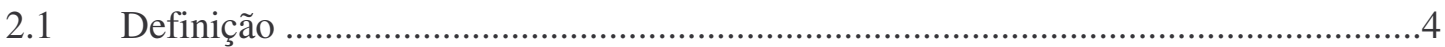

2.1.1 Afundamento de Tensão (voltage sag).............................................................

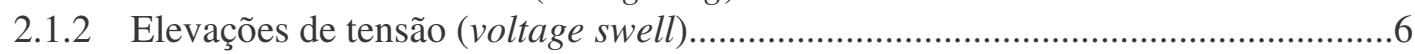

2.1.3 Interrupção de Tensão...................................................................................

2.2 Caracterização de Variações Momentâneas de Tensão...............................................8

2.2.1 Caracterização de Eventos Monofásicos............................................................. 8

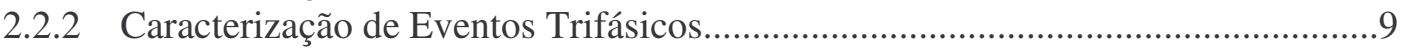

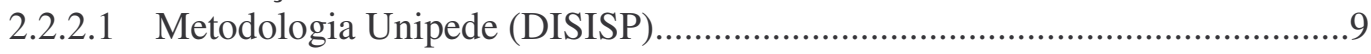

2.2.2.2 Metodologia do EPRI / ELECTROTEK (EUA).........................................10

2.2.2.3 Metodologia da NRS-048 (África do Sul).................................................11

2.2.2.4 Método Proposto por Bollen......................................................................12

2.2.2.5 Caracterização Através de um Parâmetro.........................................................13

2.2.2.5.1 Método da Perda de Tensão.................................................................13

2.2.2.5.2 Método da Perda de Energia.....................................................................14

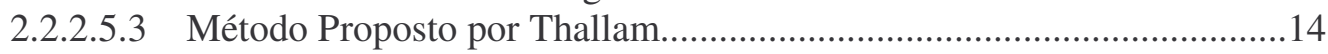

2.2.2.5.4 Método Proposto por Heydt..................................................................14

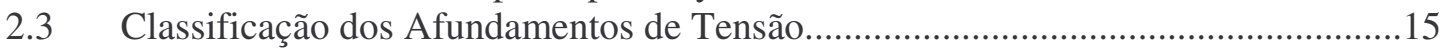

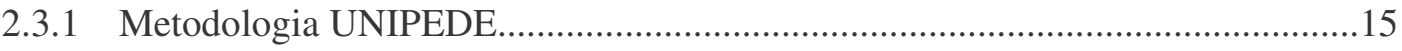

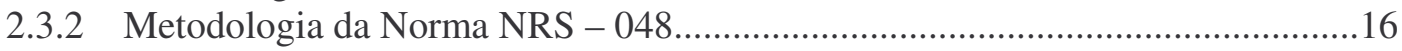

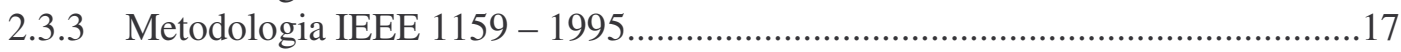

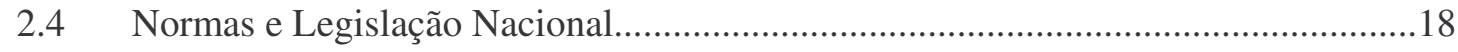

2.4.1 Procedimentos de Rede - Submódulo 2.2 e 2.8..................................................... 18

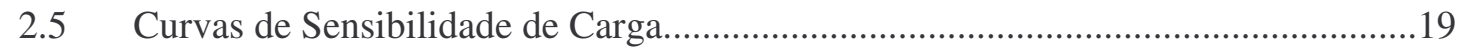

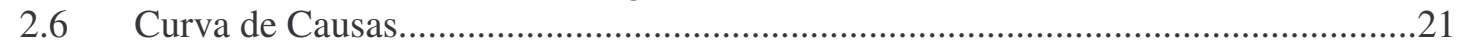

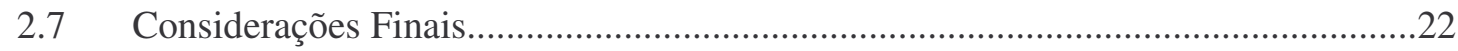

Capítulo 3 .................................................................23

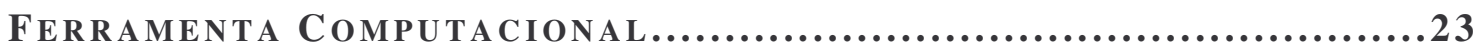

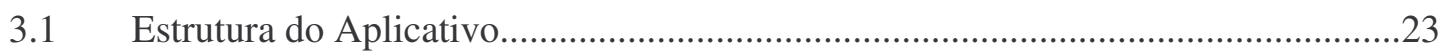

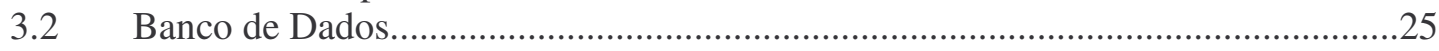

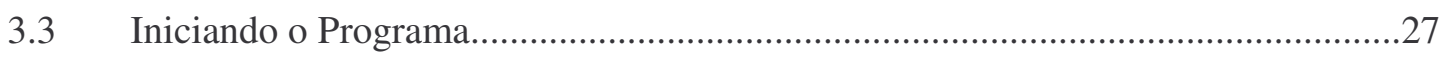

3.4 Módulo de Entrada - Leitura do Banco de Dados....................................................28

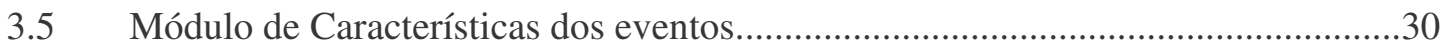

3.5.1 Estrutura do Módulo de características dos eventos...............................................30

3.5.2 Estudo de caso de caracterização de eventos.............................................................

3.5.2.1 Caracterização pela metodologia Unipede...................................................

3.5.2.2 Caracterização pela metodologia NRS - 048................................................34

3.5.2.3 Caracterização pela metodologia EPRI/ ELETROTEK..................................35

3.5.2.4 Caracterização pelos Parâmetros Únicos..........................................................36

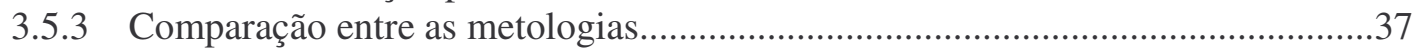

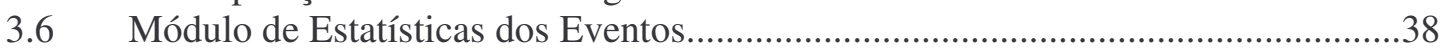

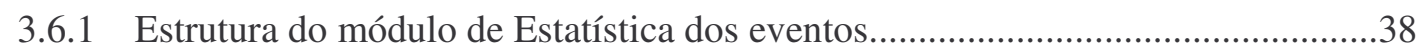

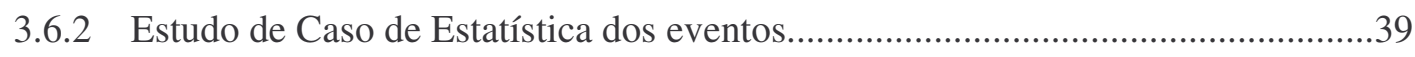


3.6.2.1 Distribuição do horário dos eventos..............................................................39

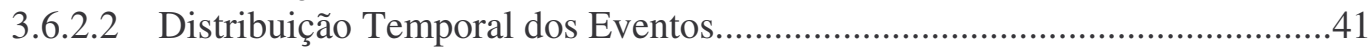

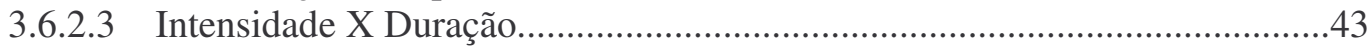

3.6.2.4 Quantidade X Intensidade e Quantidade X Duração....................................43

3.6.2.5 Distribuição dos Afundamentos por Fase.........................................................46

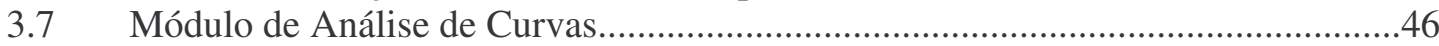

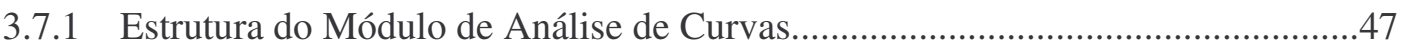

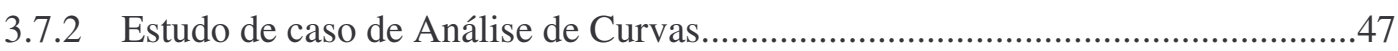

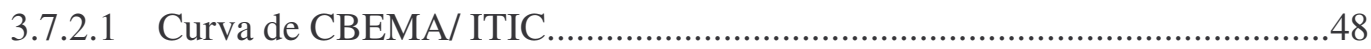

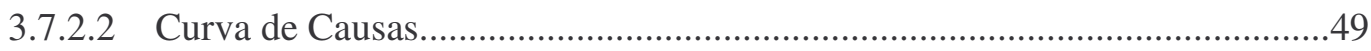

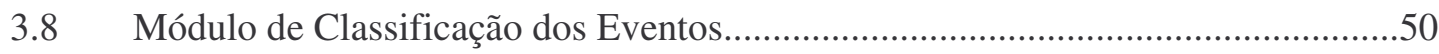

3.8.1 Estrutura do Módulo de Classificação dos Eventos .............................................50

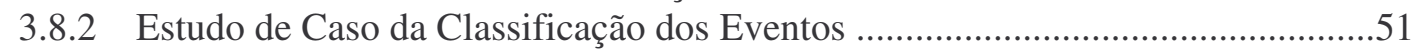

3.8.2.1 Metodologia UNIPEDE ( IEC 61000-2-8) ................................................51

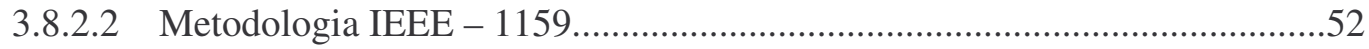

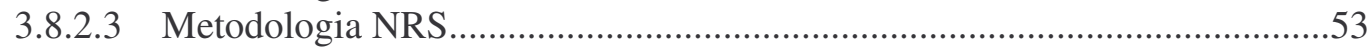

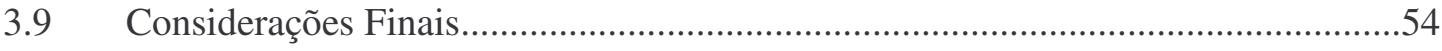

CAPÍt ULO 4 ..............................................................55

Análise Sistema Eletronorte......................................55

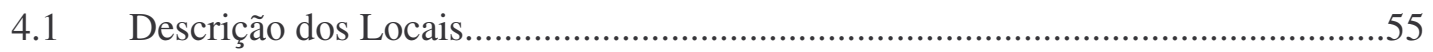

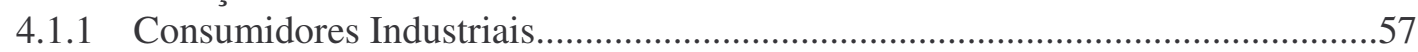

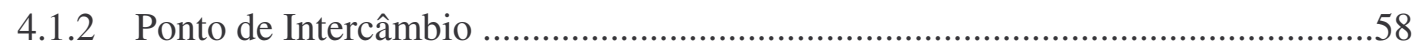

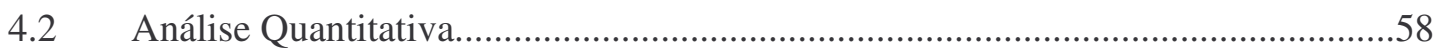

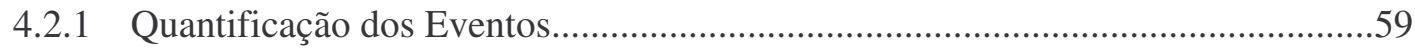

4.2.2 Análise de Ocorrências por Períodos do Dia.....................................................61

4.2.3 Análise Dias Úteis versus Final de Semana........................................................62

4.2.4 Análise entre Fases........................................................................................65

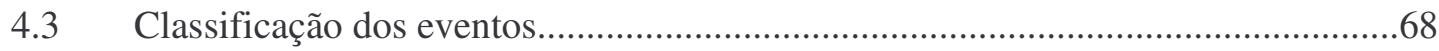

4.3.1 Classificação segundo a metodologia IEEE -1159..........................................68

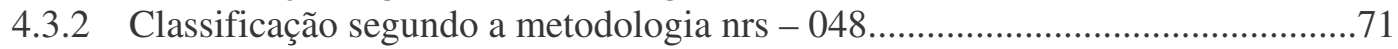

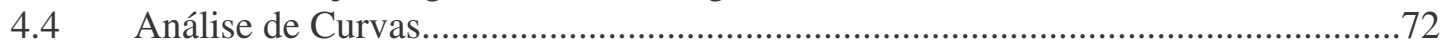

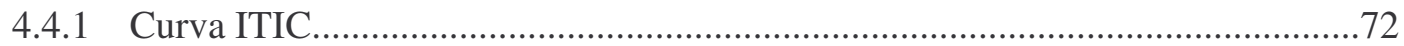

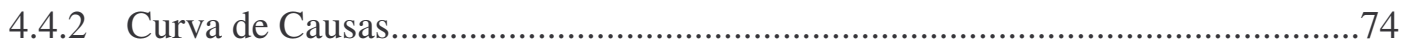

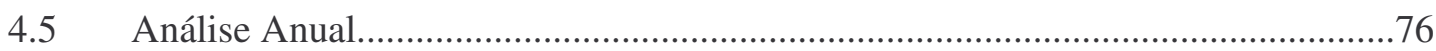

4.5.1 Metodologia Utilizada para Apresentação Anual dos Dados...............................76

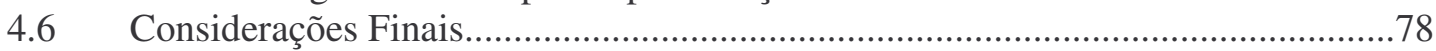

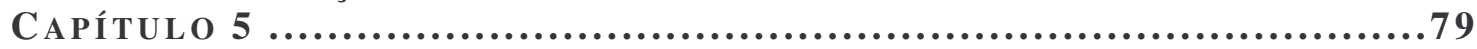

CONCLUSÃ O

REFERÊNCIAS BIBLIOGRÁFICAS.......................................82

ANEXO I......................................................................... 


\section{LISTA DE FIGURAS}

Figura 2.1 - Afundamento de tensão de $30 \%$ originado por uma falta fase-terra 5

Figura 2.2 - Afundamento de tensão causado pela partida de um motor $\quad 5$

Figura 2.3 - Elevação de tensão de $60 \%$ originado por uma falta fase-terra 6

Figura 2.4 - Interrupção momentânea devido a um curto circuito $\quad 7$

Figura 2.5 - Afundamento Monofásico 8

Figura 2.6 - Caracterização segundo metodologia da UNIPEDE $\quad 10$

Figura 2.7 - Caracterização segundo metodologia EPRI/ ELETROTEK 11

Figura 2.8 - Caracterização segundo metodologia da NRS $048 \quad 11$

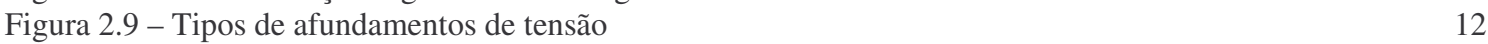

$\begin{array}{lr}\text { Figura 2.10 - Curva CBEMA } & 20\end{array}$

$\begin{array}{lr}\text { Figura } 2.11 \text { - Curva ITIC } & 20\end{array}$

Figura 2.12 - Curva de Causas dos Afundamentos 22

$\begin{array}{lr}\text { Figura } 3.1 \text { - Medidor ION } 7600 & 25\end{array}$

Figura 3.2 - Exemplo de banco de dados no Microsoft Excel 26

$\begin{array}{lr}\text { Figura } 3.3 \text { - Tela de apresentação } & 27\end{array}$

$\begin{array}{lr}\text { Figura } 3.1 \text { - Tela inicial } & 28\end{array}$

$\begin{array}{ll}\text { Figura } 3.5 \text { - Aviso de banco carregado } & 28\end{array}$

Figura 3.6 - Janela do módulo de entrada do programa (Banco de Dados). 29

Figura 3.7 - Janela do módulo de características dos eventos.

Figura 3.8 - Gráfico de Intensidade X Duração para um mês de monitoração por meio da metodologia 31

UNIPEDE.

Figura 3.9 - Gráfico de Intensidade X Duração com auxilio do recurso de Zoom 32

Figura 3.10- Gráfico de forma de onda do evento número 10 dos dados da Tabela 3.3. 33

Figura 3.11 - Dados RMS do evento número 10 dos dados da Tabela 3.3. 33

Figura 3.12 - Gráfico de Intensidade X Duração para um mês de medição norma NRS - 048.

Figura 3.13 - Gráfico de Intensidade X Duração para um mês de medição norma EPRI/ELETROTEK. 35

Figura 3.14 - Quadro onde se especifica os limiares de tensão para caracterização EPRI/ELETROTEK. 35

Figura 3.15 - Parâmetros do afundamento número 1 por fase e total. 36

Figura 3.16 - Tela da etapa de comparação entre os métodos de caracterização. 37

Figura 3.17 - Comparação de Intensidade e Duração para cada uma das metodologias. 37

Figura 3.18 - Janela do módulo de Estatísticas dos Eventos. 38

Figura 3.19 - Gráfico da distribuição dos eventos nos dias da semana. 39

Figura 3.20 - Gráfico da distribuição dos eventos nos fins de semana. $\quad 40$

Figura 3.21 - Probabilidade de ocorrência nos dias de semana. $\quad 40$

Figura 3.22 - Probabilidade de ocorrência nos finais de semana. $\quad 41$

Figura 3.23 - Gráfico da distribuição temporal dos eventos. 42

Figura 3.24 - Gráfico da distribuição da probabilidade temporal dos eventos. 42

Figura 3.25 - Gráfico da distribuição Intensidade X Duração. 43

Figura 3.26 - Gráfico da distribuição Quantidade X Intensidade. 44

Figura 3.27 - Gráfico da distribuição Quantidade X Duração. 44

Figura 3.28 - Gráfico da distribuição de probabilidade inversa acumulada por intensidade. 45

Figura 3.29 - Gráfico da distribuição de probabilidade acumulada por duração. 45

Figura 3.30 - Gráfico da distribuição de probabilidade de ocorrência de afundamentos por fase. 46

Figura 3.31 - Janela do módulo de análise de curvas. 47

$\begin{array}{ll}\text { Figura } 3.32 \text { - Janela de análise da curva CBEMA. } & 48\end{array}$

$\begin{array}{ll}\text { Figura } 3.33 \text { - Janela de análise da curva ITIC. } & 48\end{array}$

Figura 3.34 - Janela de análise da Curva de Causas. $\quad 49$

Figura 3.35 - Janela do módulo de classificação dos eventos. 50

Figura 3.36 - Classificação dos Eventos segundo metodologia UNIPEDE (IEC 61000-2-8). 51

Figura 3.37 - Classificação dos Eventos segundo metodologia UNIPEDE (IEC 61000-2-8) caracterizado 51

pelas norma UNIPEDE e NRS - 048 .
Figura 3.38- Classificação dos Eventos segundo metodologia IEEE - 1159.

$\begin{array}{ll}\text { Figura 3.38- Classificação dos Eventos segundo metodologia IEEE - } 1159 . & 52 \\ \text { Figura 3.39 - Classificação dos Eventos segundo metodologia NRS - 048. } & 53\end{array}$

Figura 3.40 - Classificação dos Eventos segundo metodologia NRS - 048/ UNIPEDE. 53

Figura 4.1 - Grandes consumidores industriais da Eletronorte. 56

Figura 4.2 - Linhas de intercâmbios entre submercados da Eletronorte. 56 
Figura 4.3 - Quantidade de eventos, elevações e afundamentos

Figura 4.4 - Gráfico da quantidade de eventos versus período do dia.

Figura 4.5 - Gráfico da quantidade de eventos versus período da semana 64

Figura 4.6 - Percentual de afundamentos por fase. 66

Figura 4.7 - Percentual de elevações por fase. $\quad 67$

Figura 4.8 - Quantidade de Eventos nas fases A, B e C 68

Figura 4.9 - Gráfico com a classificação de dez locais do sistema Eletronorte pela metodologia IEEE-1159 70

Figura 4.10 - Gráfico com a classificação de dez locais do sistema Eletronorte $\quad 72$

Figura 4.11 - Percentual de eventos por região da curva ITIC. $\quad 74$

Figura 4.12 - Percentual de eventos nas regiões 1 a 6.

Figura 4.13 - Percentual de eventos nas regiões das curvas de Causas. 76 


\section{LISTA DE TABELAS}

Tabela 2.1 - Classificação segundo UNIPEDE

Tabela 2.2 - Classificação dos afundamentos segundo a norma NRS - 048

Tabela 2.3 - Limite do Número de Afundamentos Anuais por Categoria 17

Tabela 2.4 - Classificação dos eventos segundo norma do IEEE 17

Tabela 2.5 - Classificação dos eventos segundo Procedimentos de Rede 19

Tabela 3.1 - Formato do banco de dados (tipo 1) 26

Tabela 3.2 - Dados do banco medido na subestação SE 02 29

Tabela 3.3 - Dados dos eventos 1,8 e 10 pela metodologia UNIPEDE. 32

Tabela 3.4 - Dados dos eventos 1,8 e 10 pela metodologia NRS - $048 \quad 34$

Tabela 3.5 - Dados dos eventos 1, 8 e 10 pela metodologia EPRI/ELETROTEK. 36

Tabela 3.6 - Número de afundamentos nos meses de setembro outubro e novembro 41

Tabela 3.7 - Quantidade de afundamentos por fase para os meses de setembro,outubro e novembro da Subestação Miracema

Tabela 4.1 - Quantificação dos Eventos nos Locais de Medição no período de outubro, novembro e dezembro de 2006

Tabela 4.2 - Participação em Porcentagem

Tabela 4.3 - Ocorrência de eventos por período do dia

Tabela 4.4 - Ocorrência de eventos Dias Úteis

Tabela 4.5 - Ocorrência de eventos Final de Semana

Tabela 4.6 - Participação percentual de afundamentos dias úteis versus final de semana.

Tabela 4.7 - Quantidade ocorrências de afundamentos nas três fases.

Tabela 4.8 - Percentual de afundamento nas três fases por local.

Tabela 4.9 - Quantidade ocorrências de elevações nas três fases

Tabela 4.10 - Classificação dos eventos em Albras L1 e L2, Alumar L1 e L2 e Alunorte segundo metodologia IEEE - 1159 .

Tabela 4.11 - Classificação dos eventos em Carajás, CCM, CVLD, Miracema e Tucurui segundo metodologia IEEE-1159.

Tabela 4.12 - Classificação dos eventos nos dez locais segundo a metodologia NRS - 048.

Tabela 4.13 - Quadro dos dados obtidos através da análise da curva ITIC dos dez locais em estudo.

Tabela 4.14 - Estimativa de ocorrência dos eventos em cada região da curva ITIC.

Tabela 4.15 - Percentual de ocorrência de eventos em cada região da curva de Causas.

Tabela 4.16 - Tabela do período mínimo de monitoração e precisão desejada.

Tabela 4.17 - Média semanal de ocorrência dos afundamentos. 


\section{Lista DE SÍMBOLOS}

\section{S Í M B O L O S}

Lv Perda de Tensão

$L_{E} \quad$ Perda de Energia

$E_{V S} \quad$ Energia do Afundamento de Tensão

$[\mathrm{W}]$

Vnom Tensão Nominal

$V(t) \quad$ Valor RMS de Tensão

S I G L A S

$\begin{array}{ll}\text { ANEEL } & \text { Agência Nacional de Energia Elétrica } \\ \text { CBEMA } & \text { Computer and Business Equipment Manufactures Association } \\ \text { CENELEC } & \text { Comité Européen de Normalisation Electrotechnique } \\ \text { ELECTROTEK } & \text { Electrotek Concepts, Inc. } \\ \text { ELETRONORTE } & \text { Centrais Elétricas do Norte do Brasil AS } \\ \text { EPRI } & \text { Electric Power Research Institute } \\ \text { IEC } & \text { International Eletrotechnical Commission } \\ \text { IEEE } & \text { Institute of Electrical and Electronics Engineers } \\ \text { ITIC } & \text { Information Technology Industry Curve } \\ \text { NRS } & \text { National Rationalised Specification } \\ \text { ONS } & \text { Operador Nacional do Sistema Elétrico } \\ \text { QEE } & \text { Qualidade da Energia Elétrica } \\ \text { RMS } & \text { Root Medium Square (valor eficaz) } \\ \text { VMT } & \text { Variação Momentânea de Tensão } \\ \text { VTCD } & \text { Variacão de Tensão de Curta Duração } \\ \text { UNIPEDE } & \text { Union of International Producers and Distributors of Elect. Energy }\end{array}$




\section{Capítulo 1 \\ I N T R O D U Ç Ã O}

\subsection{A S PECTOS GERAIS}

O assunto Qualidade da Energia Elétrica, ou simplesmente Qualidade da Energia (QE), ganhou maior destaque nos dias de hoje com a evolução tecnológica dos equipamentos eletrônicos que demandam um sinal isento de distorções na tensão e na corrente, para manterem um perfeito padrão de funcionamento.

Aliado ao desenvolvimento tecnológico cada vez mais presente nas sociedades, veio um incremento na exigência de obter-se energia com a qualidade necessária à preservação dos equipamentos e produção. Sendo assim, diante de um mercado globalizado e cada vez mais competitivo, onde há incessante procura por maior produtividade, redução de custos e qualidade nos serviços, torna-se indispensável a busca pelo desenvolvimento e melhoria da energia provida aos usuários, reduzindo-se as supressões econômicas advindas da poluição elétrica. (OLIVEIRA, 2005; AFONSO, MARTINS, 2004)

Destarte, prevê-se que será fundamental um melhor monitoramento da qualidade da energia elétrica, tanto em termos de controle de tensão como do ponto de vista de eliminação de diversos distúrbios que a afetam.

Um elevado número de interrupções nos processos industriais, mesmo sem interrupção no fornecimento de energia elétrica, tem sido verificado como resultado de distúrbios causados por defeitos, muitas vezes, a grandes distâncias do consumidor. Tais defeitos provocam variações momentâneas de tensão, que na literatura internacional têm sido denominadas de voltage sag (afundamento momentâneo da tensão) e voltage swell (elevação momentânea da tensão). Nestes casos, a monitoração da qualidade da energia elétrica representa uma providência essencial para a caracterização e identificação precisa dos fenômenos eletromagnéticos envolvidos que afetam as cargas sensíveis do consumidor.

A partir do diagnóstico obtido, podem-se identificar algumas alternativas para melhor compatibilizar os fenômenos intrínsecos ao sistema elétrico com as características de 
sensibilidade das cargas do consumidor. Algumas destas alternativas podem ser implementadas pelas empresas de energia no sentido de reduzir o número de ocorrências ou atenuar a severidade das mesmas.

Neste contexto, o desenvolvimento de metodologias direcionadas à análise de fenômenos de variação da tensão possui um grande valor, pois é a partir destas que será realizada a melhor avaliação dos fenômenos, e ainda será possibilitada uma diagnose sobre os sistemas de transmissão e distribuição de energia.

Como subsídio para o estudo e discussão do tema, o presente trabalho apresenta uma ferramenta computacional desenvolvida para a análise de bancos de dados contendo amostras armazenadas dos valores de tensão durante a ocorrência de elevações e/ou afundamentos no sistema (análise off-line). A ferramenta computacional permite a interpretação e comparação dos valores encontrados com os limites adotados nas principais normas e recomendações, tais como: Recomendações IEEE, Norma Sul-Africana NRS, Metodologia UNIPEDE, Metodologia EPRI/ELECTROTEK. São apresentadas as curvas CBEMA, ITIC e de causas, onde se podem extrair informações que permitem a comparação entre as incidências dos distúrbios e a sensibilidade das cargas.

Após a apresentação da ferramenta, será realizado, neste trabalho, um estudo aplicado ao sistema Eletronorte, efetuando uma análise conjunta de onze locais de medição, a saber: Albrás L1 e L2, Alumar L1 e L2, Alunorte, CCM, Carajás, CVLD, Marabá e Miracema. Tal pesquisa visa fornecer argumentos para a definição de indicadores e índices de referência confiáveis para a continuidade e conformidade da energia suprida pelo sistema.

\subsection{ESTRUTURA DO TRABALHO}

Este trabalho apresenta-se convencionalmente desenvolvido, conforme a seguinte a estrutura:

- Capítulo 2: Orientado a destacar os principais conceitos associados às variações momentâneas de tensão nos sistemas elétricos de potência, este tópico ilustra também um resumo das principais normas e recomendações nacionais e internacionais sobre o assunto.

- Capítulo 3: Dirigido a introduzir a ferramenta computacional para análise das variações momentâneas de tensão, exibindo sua estrutura, seus quatros módulos, que possibilitam as análises quantitativas, qualitativas e a caracterização dos eventos. Em um de seus itens é 
apresentado o banco de dados analisado no estudo de caso realizado na seqüência do capítulo.

- Capítulo 4: Voltado à análise dos onze pontos disponíveis no sistema Eletronorte, onde será realizada a análise global durantes três meses de medição, possibilitando assim a comparação entre os locais de análise.

- Capítulo 5: São realizadas a conclusões finais deste trabalho. 


\section{Capítulo 2}

\section{VARIAÇÕES MOMENTÂNEAS DE TENSÃO}

Neste capítulo, são abordados os tópicos concernentes ao entendimento das variações momentâneas de tensão. Inicialmente, é feita a definição do fenômeno e são expostas as metodologias de caracterização. Em seguida, é feita uma listagem das principais normas internacionais de classificação deste distúrbio. Ao final são mostradas as curvas de sensibilidade, que ilustram os efeitos deste distúrbio nos equipamentos eletrônicos.

\subsection{DEFINIÇÃ O}

As variações momentâneas de tensão apresentam duração típica entre 0,5 ciclo a 3 minutos, definidas pelo intervalo de tempo decorrido entre o instante em que o valor eficaz da tensão ultrapassa a faixa de tolerância e o instante em que a mesma retorna. Sendo esta, normalmente delimitada por um desvio de $10 \%$ acima ou abaixo da tensão de referência.

Este tipo de distúrbio está associado, principalmente, a faltas em sistemas de transmissão e de distribuição. Mas pode ser também causado pela energização de grandes cargas, partidas de grandes motores e pela corrente de energização de um transformador (SILVA, 2001).

Dependendo do local de ocorrência da falta, da origem causadora desta e das condições do sistema, a mesma pode vir a resultar tanto em um afundamento de tensão como em uma elevação, ou mesmo uma interrupção no suprimento de energia (DUGAN,1997).

\subsubsection{Afundamento de tensão (Voltage $S A G$ )}

Afundamento de tensão, também conhecido na literatura internacional como voltage sag ou voltage dip, são definidos como uma subtensão, caracterizados por uma redução no valor eficaz da tensão entre 0,1 e 0,9 pu e com duração entre 0,5 ciclo e 3 minutos (OLIVEIRA, 2005). Como exemplo tem-se a Figura 2.1, que mostra um afundamento de tensão típico, resultante de uma falta fase-terra. Observa-se um decréscimo de $30 \%$ na tensão por um período de aproximadamente 4 ciclos (DELMONT, 2003). 


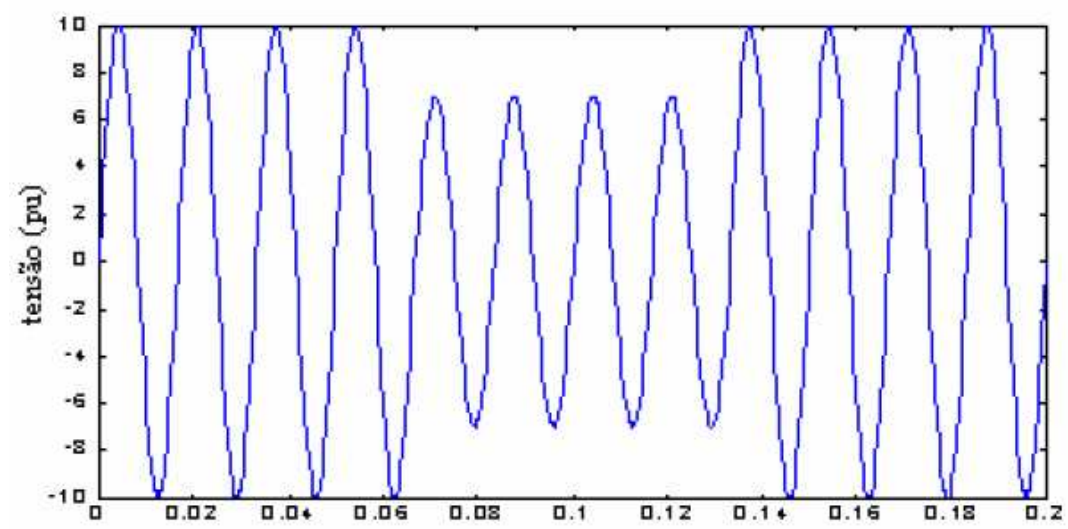

Figura 2.1 - Afundamento de tensão de 30\% originado por uma falta fase-terra (DELMONT, 2003).

Para ilustrar o afundamento de tensão causado pela partida de um motor de indução tem-se a Figura 2.2. Como é conhecido, durante a partida de um motor de indução, este absorve uma corrente de 6 a 10 vezes a corrente nominal, resultando em uma queda significativa na tensão de suprimento. Observa-se que, neste caso, a tensão cai rapidamente para 0,8 pu e, em um período de aproximadamente 3 segundos, retorna ao seu valor nominal (DELMONT, 2003).

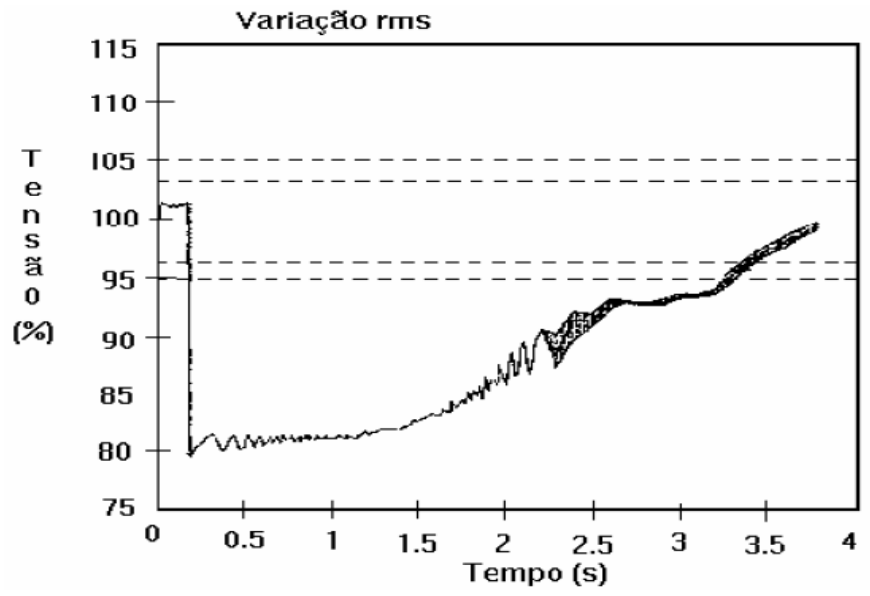

Figura 2.2 - Afundamento de tensão causado pela partida de um motor (DUGAN,1996).

O principal efeito destes distúrbios é o mau funcionamento dos equipamentos eletrônicos microprocessados, em especial os computadores. Entretanto, determinar os níveis de sensibilidade de tais equipamentos torna-se uma tarefa difícil, devido ao grande número de medições necessárias para a coleta de dados, aliado às dificuldades de se ter equipamentos de medição em condições reais de campo (OLIVEIRA, 2005). 
Neste sentido, algumas ferramentas como as curvas de sensibilidade de cargas, para a avaliação de efeitos dos afundamentos, são de grande importância. Estas permitem estimativas confiáveis sobre o comportamento dos equipamentos quando sujeitos à ocorrência destes distúrbios.

Afundamentos de tensão com período inferior a $10 \mathrm{~ms}$ e abaixo de $10 \%$ não são levados em consideração. Isto se explica pelo fato de que os distúrbios com período de duração abaixo de 10ms são considerados como transitórios e quedas de tensão menores de $10 \%$ são toleradas pela maioria dos equipamentos elétricos (DELMONT, 2003).

\subsubsection{ELEVAÇÃO DE TENSÃo (VOLTAGE SWELL)}

Elevação de tensão, ou ainda na literatura internacional, voltage swell, é definida como um aumento entre 1,1 e 1,8 pu na tensão eficaz, com duração entre 0,5 ciclo e 3 minutos (OLIVEIRA, 2005).

Assim como os afundamentos de tensão, as elevações de tensão estão geralmente associadas com as condições de falta do sistema, principalmente os curtos-circuitos fase-terra, visto que as fases não defeituosas tendem a sofrer uma elevação de tensão. Este fenômeno pode também estar associado à saída de grandes blocos de cargas ou à energização de grandes bancos de capacitores, porém ocorrendo em uma freqüência muito menor se comparada com as sobretensões provenientes de faltas fase-terra nos sistemas de transmissão e distribuição. A Figura 2.3 ilustra uma elevação de tensão causada por uma falta fase-terra (DUGAN,1996).

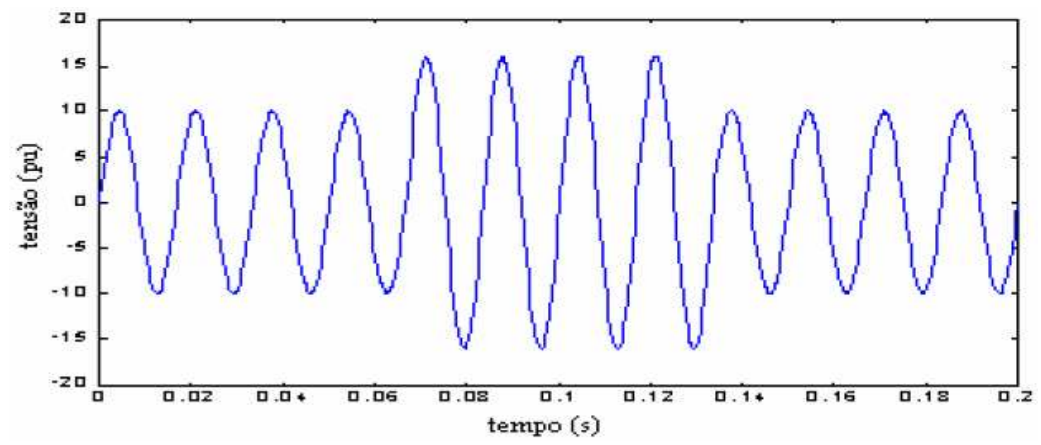

Figura 2.3 - Elevação de tensão de 60\% originado por uma falta fase-terra (DELMONT,2003). 
As elevações de tensão são caracterizadas pelas magnitudes (valores eficazes) e suas durações. A severidade de uma elevação de tensão durante uma condição de falta é função do local da falta, da impedância do sistema e do aterramento do mesmo. A duração da elevação está intimamente ligada aos ajustes dos dispositivos de proteção, à natureza da falta (permanente ou temporária) e a sua localização na rede elétrica. Em situações de elevação de tensão oriundas de saídas de grandes cargas ou energização de grandes bancos de capacitores, o tempo de duração da elevação depende da resposta dos dispositivos reguladores de tensão das unidades geradoras, do tempo de resposta dos transformadores de tap variável e da atuação de compensadores síncronos que porventura existam no sistema (DELMONT, 2003).

\subsubsection{INTERRUPÇÃo DE TENSÃO}

Uma interrupção de curta duração ocorre quando a tensão de suprimento atinge um valor menor que 0,1 pu por um período de tempo não-superior a 3 minutos.

As interrupções podem ser causadas por faltas no sistema de energia, falhas de equipamentos e mau funcionamento de sistemas de controle (DUGAN, 1996).

Algumas interrupções podem ser precedidas por um afundamento de tensão quando estas são devidas a faltas no sistema supridor. O afundamento de tensão ocorre no período de tempo entre o início de uma falta e a operação do dispositivo de proteção do sistema. A Figura 2.4 mostra uma interrupção momentânea devido a um curto-circuito, posteriormente a um afundamento de tensão de 80\% (DELMONT, 2003).

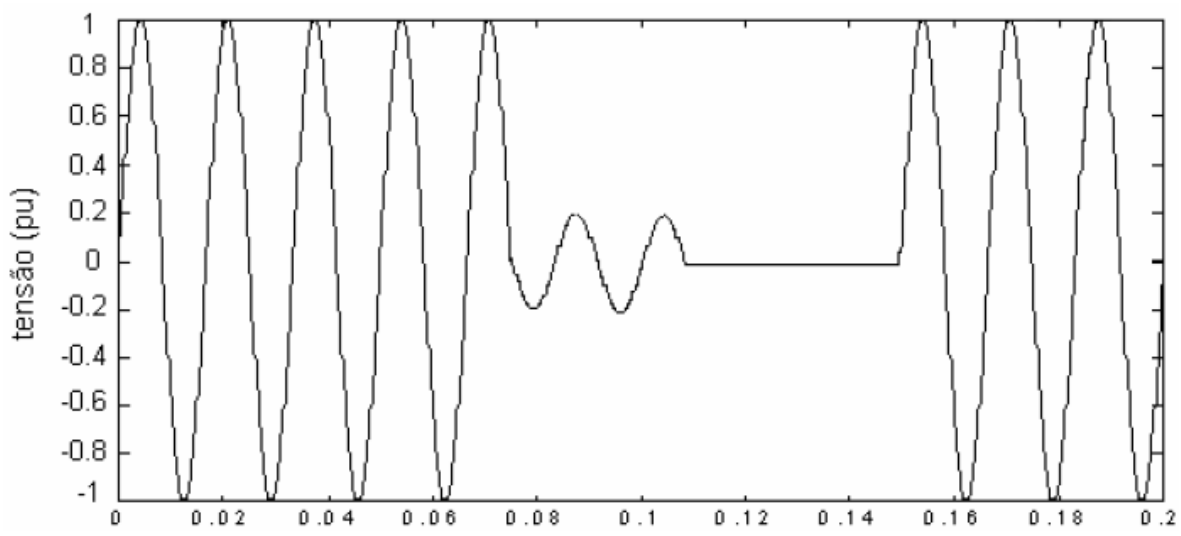

Figura 2.4 - Interrupção momentânea devido a um curto circuito (DELMONT,2003). 


\subsection{CaracterizaÇão de VARIAÇões Momentâneas de Tensão}

A caracterização convencional das VMTs se dá por meio dos parâmetros magnitude e duração. No entanto, há de se diferenciar a forma de caracterização de eventos em sistemas monofásicos dos eventos em sistemas trifásicos.

\subsubsection{CaracterizaÇão de Eventos Monofásicos}

A partir do comportamento do valor eficaz da tensão em função do tempo pode ser determinada a intensidade e a duração do evento. A intensidade do afundamento de tensão é o menor valor da tensão remanescente durante a ocorrência do evento. A duração do evento é o tempo durante o qual o valor eficaz da tensão permanece abaixo do patamar de 0,90 p.u. da tensão de referência (nominal, pré-falta, operativa, etc.). Pode-se observar de uma melhor forma os conceitos de intensidade e duração através do evento mostrado na Figura 2.5.

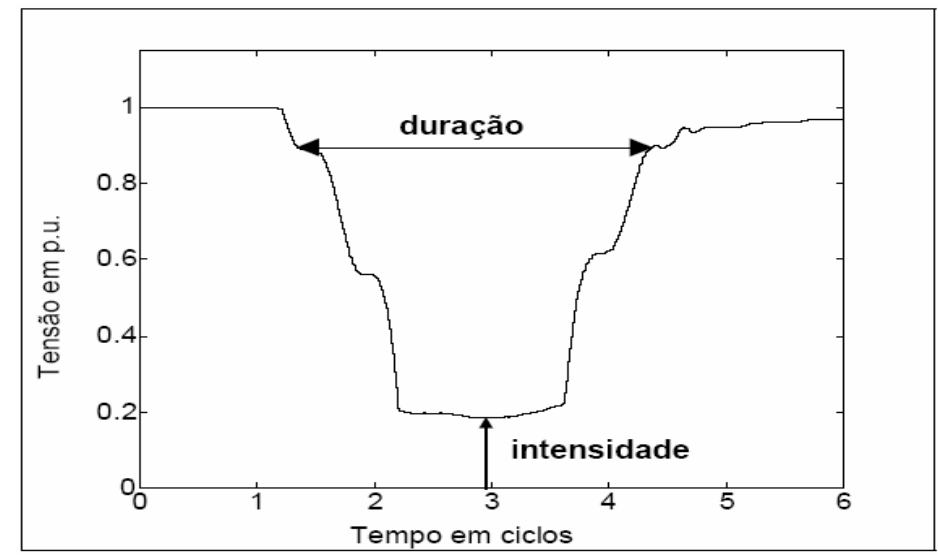

Figura 2.5 - Afundamento Monofásico (LEBORGNE, 2003).

A Figura 2.5 ilustra um afundamento de tensão que, segundo a definição acima, possui duração de aproximadamente 3 ciclos e intensidade de 0,2 pu.

Da mesma forma, para a caracterização das elevações de tensão tem-se sua duração definida como o tempo durante o qual o valor EFICAZ da tensão permanece acima do patamar de 1,1 
p.u. da tensão de referência. A intensidade é determinada pela máxima magnitude alcançada durante o período do evento.

\subsubsection{CARACTERIZAÇÃo de Eventos Trifásicos}

Uma ocorrência no sistema de potência pode afetar uma, duas ou as três fases. A intensidade e a duração do afundamento de tensão resultante em cada fase podem diferenciar-se substancialmente. Logo, deve-se definir como os eventos trifásicos são caracterizados, de acordo com a metodologia ou recomendação escolhidas, observando que estas diferem entre si em alguns aspectos.

\subsubsection{METODOLOGIA UNIPEDE (DISISP)}

A União Internacional de Produtores e Distribuidores de Energia Elétrica, uma associação da European Industry of Eletricity, é responsável por várias campanhas de medição em diferentes países da Europa (França, Itália, Alemanha, Suíça e outros), resultando no estabelecimento de normas e indicadores para o abastecimento de energia, e ainda verificando a qualidade da energia fornecida .

Na metodologia UNIPEDE, a intensidade de um afundamento de tensão é definida pela intensidade da fase que apresenta a maior queda do valor eficaz de tensão ocorrida entre as três fases, tomando como medida os desvios percentuais em relação à tensão nominal. Por sua vez, a duração do afundamento de tensão é dada pelo período de tempo decorrido a partir do instante em que a tensão de uma das fases foi inferior ao limite de $90 \%$, até o instante em que

a tensão de todas as fases seja superior a este limite, observando aqui a agregação (embaralhamento) das fases. A Figura 2.6 ilustra um afundamento trifásico. 


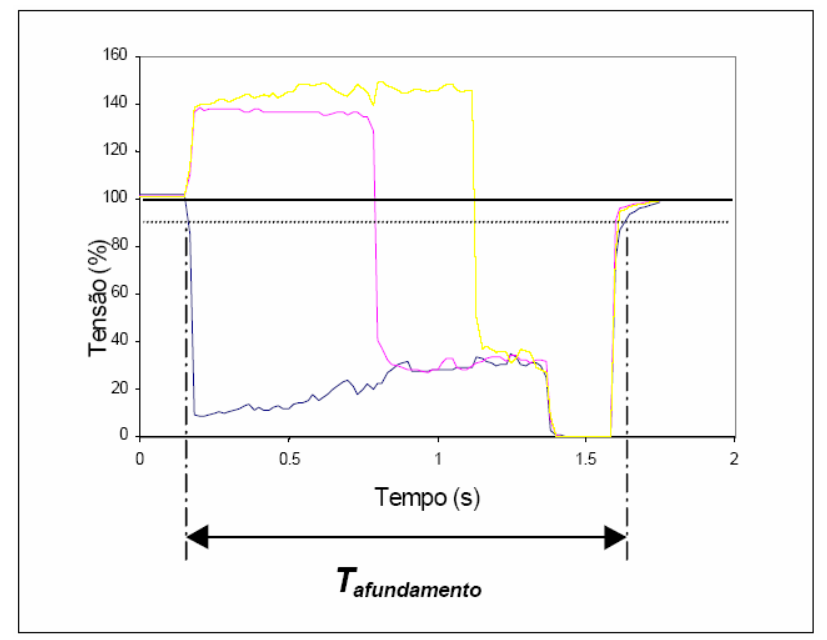

Figura 2.6 - Caracterização segundo metodologia da UNIPEDE (LEBORGNE,2003).

Com base na definição da UNIPEDE na Figura 2.6 se observa um afundamento de tensão cuja duração correspondente a $T_{\text {afundamento, }}$ e sua intensidade é 1 p.u.

\subsubsection{METODOLOGIA DO EPRI / ELECTROTEK (EUA)}

O Electric Power Research Institute é uma instituição independente, criada em 1973, com a intenção de fornecer estudos e resoluções em relação ao fornecimento de energia e à qualidade deste. Os membros e organizações associadas ao EPRI correspondem a 90\% de toda energia gerada nos Estados Unidos da América, sendo desta forma o principal instituto de pesquisa relacionado à qualidade da energia no país.

Segundo esta metodologia, a caracterização é definida pelo par intensidade e duração. A intensidade é determinada pela mínima tensão remanescente registrada durante o evento. E a duração pelo período de tempo em que o valor eficaz da tensão na fase representativa, ou seja, fase em que ocorre o maior desvio, viola um limite específico de tensão indicado para avaliar o distúrbio.

Esta norma ainda contempla de maneira diferenciada os casos de afundamentos que não possuem formato retangular, atribuindo a estes durações conforme limiares específicos. Para melhor esclarecimento desta abordagem, considere o evento apresentado na Figura 2.7. 


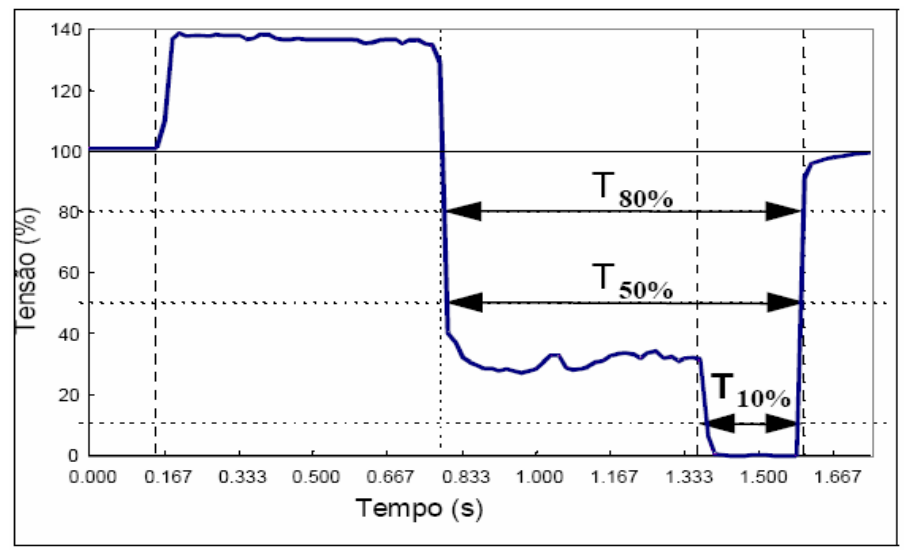

Figura 2.7 - Caracterização segundo metodologia EPRI/ ELETROTEK (LEBORGNE, 2003).

A Figura 2.7 demonstra a duração do afundamento avaliado segundo três limiares: 80\%, 50\% e 10\%. Sendo os valores T80\%, T50\% e T10\% representativos às durações para os afundamentos cujas intensidades atingem $80 \%, 50 \%$ e $10 \%$, respectivamente.

\subsubsection{Metodologia da NRS-048 (África do SUl)}

Elaborada pela South African Electricity Suply Industry e aprovada pelo National Electricity Regulator, é fundamentada em diversas normas internacionais, tendo como principais, as diretrizes estabelecidas pela IEC e CENELEC.

De acordo com a norma, a intensidade de um afundamento de tensão trifásico é definida como a maior queda do valor eficaz da tensão ocorrida nas três fases, tomada como o desvio percentual em relação a uma tensão declarada, por exemplo a tensão nominal ou a tensão operativa do sistema. Sua duração é caracterizada como sendo a duração associada à pior fase afetada (fase representativa) durante a ocorrência do evento. A Figura 2.8 apresenta a caracterização de um afundamento de tensão segundo esta metodologia.

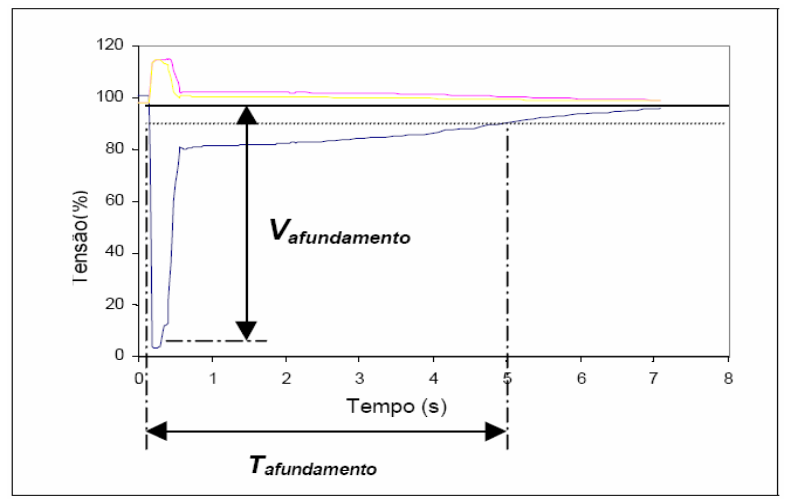

Figura 2.8 - Caracterização segundo metodologia da NRS 048 (LEBORGNE, 2003). 
De acordo com a norma, temos um afundamento de tensão de intensidade $\mathrm{V}_{\text {afundamento }} \mathrm{e}$ duração $\mathrm{T}_{\text {afundamento }}$ Raciocínio análogo deve ser tomado para a caracterização da elevação presente.

\subsubsection{MÉtodo Proposto POR Bollen}

Ao contrário de outros métodos que caracterizam os afundamentos de tensão pelo par intensidade e duração, o método proposto por Bollen considera a assimetria e o desequilíbrio dos fasores de tensão durante a ocorrência do distúrbio, o que permite uma melhor avaliação dos efeitos de variações momentâneas de tensão em equipamentos trifásicos (BOLLEN, 1998).

O método considera diversos tipos de faltas; as conexões (delta e estrela) utilizadas nos equipamentos elétricos e nos enrolamentos dos transformadores. Ainda assume-se que as impedâncias de seqüência positiva e negativa da fonte são iguais, resultando em quatro tipos principais de afundamentos de tensão mostrados na Figura 2.9.

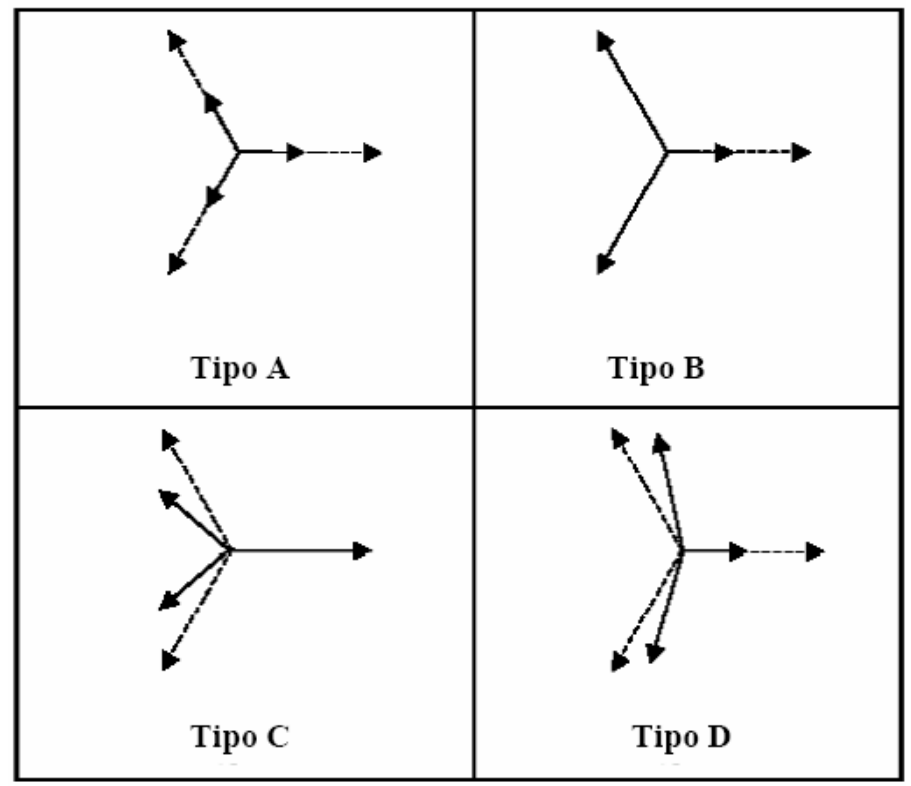

Figura 2.9 - Tipos de afundamentos de tensão (BOLLEN, 1998). 
Nota-se que as faltas do tipo A e tipo B sofrem alterações somente no módulo do fasor de tensão, enquanto as faltas do tipo C e D sofrem alterações tanto no módulo quanto no ângulo de fase do fasor. Estas características estão diretamente relacionadas à origem da falta, sendo o tipo A devido às faltas trifásicas e os tipos B, C e D devidos às faltas bifásicas e às monofásicas. Os afundamentos tipo C e D são devidos a faltas Fase-Terra, Fase-Fase e Fase-Fase-Terra.

Deve-se ressaltar que o tipo de afundamento percebido nos terminais de uma carga não depende somente do tipo da falta original. Como exemplo, um afundamento do tipo C pode se transformar em um afundamento tipo D quando se propaga através de um transformador com conexão $\Delta / Y$. E ainda um afundamento tipo $\mathrm{C}$ será enxergado como sendo do tipo D quando a carga está conectada entre fases.

\subsubsection{CaracterizaÇão Através de um Parâmetro}

Algumas propostas têm sido apresentadas para caracterizar os eventos através de um único parâmetro. Embora isto leve à perda de informação, o método a um parâmetro simplifica a comparação entre eventos, entre desempenho de locais específicos (barras) e sistemas. A grande desvantagem do método é que seu resultado não se relaciona diretamente com o comportamento dos equipamentos que sofreram com as alterações medidas.

\subsection{MÉtodo dA PERda de TENSÃo}

A perda da tensão $\left(\mathrm{L}_{V}\right)$ é definida como a integral da queda de tensão durante o afundamento, de acordo com a Equação 2.1 (IEEE P1564, 2000).

$$
L_{V}=\int\left\{1-\frac{V(t)}{V_{n o m}}\right\} d t
$$


Onde:

Vnom - tensão nominal no local de medição;

$V(t)$ - valor eficaz da tensão durante o afundamento.

\subsection{Método da Perda de Energia}

A perda de energia $\left(\mathrm{L}_{\mathrm{E}}\right)$ é definida como a integral da queda de energia durante o evento, considerando a carga como sendo do tipo impedância constante. A Equação 2.2 mostra como pode ser realizado este cálculo (IEEE P1564, 2000)..

$$
L_{E}=\int\left\{1-\left\{\frac{V(t)}{V_{\text {nom }}}\right\}^{2}\right\} d t
$$

\subsection{Método Proposto por Thallam}

A proposta de Thallam define a energia do afundamento de tensão conforme Equação 2.3 (IEEE P1564, 2000).

$$
E_{V S}=\int\left\{1-\frac{V(t)}{V_{\text {nom }}}\right\}^{2} d t
$$

\subsection{MÉtodo Proposto POR HeYdT}

Heydt considera que a curva de sensibilidade dos equipamentos representa uma curva de energia constante. Eventos localizados abaixo da curva de sensibilidade possuem um valor de energia menor do que limiar de sensibilidade da carga e, portanto, provocam o desligamento da mesma (IEEE P1564, 2000).

Assim, adotando a envoltória inferior da curva CBEMA, ilustrada na Figura 2.10, como uma curva padrão de sensibilidade, obtém-se a Equação 2.4. Portanto, a metodologia de Heydt mede quanto os eventos se afastam desta curva de referência. 


$$
W=\int\left\{1-\frac{V(t)}{V_{\text {nom }}}\right\}^{3,14} d t
$$

\subsection{ClassificaÇão dos Afundamentos de Tensão.}

Conforme visto nos itens anteriores, existem diversos métodos para caracterização dos afundamentos e elevações de tensão. Estes métodos objetivam obter os parâmetros dos eventos que, em sua maioria, são apenas a amplitude e a duração.

Para a etapa de classificação dos eventos, as metodologias atribuem intervalos que enquadram as variações momentâneas de tensão em faixas divididas por intensidade e duração. As principais metodologias estão descritas a seguir.

\subsubsection{METOdologia UNIPEDE}

A classificação dos afundamentos de tensão segundo a metodologia UNIPEDE é definida pela norma IEC 61000-2-8. Para um determinado intervalo a tabela indica o número de afundamentos de tensão registrados para cada faixa de intensidade e duração. A divisão dos eventos conforme faixas de intensidade e duração em conformidade com a norma, pode ser observada na Tabela 2.1.

Tabela 2.1 - Classificação segundo UNIPEDE.

\begin{tabular}{|l|c|c|c|c|c|c|c|}
\hline $\begin{array}{l}\text { Intensidade / } \\
\text { Duração }\end{array}$ & $\begin{array}{c}0,5-1 \\
\text { ciclo }\end{array}$ & $\begin{array}{c}1 \text { ciclo }- \\
100 \mathrm{~ms}\end{array}$ & $\begin{array}{c}100 \mathrm{~ms}- \\
500 \mathrm{~ms}\end{array}$ & $\begin{array}{c}500 \mathrm{~ms}- \\
1 \mathrm{~s}\end{array}$ & $\begin{array}{c}1 \mathrm{~s}- \\
3 \mathrm{~s}\end{array}$ & $\begin{array}{c}3 \mathrm{~s}- \\
20 \mathrm{~s}\end{array}$ & $\begin{array}{c}20 \mathrm{~s}- \\
3 \mathrm{~min}\end{array}$ \\
\hline $70-90 \%$ & & & & & & & \\
\hline $40-70 \%$ & & & & & & & \\
\hline $1-40 \%$ & & & & & & & \\
\hline$<1 \%$ & & & & & & & \\
\hline
\end{tabular}




\subsubsection{Metodologia da NORMA NRS - 048}

A norma NRS - 048 também classifica os afundamentos em intervalos de intensidade e duração, caracterizando cada região através das letras X, Y, S, Z, T. Deve-se ressaltar, que a definição dos limites de tempo entre as regiões e suas faixas de amplitude estão diretamente relacionadas com os tempos de atuação dos sistemas de proteção de transmissão e distribuição. A Tabela 2.2 mostra estas regiões.

Tabela 2.2 - Classificação dos afundamentos segundo a norma NRS - 048.

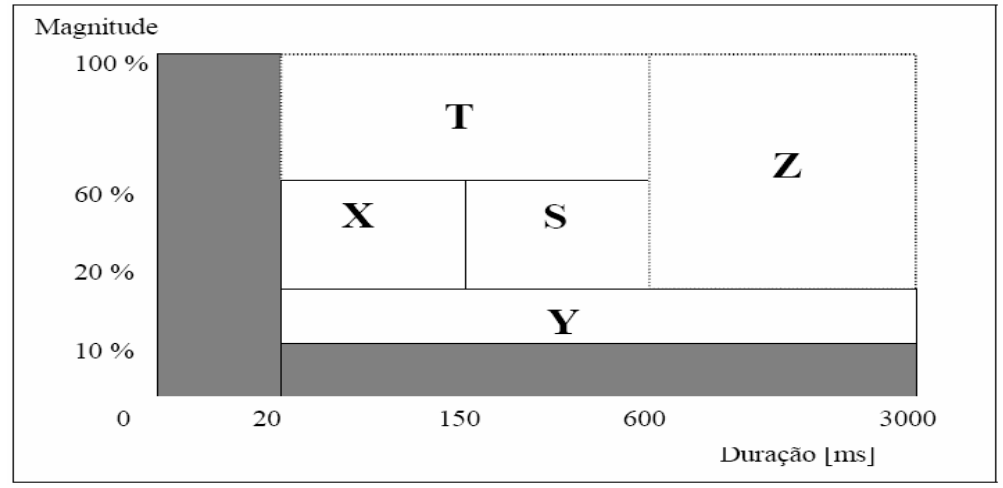

Uma breve análise das regiões revela informações bastante relevantes para a forma de classificação adotada. Na região Y tem-se os eventos de até 0,8 pu. Não ocorre a divisão da região por intervalos de tempo devido à maioria das cargas suportarem afundamentos nesta região sem apresentarem falhas. A região X, em que tem-se a duração de 20 ms até $150 \mathrm{~ms}$ e intensidade entre 0,8 pu e $0,4 \mathrm{pu}$, relaciona-se diretamente a defeitos ocorridos no sistema de transmissão. Na região S, em que a duração é definida pelo intervalo entre 150 a $600 \mathrm{~ms}$, temse os defeitos relacionados ao sistema de distribuição.

Os eventos da região $\mathrm{T}$ abrangem aqueles de grande intensidade e de curta duração e os eventos em Z são de grande duração. Eles podem levar um grande número de cargas sensíveis à interrupção.

A norma NRS 048 ainda estabelece limites para o número aceitável de afundamentos de tensão por ano, para cada tipo de afundamento. Estes limites são definidos por classe de tensão e por tipo de sistema, ou seja, urbano, rural, etc. A Tabela 2.3 mostra estes limites. 
Tabela 2.3 - Limite do Número de Afundamentos Anuais por Categoria.

\begin{tabular}{|c|c|c|c|c|c|}
\hline \multicolumn{7}{|c|}{ Número de Afundamentos de Tensão Por Ano } \\
\hline $\begin{array}{c}\text { Faixa de Tensão } \\
{[\mathrm{KV}]}\end{array}$ & $\mathbf{Z}$ & $\mathbf{T}$ & $\mathbf{S}$ & $\mathbf{X}$ & $\mathbf{Y}$ \\
\cline { 2 - 6 } & 20 & 30 & 30 & 100 & 150 \\
\hline $\mathbf{6 , 6}<\mathbf{4 4}$ & 49 & 54 & 69 & 215 & 314 \\
\hline $\mathbf{6 , 6}<\mathbf{4 4}$ (rural) & 16 & 25 & 25 & 80 & 120 \\
\hline $\mathbf{4 4}<\mathbf{1 3 2}$ & 5 & 6 & 11 & 45 & 88 \\
\hline $\mathbf{2 2 0}<\mathbf{7 6 5}$ & \multicolumn{5}{c}{} \\
\hline
\end{tabular}

\subsubsection{Metodologia IEEE 1159 - 1995}

Na Tabela 2.4 apresenta-se a classificação dos eventos segundo a norma IEEE 1159-1995.

Esta norma não classifica os afundamentos de tensão segundo a sua intensidade, somente distingue os afundamentos pela sua duração.

Tabela 2.4 - Classificação dos eventos segundo norma do IEEE.

\begin{tabular}{|c|c|c|}
\hline Categoria & Duração & Intensidade p.u. \\
\hline \multicolumn{3}{|l|}{ Instantâneo } \\
\hline Afundamento & 0,5 até 30 ciclos & 0,1 até 0,9 \\
\hline Elevação & 0,5 até 30 ciclos & 1,1 até 1,8 \\
\hline \multicolumn{3}{|l|}{ Momentâneo } \\
\hline Interrupção & 0,5 ciclos até $3 \mathrm{~s}$ & $<0,1$ p.u. \\
\hline Afundamento & 30 ciclos até $3 \mathrm{~s}$ & 0,1 até 0,9 \\
\hline Elevação & 30 ciclos até $3 \mathrm{~s}$ & 1,1 até 1,8 \\
\hline \multicolumn{3}{|l|}{ Temporário } \\
\hline Interrupção & $3 \mathrm{~s}$ até $1 \mathrm{~min}$ & $<0,1$ p.u. \\
\hline Afundamento & $3 \mathrm{~s}$ até $1 \mathrm{~min}$ & 0,1 até 0,9 \\
\hline Elevação & $3 \mathrm{~s}$ até $1 \mathrm{~min}$ & 1,1 até 1,8 \\
\hline
\end{tabular}




\subsection{Normas E Legislação NaCiOnAL}

No Brasil, a responsabilidade da indicação de parâmetros e normas com relação à ocorrência, caracterização e classificação das variações momentâneas de tensão, são atribuídas ao Operador Nacional do Sistema (ONS) através dos Procedimentos de Rede.

\subsubsection{Procedimentos de Rede - Submódulo 2.2 E 2.8}

São documentos elaborados em conjunto com os Agentes e homologados pela ANEEL, estabelecendo requisitos e procedimentos técnicos para o planejamento, implantação, uso e operação do Sistema Interligado Nacional. Sendo este submódulo o responsável por estabelecer "Padrões de Desempenho da Rede Básica".

Pelos critérios estabelecidos no procedimento, a Variação da Tensão de Curta Duração tem amplitude definida pelo valor extremo do valor eficaz (média quadrática) da tensão em relação à tensão nominal do sistema no ponto considerado, enquanto perdurar o evento. A duração é determinada pelo intervalo de tempo decorrido entre o instante em que o valor eficaz da uma das fases, em relação à tensão nominal do sistema no ponto considerado, ultrapassa determinado limite e o instante em que todas estas voltam a cruzar este limite. Sendo para as elevações o limite de 1,1 pu e para os afundamentos o limite de 0,9 pu.

No entanto, nesta legislação, para verificar o desempenho da rede, são permitidas outras formas de agregação das fases, sendo estas:

- Agregação por parâmetros críticos - a duração do evento é definida como a máxima duração entre os três eventos fase-neutro, ou seja, se escolhe a fase em que o evento teve maior duração como a representativa.

- Agregação pela fase crítica - a duração do evento é definida como a duração do evento fase neutro de amplitude crítica, ou seja, amplitude mínima para afundamento e máxima para elevação. 
A recomendação também classifica os eventos de acordo com a duração e intensidade, de acordo com a Tabela 2.5.

Tabela 2.5- Classificação dos eventos segundo Procedimentos de Rede.

\begin{tabular}{|c|c|c|c|}
\hline Classificação & Denominação & $\begin{array}{l}\text { Duração da } \\
\text { Variação }\end{array}$ & $\begin{array}{l}\text { Amplitude da tensão } \\
\text { (valor eficaz) em relação } \\
\text { à tensão nominal }\end{array}$ \\
\hline $\begin{array}{l}\text { Variação } \\
\text { Momentânea de } \\
\text { Tensão }\end{array}$ & $\begin{array}{l}\text { Interrupção } \\
\text { Momentânea de } \\
\text { Tensão }\end{array}$ & $\begin{array}{c}\text { Inferior ou igual a três } \\
\text { segundos }\end{array}$ & inferior a $0,1 \mathrm{pu}$ \\
\hline $\begin{array}{l}\text { Variação } \\
\text { Momentânea de } \\
\text { Tensão }\end{array}$ & $\begin{array}{l}\text { Afundamento } \\
\text { Momentâneo de } \\
\text { Tensão }\end{array}$ & $\begin{array}{l}\text { Superior ou igual a } \\
\text { um ciclo e inferior ou } \\
\text { igual a três segundos }\end{array}$ & $\begin{array}{l}\text { superior ou igual a } 0,1 \mathrm{e} \\
\text { inferior a } 0,9 \mathrm{pu}\end{array}$ \\
\hline $\begin{array}{l}\text { Variação } \\
\text { Momentânea de } \\
\text { Tensão }\end{array}$ & $\begin{array}{l}\text { Elevação } \\
\text { Momentânea de } \\
\text { Tensão }\end{array}$ & $\begin{array}{l}\text { Superior ou igual a } \\
\text { um ciclo e inferior ou } \\
\text { igual a três segundos }\end{array}$ & superior a $1,1 \mathrm{pu}$ \\
\hline $\begin{array}{l}\text { Variação Temporária } \\
\text { de Tensão }\end{array}$ & $\begin{array}{l}\text { Interrupção } \\
\text { Temporária de } \\
\text { Tensão }\end{array}$ & $\begin{array}{c}\text { superior a três } \\
\text { segundos e inferior } \\
\text { ou igual a um minuto }\end{array}$ & inferior a $0,1 \mathrm{pu}$ \\
\hline $\begin{array}{l}\text { Variação Temporária } \\
\text { de Tensão }\end{array}$ & $\begin{array}{l}\text { Afundamento } \\
\text { Temporário de } \\
\text { Tensão }\end{array}$ & $\begin{array}{c}\text { superior a três } \\
\text { segundos e inferior } \\
\text { ou igual a um minuto }\end{array}$ & $\begin{array}{l}\text { superior ou igual a } 0,1 \mathrm{e} \\
\text { inferior a } 0,9 \mathrm{pu}\end{array}$ \\
\hline $\begin{array}{l}\text { Variação Temporária } \\
\text { de Tensão }\end{array}$ & $\begin{array}{l}\text { Elevação Temporária } \\
\text { de Tensão }\end{array}$ & $\begin{array}{c}\text { superior a três } \\
\text { segundos e inferior } \\
\text { ou igual a um minuto }\end{array}$ & superior a $1,1 \mathrm{pu}$ \\
\hline
\end{tabular}

\subsection{Curvas de Sensibilidade de CARga}

As curvas de sensibilidade de carga têm por objetivo relacionar o impacto causado pelas VMTs com a sensibilidade de equipamentos eletro-eletrônicos, o que permite uma análise mais embasada quanto à severidade de um evento medido em relação a seu efeito.

Introduzida em 1978 por Thomas Key, a curva CBEMA (Computer Business Equipment Manufacturer Association), publicada na norma IEEE-446, foi originalmente desenvolvida para a análise da sensibilidade de computadores mainframe. No entanto, posteriormente esta também foi utilizada para outros equipamentos elétricos como equipamentos 
microprocessados, microcomputadores, etc (CARVALHO, 2000). A Figura 2.10 apresenta a curva CBEMA.

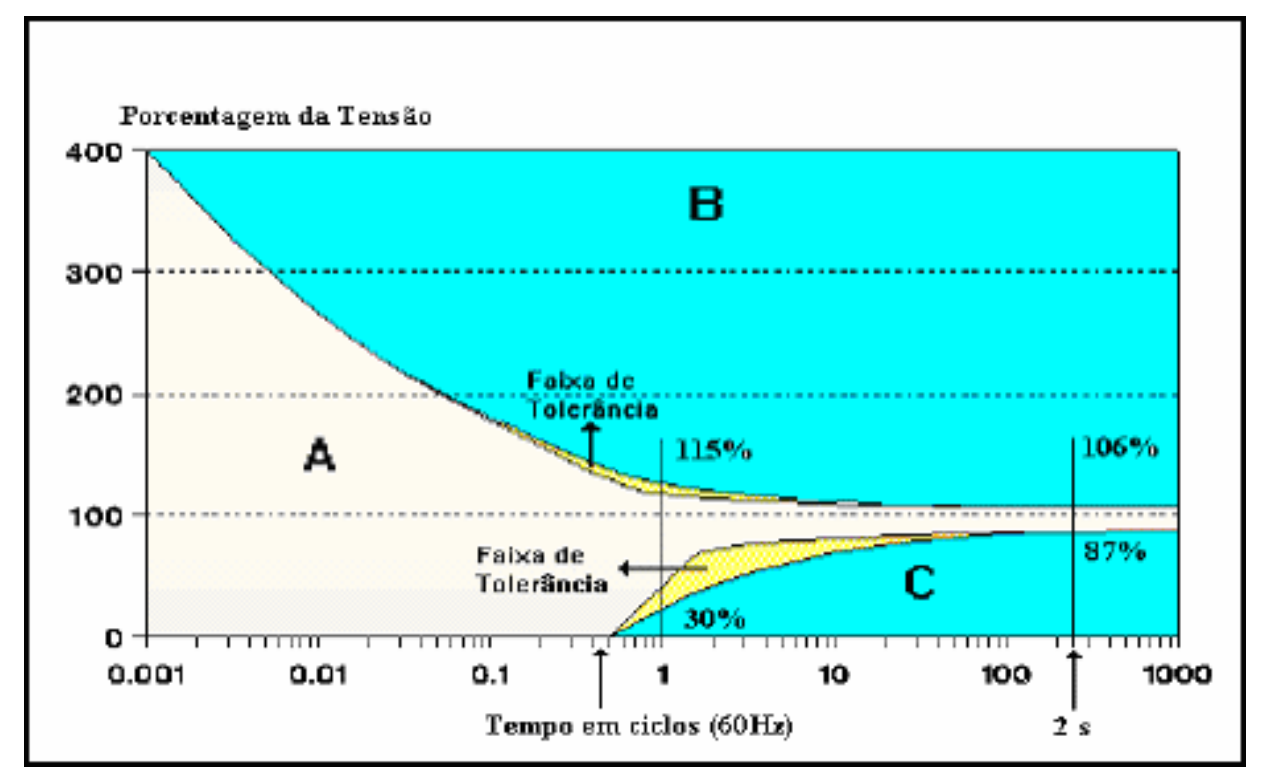

Figura 2.10 - Curva CBEMA.

Posteriormente, para uma melhor adaptação à sensibilidade dos modernos equipamentos e dispositivos eletrônicos, a curva CBEMA foi modificada trazendo como resultado a curva ITIC (Information Tecnology Industry Council). A curva ITIC é apresentada na Figura 2.11.

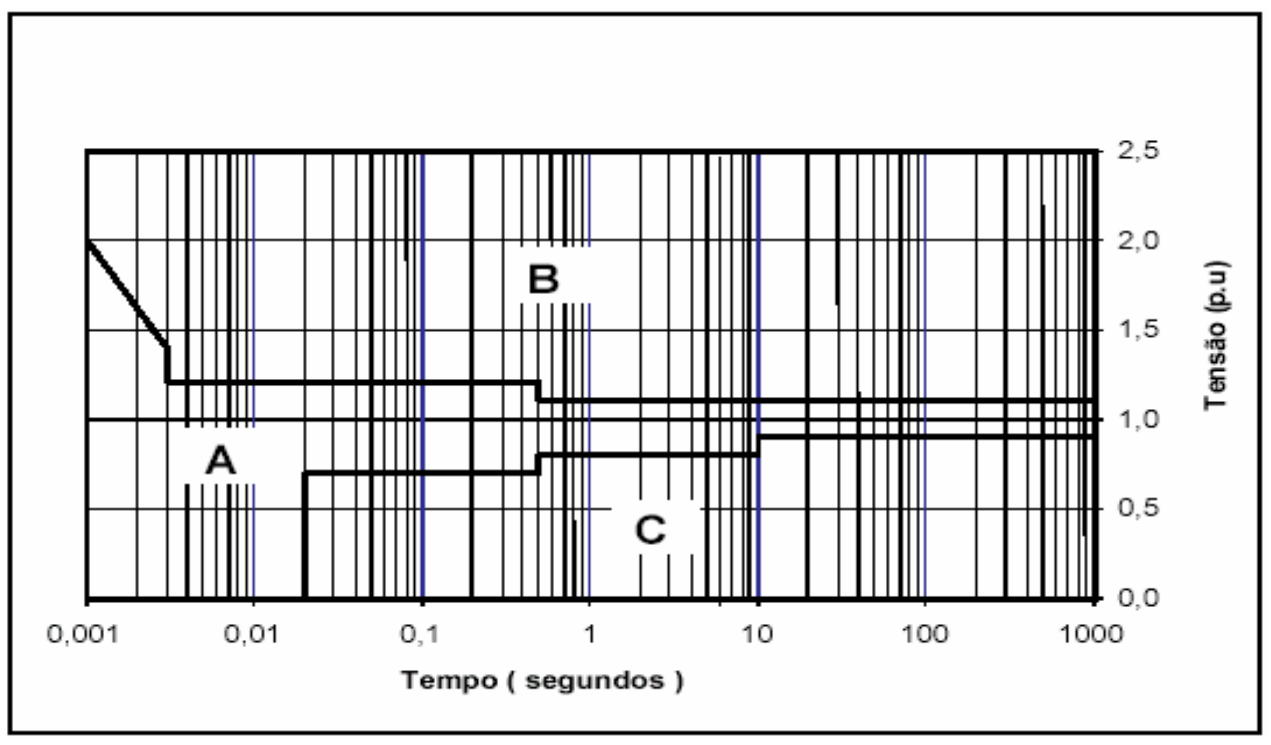

Figura 2.11 - Curva ITIC(LEBORGNE, 2003). 
Observa-se na curva CBEMA e na curva ITIC a existência de três regiões de operação.

A região A representa a região de imunidade, ou seja, a ocorrência de eventos dentro desta área não representará problemas aos equipamentos, resultando assim na operação normal do equipamento eletrônico.

A região $\mathrm{B}$ é denominada região de susceptibilidade. A ocorrência de elevações de tensão nesta área pode provocar danos aos equipamentos, como por exemplo, a ruptura da isolação. Os danos causados ao equipamento, nesta região, são de natureza permanente, resultando até mesmo na inutilização permanente deste.

A região $C$ é chamada região de sensibilidade. A ocorrência de afundamentos de tensão nesta área pode ocasionar a parada de operação. Contudo, ao contrário da região B, aqui não existe a possibilidade de danos permanentes ao equipamento.

Vale ressaltar ainda que a IEC (International Electrotechnical Commission), apesar de não fornecer uma curva de sensibilidade, estabelece níveis para testes em equipamento eletrônicos e sua sensibilidade frente a afundamentos de tensão (IEC 61000-4-11).

\subsection{Curva de Causas}

Na seção precedente foram mostradas as curvas CBEMA e ITIC. Estas curvas representam os efeitos das VMTs em equipamentos eletrônicos. Como o próprio nome denota, a curva de causas tenta encontrar uma possível causa de acordo com a duração e a intensidade. Na Figura 2.12 são mostradas diversas regiões delimitadas, cujos números representam as seguintes origens para afundamentos (BOLLEN, 1998):

1. Faltas no sistema de Transmissão;

2. Faltas no sistema de distribuição remoto; 
3. Faltas no sistema de distribuição local;

4. Partida de grandes motores;

5. Interrupções Curtas;

6. Fusíveis.

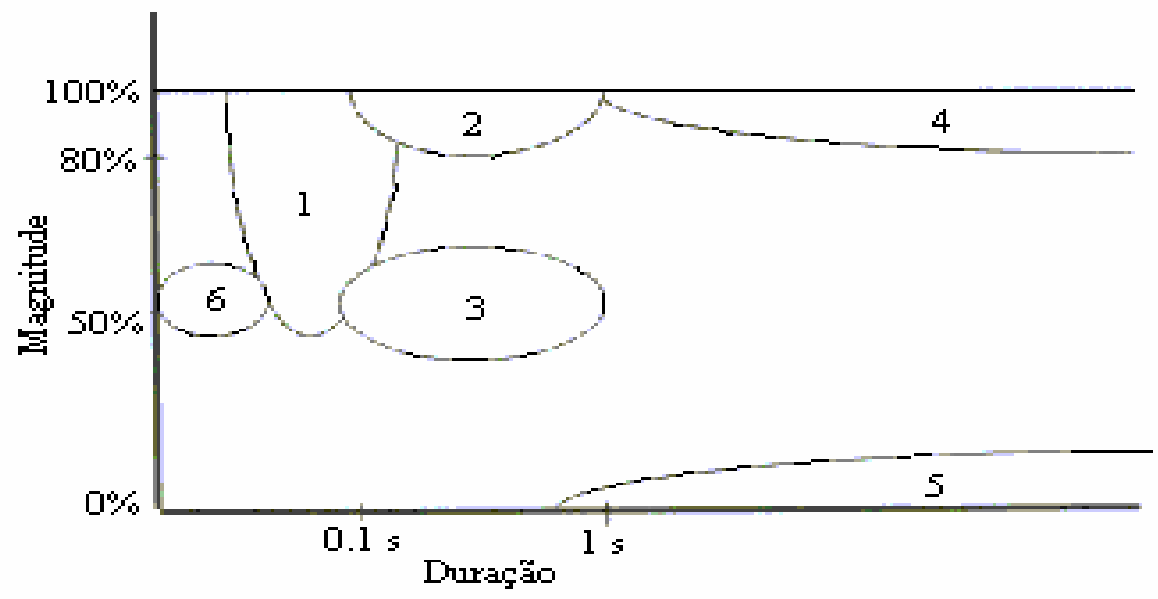

Figura 2.12 - Curva de causas dos afundamentos (BOLLEN, 1998).

\subsection{CONSIDERAÇõeS FinaIS}

Este capítulo apresentou os fundamentos básicos das variações momentâneas de tensão, bem como um resumo das principais normas e recomendações internacionais sobre esse distúrbio, suas principais caracteristicas .

No capítulo seguinte será apresentada a ferramenta computacional desenvolvida para análise e qualificação das variações momentâneas de tensão, e posteriormente, o estudo do sistema ELETRONORTE, proposto. 


\section{Capítulo 3}

\section{FERRAMENTACOMPUTACIONAL}

O presente capítulo se presta a apresentar a ferramenta computacional desenvolvida, intitulada PROGRAMA DE QUALIDADE DA ENERGIA ELÉTRICA - MÓDULO DE VARIACÕES MOMENTÂNEAS DE TENSÃO. O software consiste em uma ferramenta para auxiliar a quantificação, caracterização e classificação das Variações Momentâneas de Tensão presentes no sistema elétrico, valendo-se de recursos gráficos e análises simples e objetivas. Sua motivação está baseada em três questões fundamentais:

- A necessidade de um tratamento gráfico e estatístico das elevações e afundamentos de tensão;

- A possibilidade de uma análise das Variações Momentâneas de Tensão a partir de dados medidos (análise off-line) em qualquer ambiente, observando e comparando os resultados com os limites estabelecidos pelas principais normas e recomendações internacionais;

- A grande quantidade de dados gerados pelas medições.

\subsection{ESTRUTURA DO APLICATIVO}

O aplicativo, ou software, que será apresentado a seguir foi desenvolvido por meio do programa "MATLAB 7.0". Mais que um software líder na área de computação numéricocientífica, o MATLAB é um ambiente integrado de computação numérica e modelamento de sistemas, adotado como ferramenta de desenvolvimento padrão pelas principais universidades e empresas no Brasil e no mundo.

O MATLAB é o núcleo de um ambiente de computação numérica baseado em matrizes que integra:

- Funções de tratamento numérico de alta performance;

- Sofisticados recursos de geração de gráficos para visualização de dados;

- Linguagem de programação de alto nível. 
Para a execução do aplicativo e para a instalação do MATLAB 7.0, recomenda-se um microcomputador Pentium IV - 1.5 GHz ou superior com, no mínimo, 512 MB de RAM.

O aplicativo é constituído por cinco módulos, descritos sucintamente a seguir:

- Módulo de Entrada (Leitura do Banco de Dados): A partir dele tem-se acesso aos outros módulos do programa, onde serão realizadas as análises. É onde é feito o carregamento do banco de dados desejado para análise. Também são mostradas informações sobre o banco.

- Características dos eventos: Ao selecionar este módulo é feita uma análise para a extração dos dois principais parâmetros para a caracterização das Variações Momentâneas de tensão. São eles: intensidade e duração. Em seguida visualiza-se os diferentes afundamentos ou elevações de tensão em um gráfico. Selecionando-se os eventos, obtêm-se imediatamente os parâmetros das VMTs. É possível ainda comparar os valores de intensidade e duração caracterizados pelas principais normas e recomendações internacionais. Este módulo permite também a caracterização de afundamentos de acordo com a metodologia de um único parâmetro.

- Estatísticas dos eventos: Neste módulo obtêm-se diferentes gráficos, possibilitando verificar a frequiência de ocorrência das Variações Momentâneas de Tensão sob a ótica de dias, de diferentes períodos do dia, da intensidade, da duração, dos dias da semana, bem como das fases.

- Análise de Curvas: Neste módulo é realizada a plotagem dos eventos sobre as curvas ITIC e CBEMA, bem como a curva de causas. Estas permitem ao usuário visualizar as possíveis causas e as conseqüências de cada evento sobre os equipamentos.

- Classificação segundo as Normas: Módulo que enquadra cada um dos eventos em diferentes níveis segundo as metodologias IEEE 1159, IEC e NRS - 048. Ainda é possível realizar a comparação das classificações resultantes de diferentes métodos de caracterização. 


\subsection{B A NCO DE DADOS}

Para a captura das amostras de Variações Momentâneas de Tensão é necessário dispor de instrumentos de medição específicos. No caso do banco de dados analisado neste trabalho, utilizou-se o medidor ION 7600. Trata-se de um medidor trifásico composto de quatro entradas de tensão e cinco entradas de corrente. A Figura 3.1 ilustra o painel frontal deste equipamento:

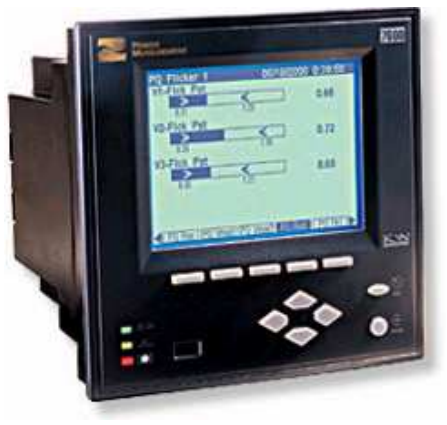

Figura 3.1 - Medidor ION 7600

Colhidos os dados, é necessário gerar o banco de dados como arquivo de planilha com extensão "xls". O arquivo pode ser gerado manualmente no Microsoft Excel, desde que obedeça ao padrão estabelecido pelo aplicativo:

- O arquivo deve possuir 3 planilhas: a primeira com os dados do local de medição; a segunda contém os dados dos afundamentos, denominada SAG_SWELL; e a terceira os valores eficazes medidos em High Speed de acordo com uma janela deslizante de largura de 1 ciclo, tomada ponto a ponto durante o processo de amostragem.

- Na planilha SAG_SWELL, inicia-se com uma linha que informará as grandezas medidas: horário, duração, tensão nas três fases, tensão nominal, tensão de referência para o afundamento e tensão de referência para a elevação.

- A primeira coluna deverá ser a do horário. O arquivo gerado a partir do medidor já traz as informações de data e hora da medição.

- Após a coluna do tempo, estarão as colunas com valores de duração, tensão mínima medida (p.u), tensão máxima medida (p.u), tensão média (p.u), referência para afundamento, referência para elevação e a tensão nominal.

- Na terceira planilha estão armazenados os dados instantâneos das variações de energia. Assim que foi detectada a violação, em uma das fases, do valor referenciado de tensão limite da planilha 2, o equipamento de medição começa a medir a tensão 
instantânea nas três fases, permanecendo até que todas restabeleçam seus valores acima ou abaixo da tolerância.

- É imprescindível que sejam feitos alguns ajustes nos valores das primeiras colunas das planilhas 2 e 3. Com a planilha Microsoft Excel aberta, deve-se selecionar toda a primeira coluna, clicar com o botão direito e, na opção formatar, mudar o formato dos dados de data para número com 10 casas decimais.

- É também fundamental que os títulos das planilhas 2 e 3 sejam renomeados, respectivamente, para SAG_SWELL e RMS, o que possibilitará ao usuário permutar a posição destas.

A Tabela 3.1 resume o formato de banco de dados aceito pelo programa, e a Figura 3.2 ilustra esse banco.

Tabela 3.1 - Formato do banco de dados (tipo 1).

\begin{tabular}{|c|c|c|c|c|c|c|c|c|c|}
\hline Tempo & Duração & $\mathbf{V}_{\text {fase Min }}$ & $\mathbf{V}_{\text {fase Max }}$ & $\mathbf{V}_{\text {fase média }}$ & $\mathbf{V}_{\text {fase Engy }}$ & .... & $\mathbf{V}_{\text {Nominal }}$ & $\begin{array}{c}\text { Limite } \\
\text { Swell }\end{array}$ & Limite Sag \\
\hline $\begin{array}{c}\text { Data e } \\
\text { Hora }\end{array}$ & $\begin{array}{l}\text { Dados em } \\
\text { segundos }\end{array}$ & $\begin{array}{c}\text { Menor } \\
\text { tensão } \\
\text { medida } \\
\text { durante o } \\
\text { 'sag/swell } \\
\text { na fase a } \\
\text { dado em } \\
\text { p.u }\end{array}$ & $\begin{array}{c}\text { Maior } \\
\text { tensão } \\
\text { medida } \\
\text { durante o } \\
\text { ‘sag/swell } \\
\text { na fase a } \\
\text { em p.u }\end{array}$ & $\begin{array}{c}\text { Tensão } \\
\text { média } \\
\text { medida } \\
\text { durante o } \\
\text { 'sag/ } \\
\text { swell na } \\
\text { fase a } \\
\text { em p.u }\end{array}$ & & $\begin{array}{c}\text { As } \\
\text { colunas } \\
\text { com as } \\
\text { tensões } \\
\text { repetem- } \\
\text { se para as } \\
\text { demais } \\
\text { fases }\end{array}$ & $\begin{array}{c}\text { Dado } \\
\text { em } \\
\text { volts }\end{array}$ & $\begin{array}{c}\text { Valor } \\
\text { acima do } \\
\text { qual passa } \\
\text { a ser uma } \\
\text { elevação }\end{array}$ & $\begin{array}{c}\text { Valor abaixo } \\
\text { do qual } \\
\text { passa a ser } \\
\text { um } \\
\text { afundamento }\end{array}$ \\
\hline
\end{tabular}

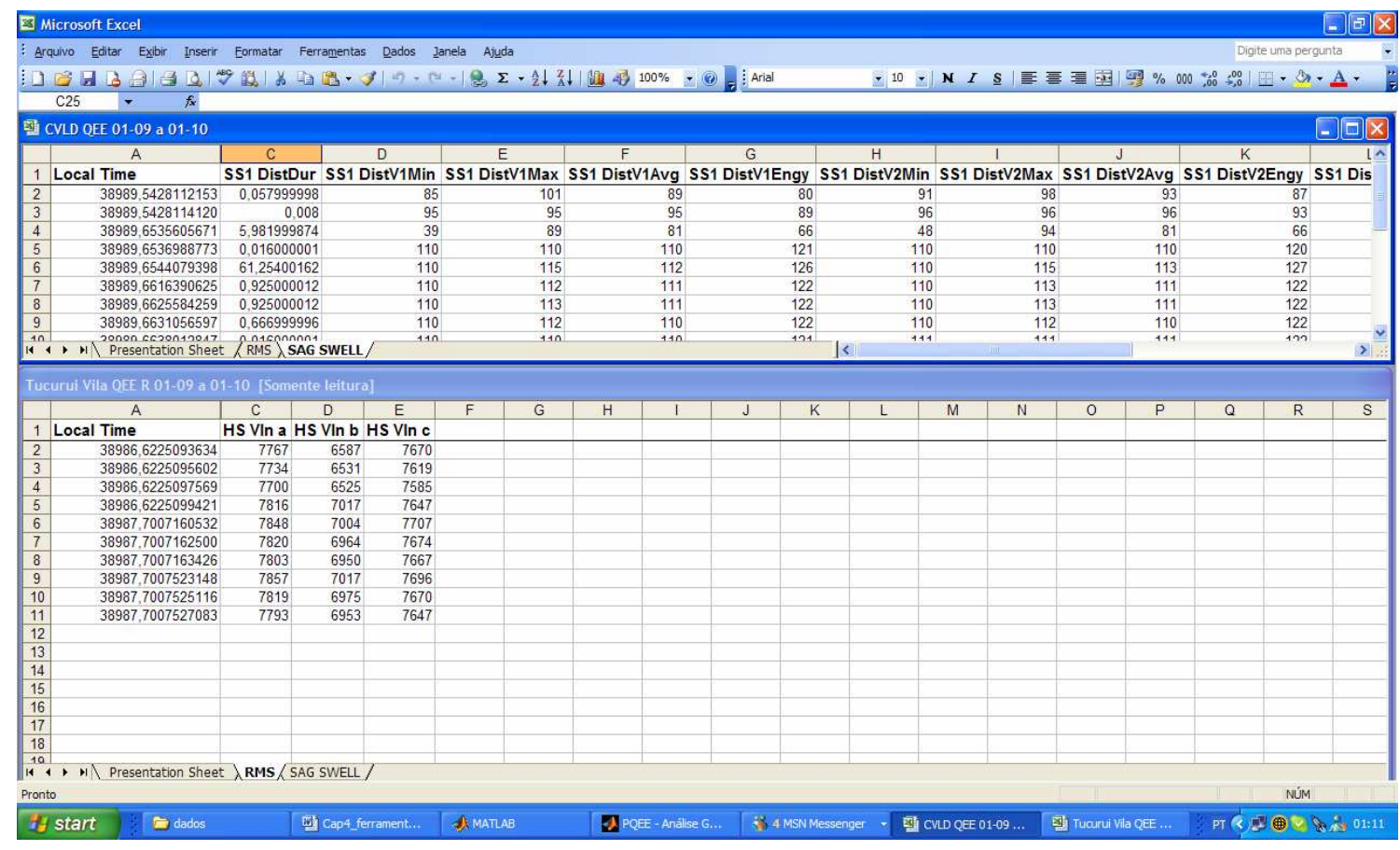

Figura 3.2 - Exemplo de banco de dados no Microsoft Excel. 


\subsection{INICIA N D O PROGRAMA}

O programa deve ser aberto dentro do MatLab 7.0. Após este ser iniciado, escolhe-se o diretório que contém a pasta do aplicativo no menu "Current Directory". O próximo passo é digitar o nome do arquivo de inicialização, "afund", na janela "Command Window". Aparecerá uma tela de apresentação do programa, mostrada na Figura 3.3, que se fecha após 4 segundos. Em seguida tem-se a abertura da tela inicial com a descrição dos tópicos de análise contemplados pela ferramenta. Nessa, também encontra-se o botão "Iniciar Programa" ilustrado pela Figura 3.4. Ao se clicar sobre este botão inicia-se o módulo de entrada, onde é feita a leitura do banco de dados.

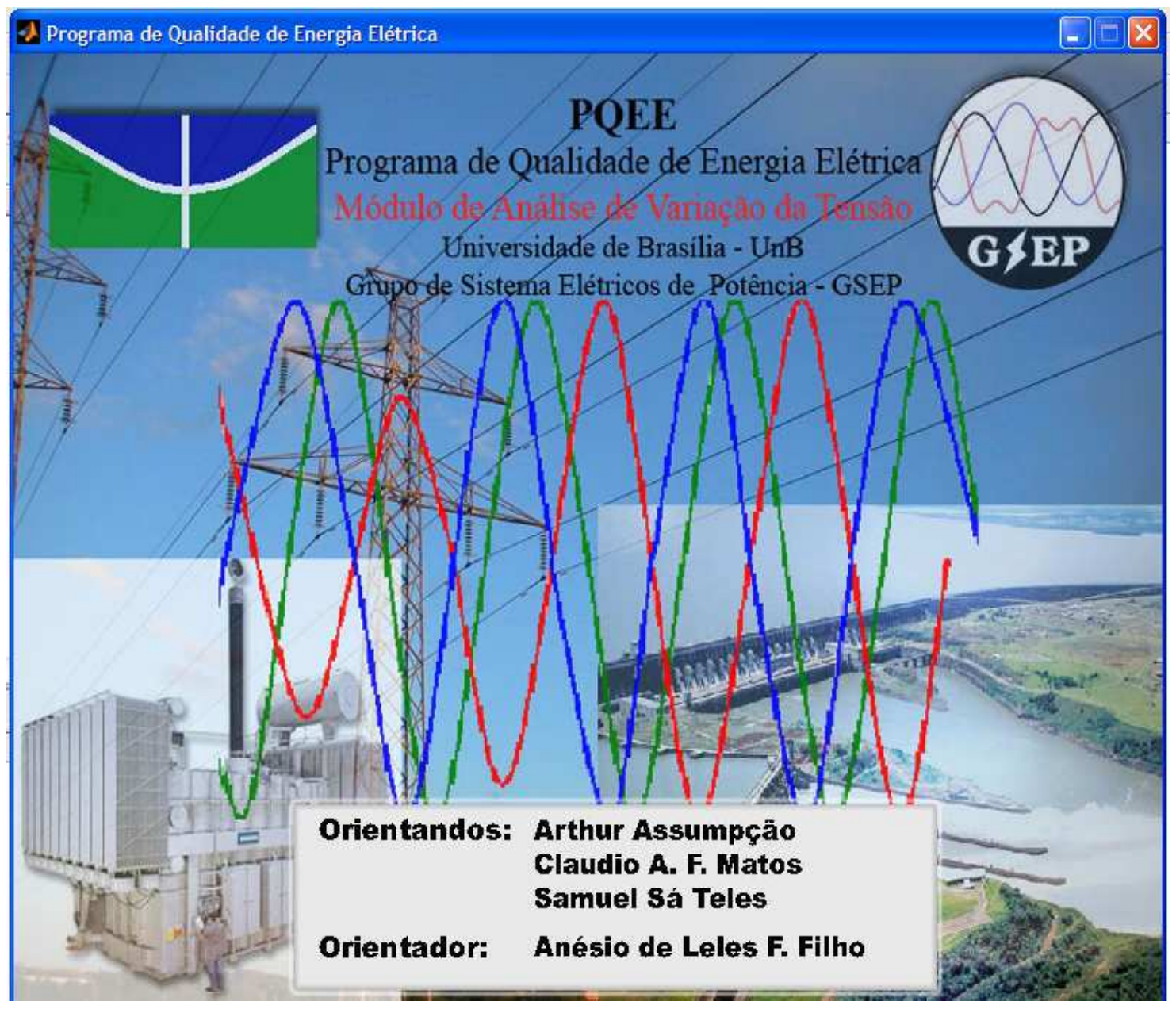

Figura 3.3 - Tela de apresentação. 


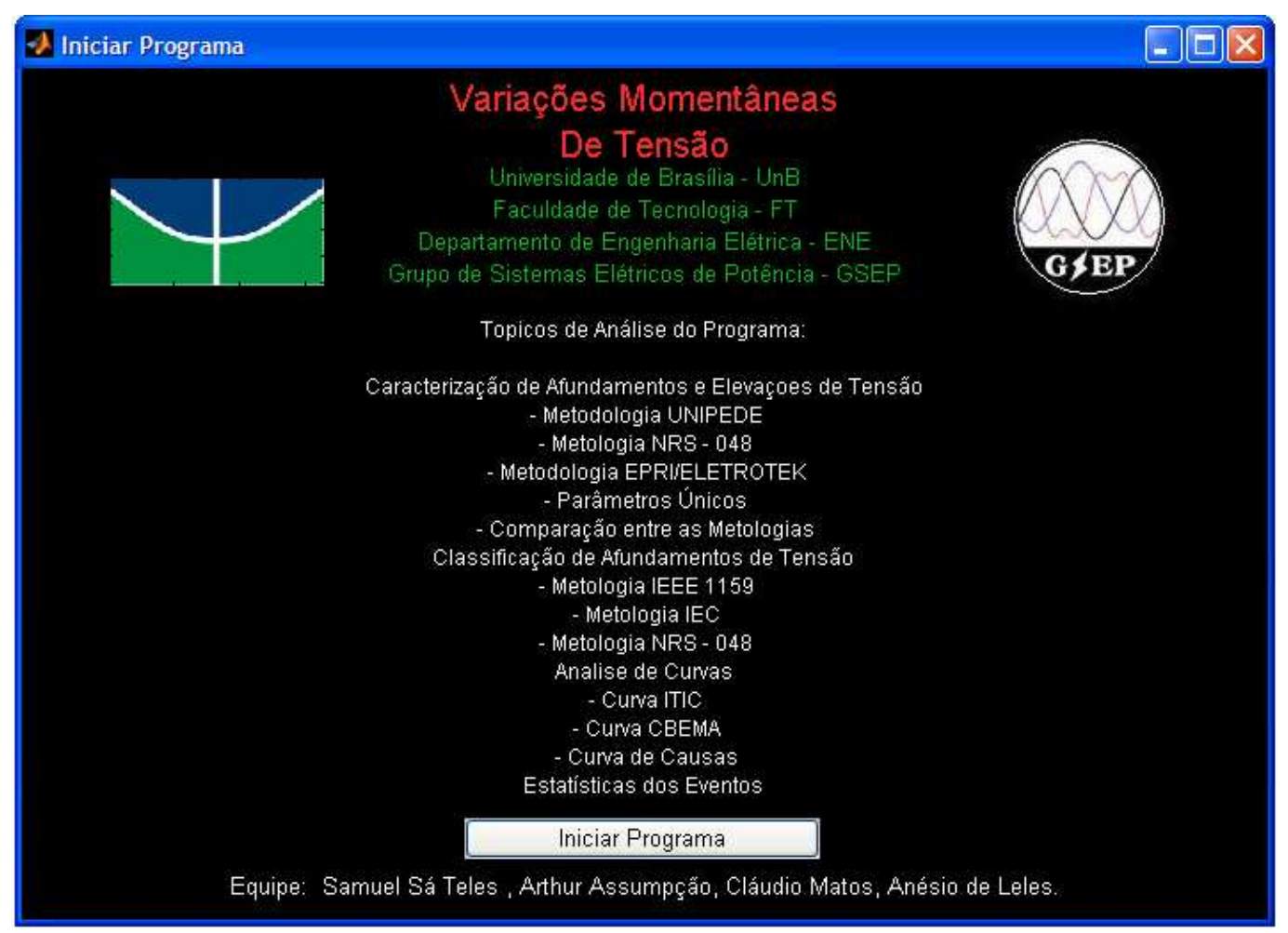

Figura 3.4 - Tela inicial.

\subsection{MÓdULO DE ENTRADA - LEITURA DO BANCODE D A D O S}

O módulo de entrada é responsável por carregar os dados medidos e dar acesso aos módulos de análise. Os botões de entrada aos diversos módulos ficam inativos até que o banco seja carregado. Há ainda a possibilidade de acesso a partir do menu superior “Arquivo”.

Para que o software leia o banco de dados, é necessário clicar sobre o botão "Carregamento de Dados". Após a escolha do banco de dados, seleciona-se o arquivo desejado. Se carregado corretamente, um aviso será mostrado em uma janela com a mensagem "Dados Carregados com Sucesso", como ilustra a Figura 3.5.

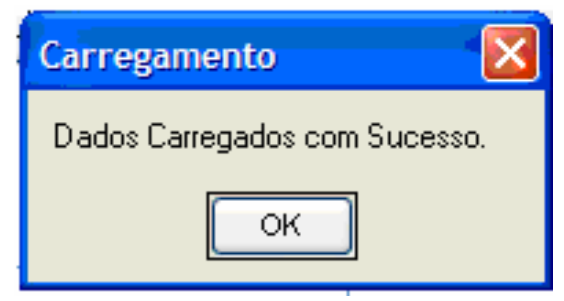

Figura 3.5 - Aviso de banco carregado. 
A partir deste momento, as seguintes informações sobre o banco utilizado estarão disponíveis na janela do módulo de entrada: nome do arquivo, tensão nominal, data e hora do primeiro e do último evento, número de eventos, número de afundamentos e de elevações. A Figura 3.6 mostra a janela deste módulo.

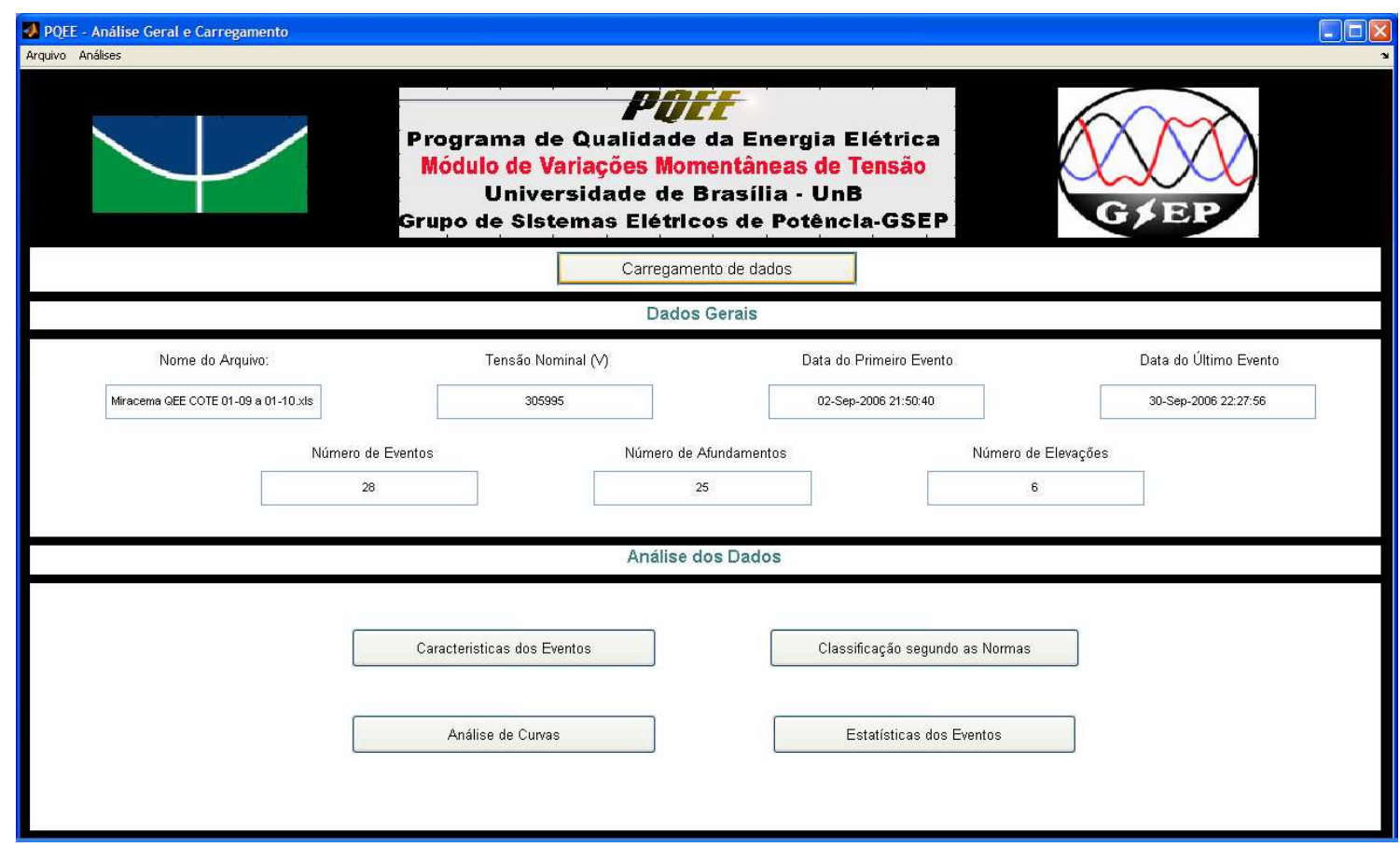

Figura 3.6 - Janela do módulo de entrada do programa (Banco de Dados).

Nos capítulos subseqüentes os módulos da ferramenta computacional serão detalhadamente apresentados. Primeiramente serão expostas suas respectivas telas e funções de análise e, em seguida, são feitos estudos de caso que mostram a aplicação de cada módulo.

Os dados utilizados são procedentes da subestação Miracema da Eletronorte. A Tabela 3.2 resume as características do banco de dados medido.

Tabela 3.2 - Dados do banco medido na subestação SE 02.

\begin{tabular}{|c|c|}
\hline Banco de Dados & Subestação Miracema \\
\hline Data de Início da Medição & 01 de setembro de 2006 \\
\hline Hora de Início da Medição & $00: 00$ hs \\
\hline Data do Fim da Medição & 30 de setembro de 2006 \\
\hline Hora do Fim da Medição & 23:59 hs \\
\hline Freqüuência de Aquisição (HS) & Meio meio ciclo \\
\hline
\end{tabular}




\subsection{Módulo de Características dos eventos}

Este item apresentará o módulo de características dos eventos. Com esta ferramenta é possível obter a distribuição dos eventos em um gráfico semilog de acordo com os parâmetros de amplitude e duração. Seu objetivo principal é permitir ao usuário verificar a quantidade, o momento da ocorrência, o tipo (afundamento ou elevação), a amplitude e a duração da VMT de acordo com as diversas normas internacionais. É possível também, obter uma análise comparativa entre as metodologias de caracterização.

Para que o módulo esteja disponível para análise, é necessário que o banco de dados do usuário contenha a planilha com as medições de tensões de linha em High Speed e a planilha com os valores da tensão em percentual, bem como os limites de afundamentos e elevações de tensão e tensão nominal. O formato do banco de dados ilustrado no item 4.4 deve ser rigorosamente respeitado, tendo as colunas 2 a 18 reservadas para essas grandezas.

\subsubsection{ESTRUTURA DO MÓdULO DE CARACTERÍSTICAS DOS EVENTOS}

O módulo pode ser acessado do botão "Características dos Eventos", na tela de entrada, ou a partir do menu superior "Análises”. Abrir-se-á a janela mostrada pela Figura 3.7. À esquerda ficam disponíveis as metodologias para análises: UNIPEDE, NRS - 048, EPRI/ELETROTEK e Parâmetro Único. Selecionando uma delas, o gráfico de intensidade pela duração presente na janela muda de acordo com a caracterização.

Selecionada a metodologia, pode-se extrair os parâmetros individualmente de cada evento clicando no botão "Selecionar um Evento". Escolhendo-se um evento tem-se o instante em que ele ocorreu, o tipo, a intensidade e a duração. Fica habilitada também a análise gráfica, onde há opção da forma de onda ou dos valores eficaz de cada amostra. 


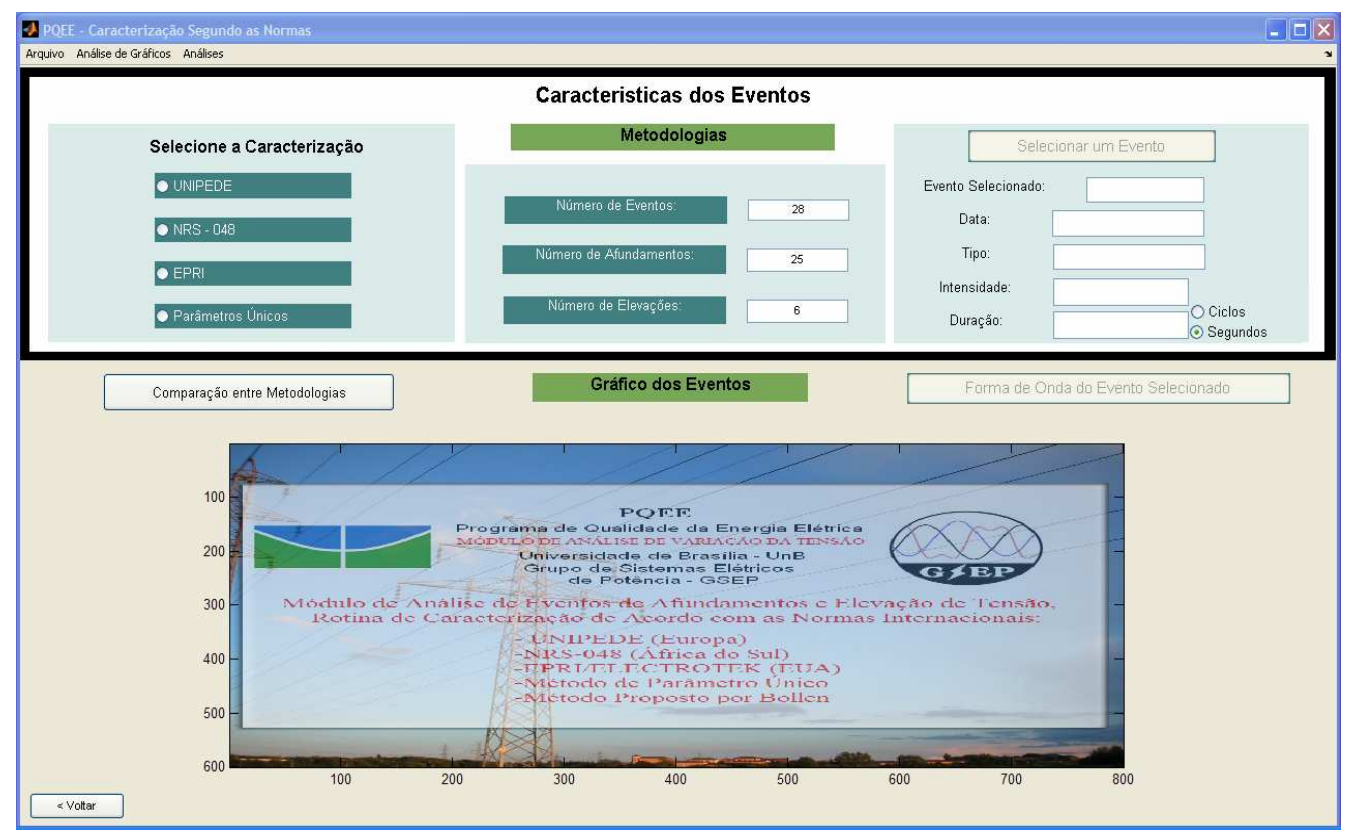

Figura 3.7 - Janela do módulo de características dos eventos.

\subsubsection{ESTUDO DE CASO DE CARACTERIZAÇÃO DE EVENTOS}

Objetivando exemplificar a utilização do módulo em questão, será feita uma análise das caracterizações, precedida da comparação entre as metodologias. O banco de dados utilizado é da Subestação Miracema, da Eletronorte.

\subsubsection{CARACTERIZAÇÃO PELA METODOLOGIA UNIPEDE}

A Figura 3.8 apresenta o gráfico com a amplitude pela duração para um mês de monitoração por meio da metodologia UNIPEDE.

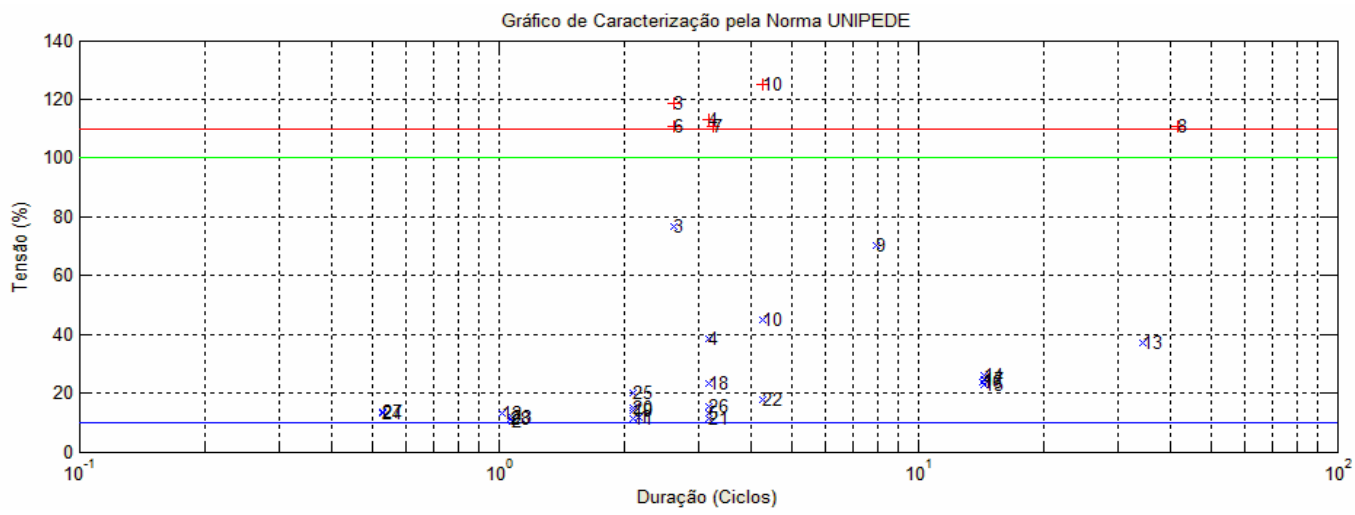

Figura 3.8 - Gráfico de Intensidade X Duração para um mês de monitoração por meio da metodologia UNIPEDE. 
Nota-se na Figura 3.8, que os afundamentos compreendem os pontos abaixo da linha verde (tensão nominal) e acima da linha azul, correspondente ao limiar de $10 \%$ da intensidade do afundamento (90\% da tensão nominal). Acima da linha vermelha estão as elevações de tensão a $110 \%$. Entre as linhas verde e vermelha não aparecem quaisquer pontos. Isto é de se esperar, haja vista que neste intervalo a tensão está dentro dos padrões atribuídos pelas normas. A Tabela 3.3 traz os parâmetros de três pontos escolhidos no gráfico, sendo eles: um afundamento, uma elevação e um evento simultâneo (afundamento e elevação).

Tabela 3.3 - Dados dos eventos 1, 8 e 10 pela metodologia UNIPEDE.

\begin{tabular}{|c|c|c|c|}
\hline Numero do Evento & $\mathbf{1}$ & $\mathbf{8}$ & $\mathbf{1 0}$ \\
\hline Data & $\begin{array}{c}\text { 22-Sep-2006 } \\
21: 50: 40\end{array}$ & $\begin{array}{c}13-\text { Sep-2006 } \\
12: 38: 18\end{array}$ & $\begin{array}{c}14-S e p-2006 \\
11: 14: 18\end{array}$ \\
\hline Tipo & Afundamento & Elevação & $\begin{array}{c}\text { Elevação/ } \\
\text { Afundamento }\end{array}$ \\
\hline Intensidade & 11.9515 & 110.961 & $125.1962 / 44.962$ \\
\hline Duração (ciclos) & 2.0791 & 39.9306 & $4.2677 / 4.2677$ \\
\hline
\end{tabular}

A visualização de um evento pode, diversas vezes, ficar comprometida em razão de uma aglomeração destes pontos em alguma região do gráfico, como observa-se para o evento 1 da Tabela 3.3. Este inconveniente pode ser solucionado fazendo-se o uso da opção de "Zoom" localizada no menu "Análise dos Gráficos". A Figura 3.9 mostra a melhor visualização do evento 1 com o auxílio do recurso de zoom.

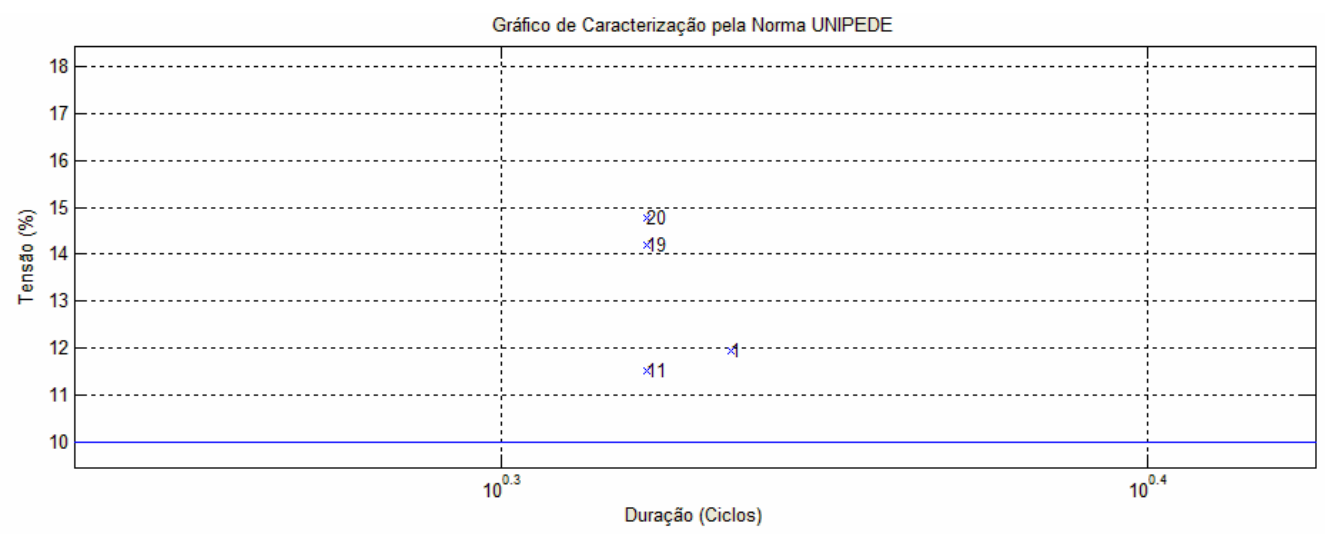

Figura 3.9 - Gráfico de intensidade X duração com auxilio do recurso de zoom.

Observa-se da Tabela 3.3, que no evento número 10 ocorreu um afundamento e uma elevação. Isso decorre do fato de que em uma das fases a tensão esteve acima do limite de $110 \%$ e 
noutra, abaixo do limite de $90 \%$. Com o clique no botão "Forma de onda do evento selecionado" é possível acompanhar sua evolução no tempo.

As Figuras 3.10 e 3.11 ilustram a forma de onda e os dados eficazes, respectivamente, do evento número 10 dos dados da Tabela 3.3.

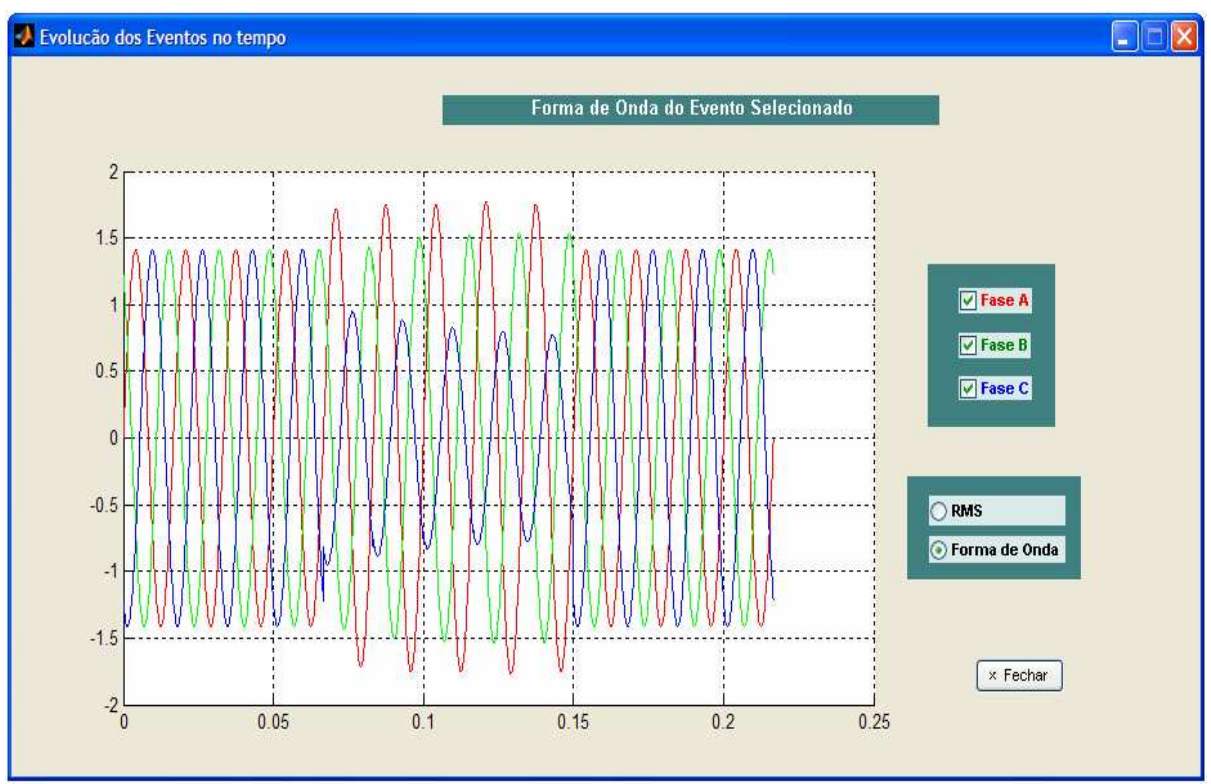

Figura 3.10- Gráfico de forma de onda do evento número 10 dos dados da Tabela 3.3.

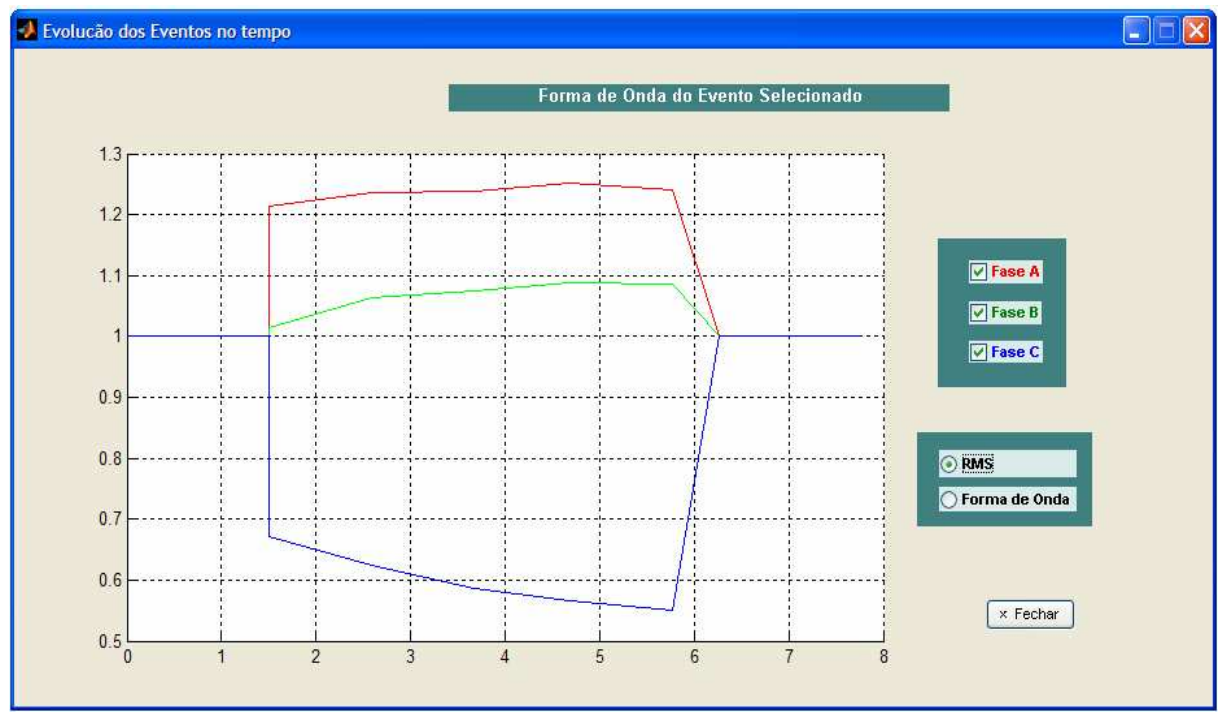

Figura 3.11 - Dados eficazes do evento número 10 dos dados da Tabela 3.3. 
Se desejável, o usuário pode selecionar apenas uma ou duas das fases, permitindo-se ter uma melhor visualização dos eventos.

\subsubsection{CARACTERIZAÇÃo PELA METOdologia NRS - 048}

A Figura 3.12 apresenta o gráfico da amplitude pela duração para o mesmo banco de dados e período do item anterior, por meio da metodologia de caracterização NRS - 048.

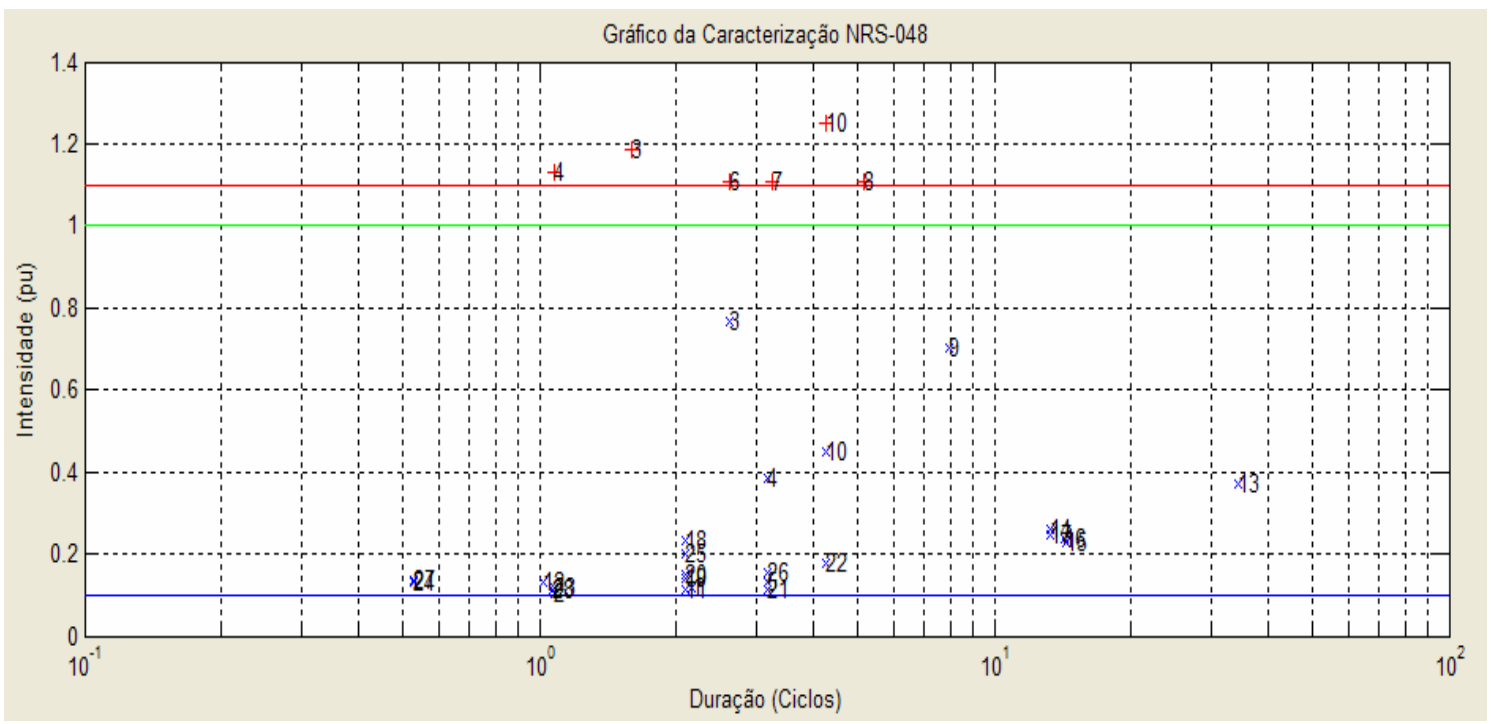

Figura 3.12 - Gráfico de Intensidade X Duração para um mês de medição norma NRS - 048.

Assim como na caracterização pela metodologia UNIPEDE, na Figura 3.12 os afundamentos compreendem os pontos acima da linha azul e abaixo da linha verde e as elevações de tensão encontram-se na parte superior à linha vermelha. A Tabela 3.4 traz os mesmos eventos selecionados na Tabela 3.3.

Tabela 3.4 - Dados dos eventos 1,8 e 10 pela metodologia NRS - 048 .

\begin{tabular}{|c|c|c|c|}
\hline Numero do Evento & $\mathbf{1}$ & $\mathbf{8}$ & $\mathbf{1 0}$ \\
\hline Data & $\begin{array}{c}02-\text { Sep-2006 } \\
21: 50: 40\end{array}$ & $\begin{array}{c}13-\text { Sep-2006 } \\
12: 38: 18\end{array}$ & $\begin{array}{c}14-\text { Sep-2006 } \\
11: 14: 18\end{array}$ \\
\hline Tipo & Afundamento & Elevação & $\begin{array}{c}\text { Elevação/ } \\
\text { Afundamento }\end{array}$ \\
\hline Intensidade & 0.11952 & 1.1096 & $1.252 / 0.4496$ \\
\hline Duração (ciclos) & 2.0791 & 4.9531 & $4,2677 / 4.2677$ \\
\hline
\end{tabular}


As diferenças entre os parâmetros de intensidade e duração entre as metodologias UNIPEDE e NRS- 048, descritos nas Tabelas 3.3 e 3.4, serão detalhadas no subitem 3.5.3 do presente capítulo.

\subsubsection{CARACTERIZAÇÃo PELA METOdologia EPRI/ ELETROTEK}

A Figura 3.13 apresenta o gráfico da amplitude pela duração, por meio da metodologia de caracterização EPRI/ELETROTEK.

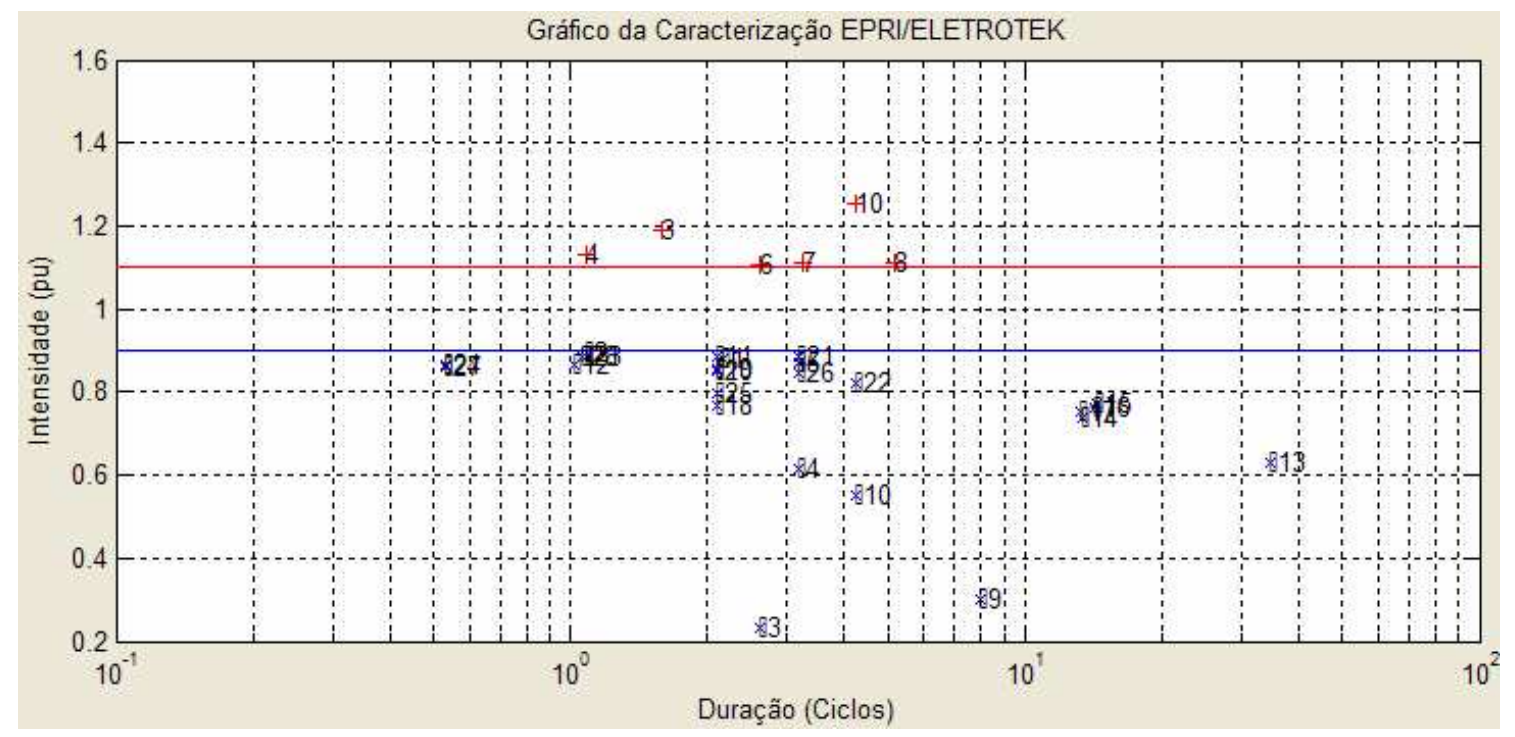

Figura 3.13 - Gráfico de Intensidade X Duração para um mês de medição norma EPRI/ELETROTEK.

Para tal metodologia nos casos de afundamentos e elevações que não possuam forma retangular, atribuem-se durações conforme limiares específicos. Logo, como um único evento pode ser atribuído mais de um valor de duração, pode-se especificar os valores no quadro da Figura 3.14, e em seguida, com um clique em "OK", a duração para o limiar escolhido aparece no local referente. A Figura 3.14 mostra o quadro onde são ilustrados os limiares da tensão.

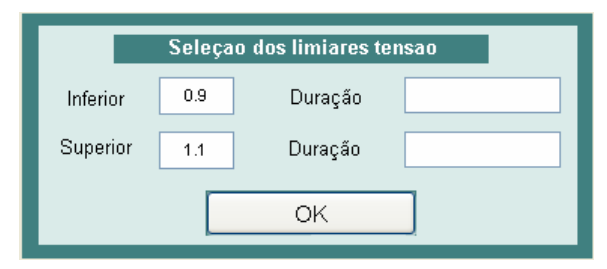

Figura 3.14 - Quadro onde se especifica os limiares de tensão para caracterização EPRI/ELETROTEK. 
No quadro representado pela Figura 3.14, colocando-se outros limites de tensão e, selecionando o botão "OK", tem-se a duração do afundamento para um outro limite de afundamento ou elevação de tensão. Nos casos em que ocorrem afundamento e elevação no mesmo evento, o programa mostra as durações para os dois limites.

A Tabela 3.5 apresenta os dados dos eventos 1,8 e 10 conforme a metodologia EPRI/ELETROTEK, para os limiares de 0,9 pu (afundamento) e 1,1 pu (elevação).

Tabela 3.5 - Dados dos eventos 1, 8 e 10 pela metodologia EPRI/ELETROTEK.

\begin{tabular}{|c|c|c|c|}
\hline Numero do Evento & $\mathbf{1}$ & $\mathbf{8}$ & $\mathbf{1 0}$ \\
\hline Data & $\begin{array}{c}\text { 02-Sep-2006 } \\
21: 50: 40\end{array}$ & $\begin{array}{c}13-\text { Sep-2006 } \\
12: 38: 18\end{array}$ & $\begin{array}{c}14-S e p-2006 \\
11: 14: 18\end{array}$ \\
\hline Tipo & Afundamento & Elevação & $\begin{array}{c}\text { Elevação/ } \\
\text { Afundamento }\end{array}$ \\
\hline Intensidade & 0.88048 & 1.1096 & $1.252 / 0.55038$ \\
\hline Duração (ciclos) & 2.0791 & 4.9531 & $4,2677 / 4.2677$ \\
\hline
\end{tabular}

\subsubsection{CaraCterizaÇão Pelos Parâmetros Únicos}

A grande virtude da metodologia por parâmetros únicos é que se pode atribuir um único valor aos afundamentos sendo, portanto, desnecessário especificar a intensidade e a duração para caracterizá-los. Na Figura 3.15 estão disponíveis os quatro parâmetros que o programa calcula referente ao afundamento número 1.

\begin{tabular}{|c|c|c|c|c|}
\hline & Fase A & Fase B & Fase C & Total \\
\hline Perda de Tensão & 0.33844 & 0.067521 & 0.037641 & 0.4436 \\
\hline Perda de Energia & 0.63859 & 0.13352 & 0.074754 & 0.84687 \\
\hline Método de Heydt & 0.0032016 & $2.0249 \mathrm{e}-005$ & $4.436 \mathrm{e}-006$ & 0.0032263 \\
\hline
\end{tabular}

Figura 3.15 - Parâmetros do afundamento número 1 por fase e total.

Na Figura 3.15 observa-se que os parâmetros foram divididos por fase. Desta forma, são obtidos os valores para cada uma delas e em seguida tem-se o valor total. Para a perda de tensão, por exemplo, tem-se que o maior resultado foi o obtido na fase A. Somando-o com os dois restantes tem-se a perda de tensão total para o afundamento selecionado. Destarte, é este 
valor que irá caracterizar o evento. Conclui-se, portanto, que as características dos afundamentos podem ser atribuídas a apenas um parâmetro, ao invés dos tradicionais intensidade e duração.

\subsubsection{COMPARAÇÃO ENTRE AS METOLOGIAS}

A Figura 3.16 apresenta a tela da comparação do banco de dados pelas três principais metodologias. À esquerda ficam as quantidades dos eventos por caracterização. À direita deve-se selecionar um evento para comparar os valores obtidos da duração e da intensidade pelas normas.

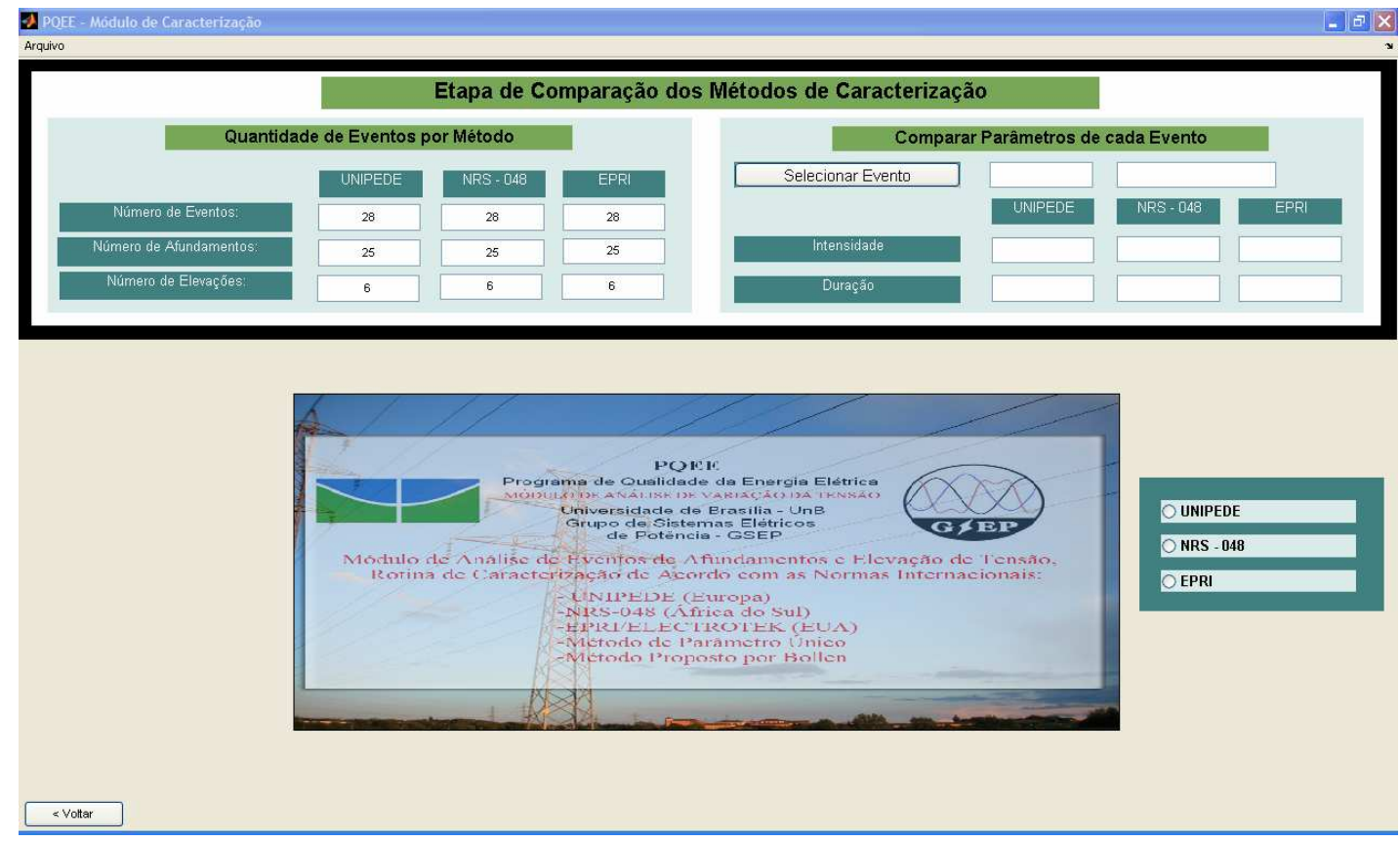

Figura 3.16 - Tela da etapa de comparação entre os métodos de caracterização.

Observa-se da Figura 3.16 que qualquer um dos gráficos de intensidade x duração das metodologias UNIPEDE, NRS - 048 e EPRI pode ser visualizado a partir da sua seleção. A Figura 3.17 mostra as diferentes intensidades e durações do evento número 1, obtidas para cada uma das três metodologias.

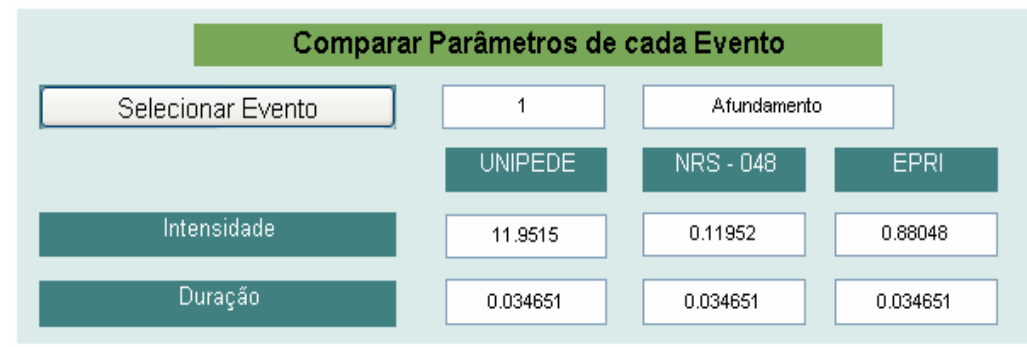

Figura 3.17 - Comparação de Intensidade e Duração para cada uma das metodologias. 
Da Figura 3.17 conclui-se que o afundamento de número 1, do banco de dados analisado, apresentou valores idênticos de duração nos três métodos propostos. Ressalta-se que os parâmetros de intensidade, apesar de apresentar-se de três formas distintas, representam mesmo valor. Isto é devido às especificidades de cada norma.

\subsection{MóduLO DE ESTATÍSTICAS DOS EVENTOS}

Neste tópico, objetiva-se analisar e quantificar aspectos relacionados às Variações Momentâneas de Tensão com o uso de ferramentas estatísticas, tais como histogramas e gráficos de barras em 3D.

\subsubsection{ESTRUTURA DO MÓdULO DE ESTATÍSTICA DOS EVENTOS}

O módulo de estatísticas dos eventos, mostrado na Figura 3.18, é acessado por meio do botão "Estatísticas dos Eventos" presente na tela de carregamento ou a partir do menu "Análises". À direita aparecem as quantidades dos eventos. No quadro à esquerda são disponibilizados seis gráficos para estudos. A Figura é alterada a cada seleção.

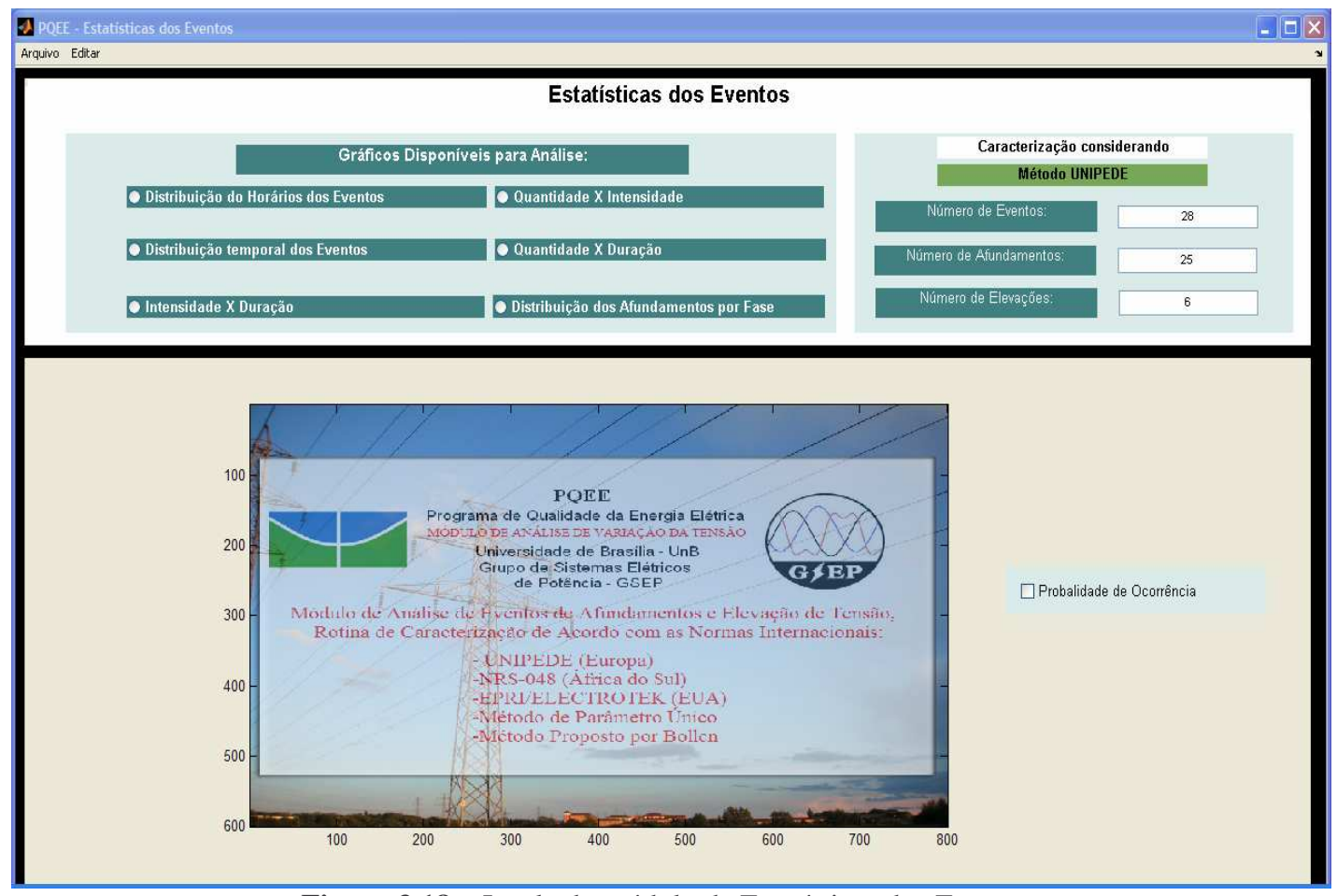

Figura 3.18 - Janela do módulo de Estatísticas dos Eventos. 
Os seis tópicos serão detalhados nos itens a seguir, através do estudo de caso. O banco de dados a ser analisado será o da Subestação Eletronorte Miracema, medido durante todo o mês de setembro. É importante mencionar que nesta etapa foi adotada a metodologia de caracterização UNIPEDE. Logo, a intensidade do afundamento considerada é o valor de quanto a tensão caiu. Sendo assim, o afundamento apresenta-se mais severo quanto maior for seu valor.

\subsubsection{ESTUDO DE CASO DE ESTATÍSTICA DOS EVENTOS}

Serão apresentadas as análises de cada um dos seis gráficos disponíveis neste submódulo do programa, precedido de tabelas com os dados utilizados.

\subsubsection{DistRIBUIÇÃO DO HORÁRIO DOS EVENTOS}

As Figuras 3.19 e 3.20 mostram a quantidade de eventos ocorridos em dias úteis e finais de semana, respectivamente, durante o mês de setembro. $\mathrm{O}$ dia foi dividido em quatro períodos: entre $0 \mathrm{~h}$ e $6 \mathrm{~h}$, entre $6 \mathrm{~h}$ e $12 \mathrm{~h}$, entre $12 \mathrm{~h}$ e $18 \mathrm{~h}$ e entre $18 \mathrm{~h}$ e $24 \mathrm{~h}$.

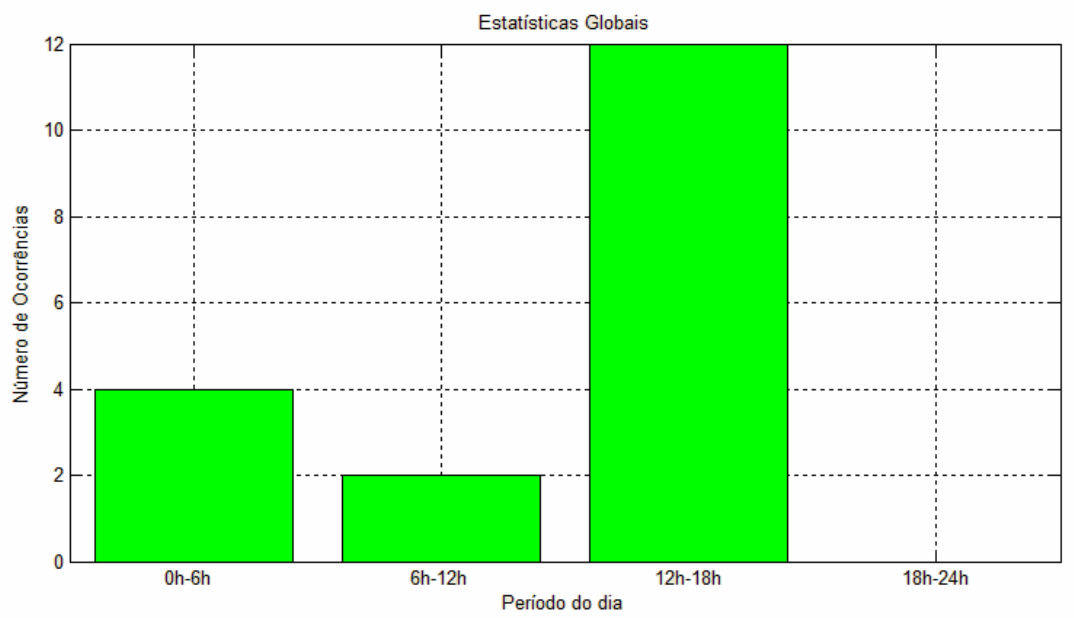

Figura 3.19 - Gráfico da distribuição dos eventos nos dias da semana. 


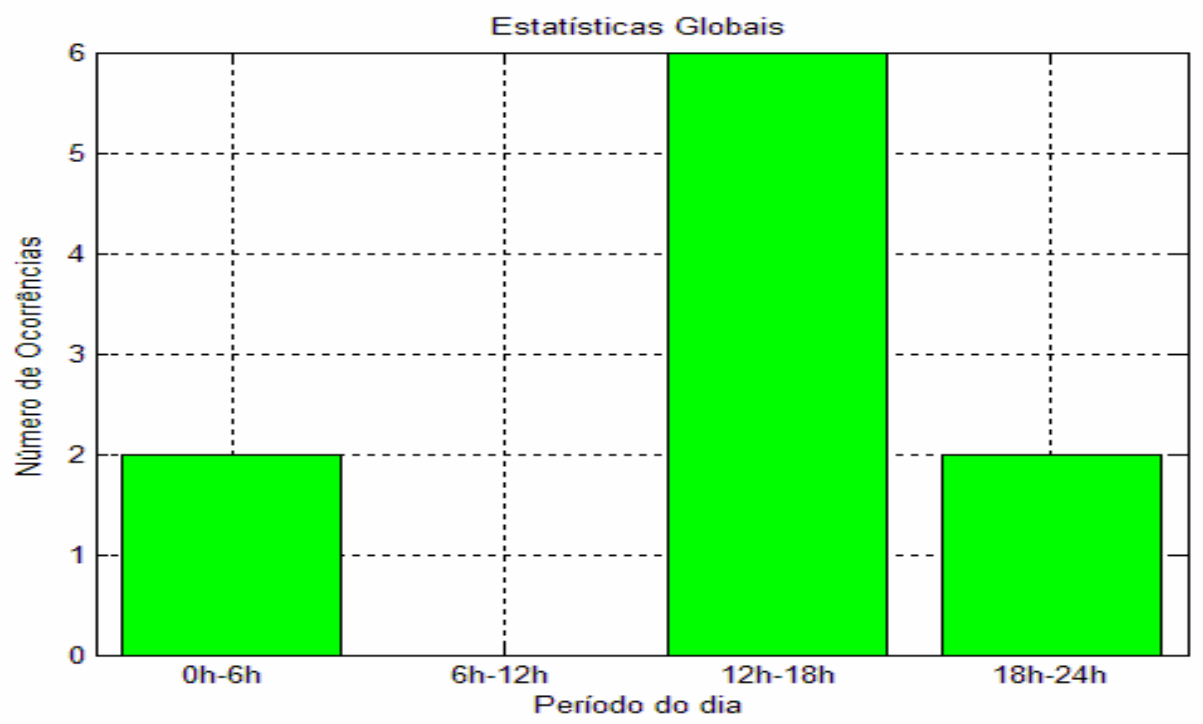

Figura 3.20 - Gráfico da distribuição dos eventos nos fins de semana.

Com o auxílio das figuras 3.19 e 3.20 visualiza-se que a grande maioria das VMTs ocorreu durante o período da tarde. As figuras 3.21 e 3.22 mostram as probabilidades de ocorrência dos eventos nos dias úteis e fins de semana.

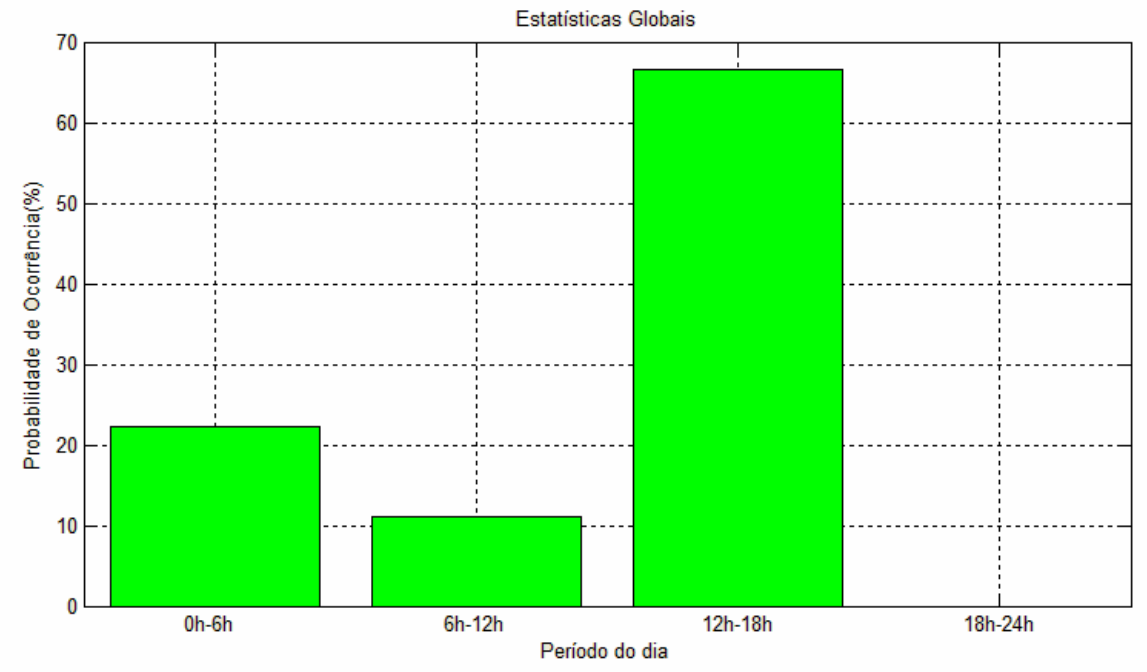

Figura 3.21 - Probabilidade de ocorrência nos dias de semana. 


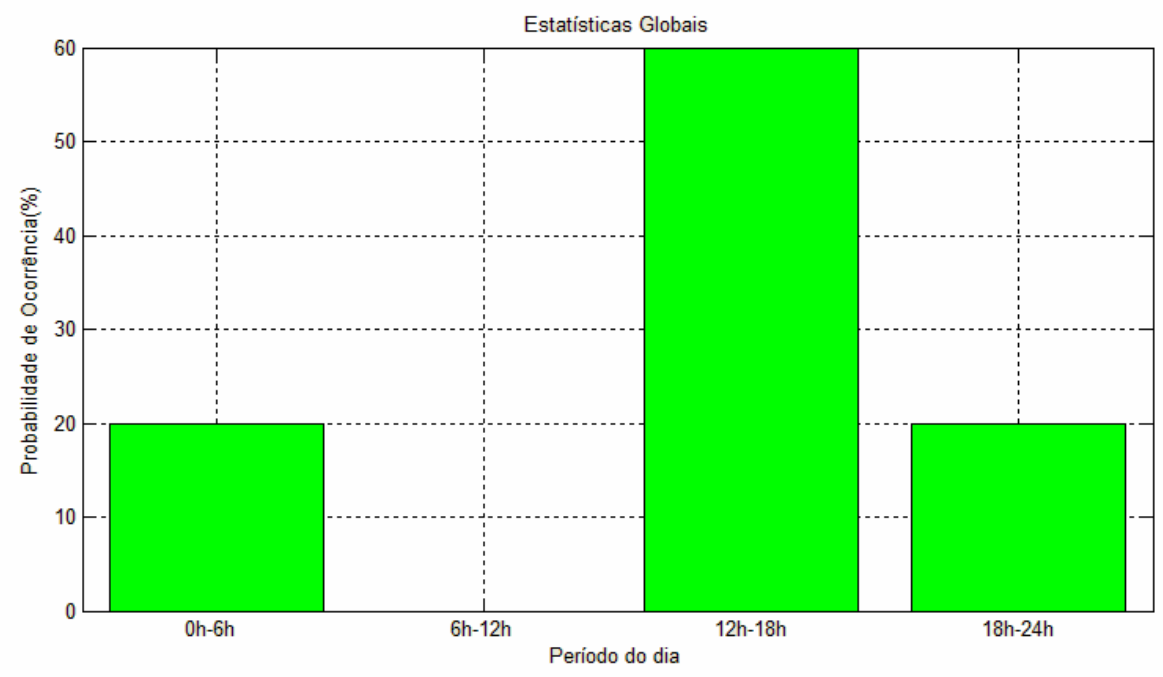

Figura 3.22 - Probabilidade de ocorrência nos finais de semana.

Observa-se das figuras 3.21 e 3.22, que as VMTs que ocorreram no período de 12 às 18 horas representam $66 \%$ e $60 \%$ dos eventos nos dias de semana e finais de semana, respectivamente.

A Tabela 3.6 apresenta os dados referentes a afundamento e elevações durante os dias de semana e finais de semana medidos na mesma subestação.

Tabela 3.6 - Número de afundamentos no mes de setembro.

\begin{tabular}{|c|c|c|}
\hline $\begin{array}{c}\text { Período do } \\
\text { dia }\end{array}$ & Dias Úteis & $\begin{array}{c}\text { Fins de } \\
\text { Semana }\end{array}$ \\
\hline 0h-6h & 4 & 2 \\
\hline $6 \mathrm{~h}-12 \mathrm{~h}$ & 2 & 0 \\
\hline $12 \mathrm{~h}-18 \mathrm{~h}$ & 12 & 6 \\
\hline $18 \mathrm{~h}-24 \mathrm{~h}$ & 0 & 2 \\
\hline
\end{tabular}

Na Tabela 3.6 observa-se que, como era de se esperar, a maioria dos eventos aconteceram em dias úteis, visualiza-se ainda que as VMTs compreendidas nos períodos de $6 \mathrm{~h}-12 \mathrm{~h}$ e $18 \mathrm{~h}-24 \mathrm{~h}$ apresentaram baixas ocorrências.

\subsubsection{Distribuição TEMPORAL DOS EVENTOS}

As Figuras 3.23 e 3.24 ilustram a distribuição temporal e a distribuição da probabilidade dos eventos medidos durante o mês de setembro. Nestes gráficos é possível identificar o número e o percentual de VMTs em cada dia e, além disso, saber em que hora a mesma ocorreu. 


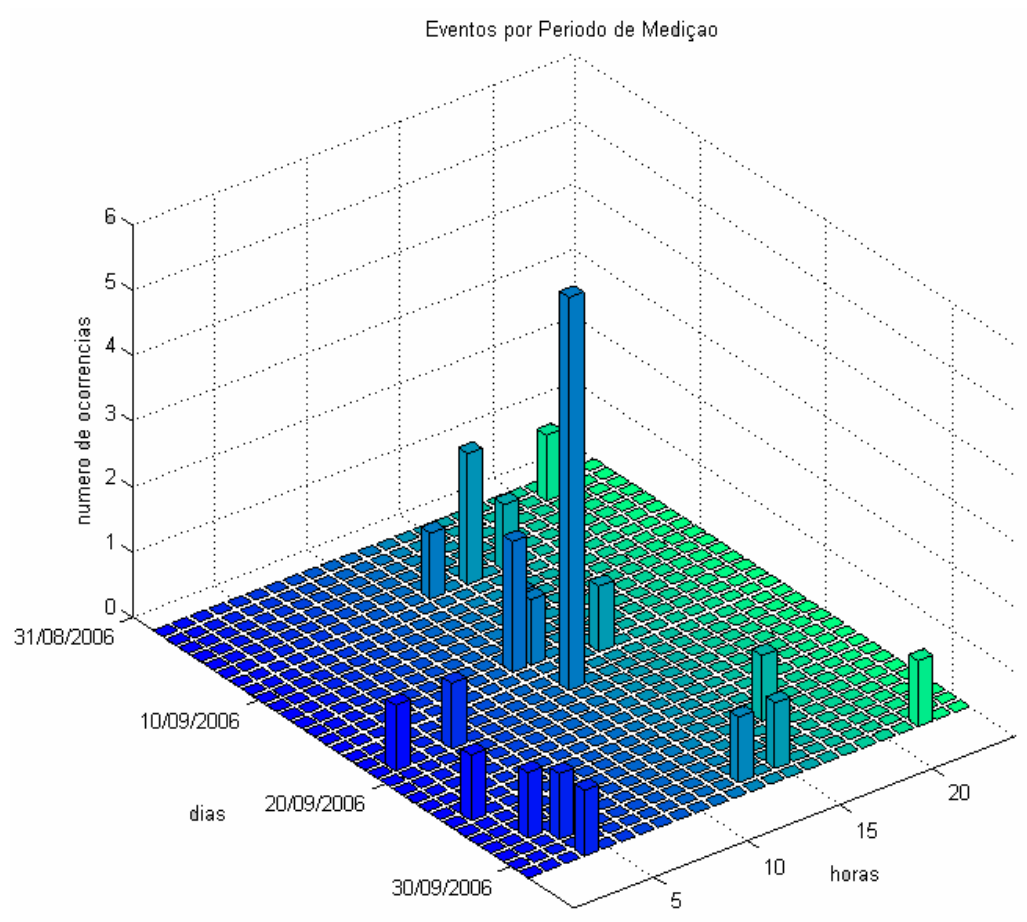

Figura 3.23 - Gráfico da distribuição temporal dos eventos.

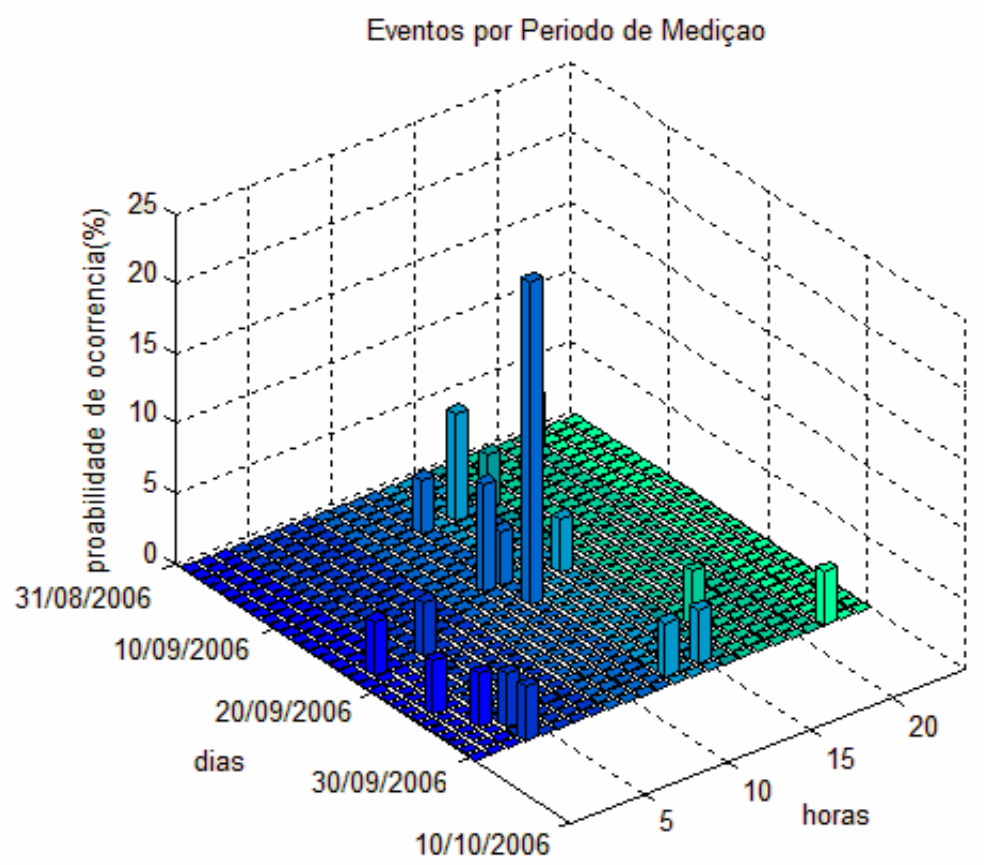

Figura 3.24 - Gráfico da distribuição da probabilidade temporal dos eventos.

Pela Figura 3.23 visualiza-se que em apenas um único dia e horário, dia 18 de setembro, entre meio dia e uma hora da tarde, foram detectados seis eventos. Entres os dias 10 e 20 nota-se a 
ocorrência de 12 VMTs o que representa $46 \%$ do total. Além disso, o gráfico da Figura 3.24 mostra que a maioria dos eventos ocorreu no período da tarde, como comprovado nas Figuras 3.19 e 3.20 .

\subsubsection{INTENSIDADE X DURAÇÃO}

A Figura 3.25 mostra, como o próprio nome diz, a distribuição dos eventos em relação à intensidade e à duração. Nota-se que houve uma predominância de eventos com menor duração e intensidade mais baixa.

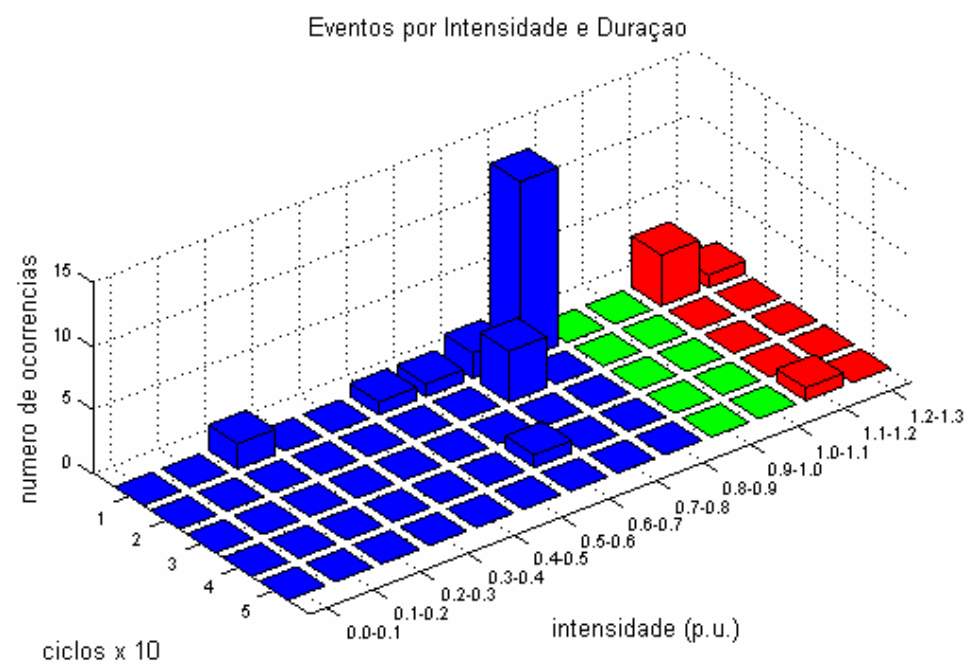

Figura 3.25 - Gráfico da distribuição Intensidade X Duração.

O gráfico da Figura 3.25 torna-se bastante ilustrativo, pois expõe os dois principais parâmetros dos afundamentos e elevações de maneira simples e direta. Desta forma, o usuário obtém um diagnóstico englobando todos os eventos ocorridos na medição, com o auxílio dos parâmetros intensidade e duração.

\subsubsection{QUantidade X Intensidade E QuAntidade X Duração}

Os histogramas representados nas Figuras 3.26 e 3.27 mostram as distribuições de probabilidade dos afundamentos e elevações em função da intensidade e da duração, 
respectivamente. Tais figuras corroboram com o comportamento visto na Figura 3.25, onde se observa a prevalência de afundamentos de baixa intensidade, onde $56 \%$ dos casos situam-se na região entre 0,8 p.u e 0,9 p.u da tensão. As durações, predominantemente curtas, estiveram situadas em valores entre 0,5 e 5 ciclos.

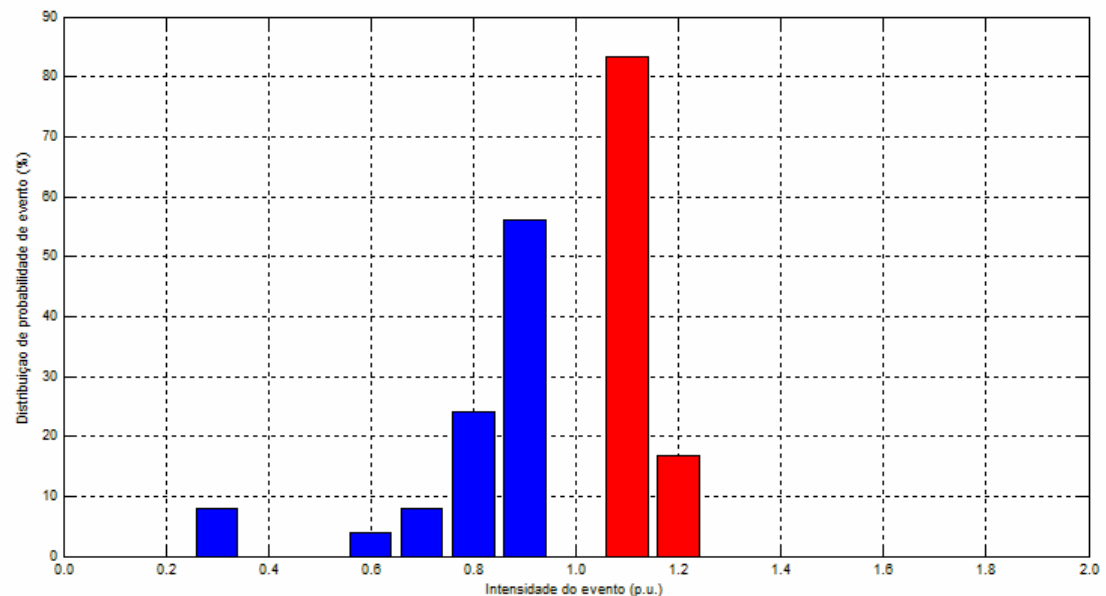

Figura 3.26 - Gráfico da distribuição Quantidade X Intensidade.

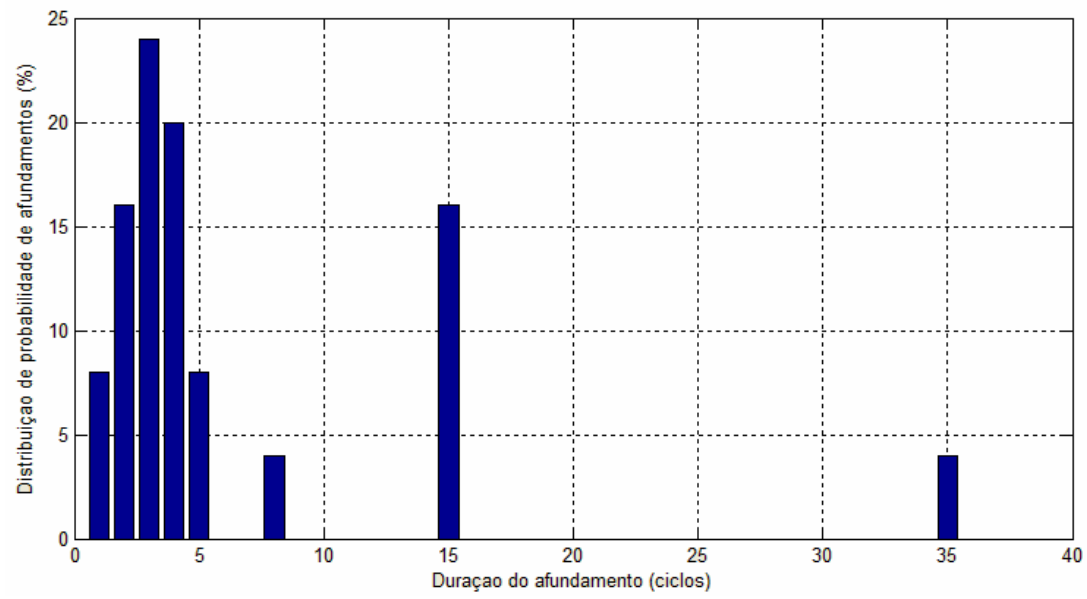

Figura 3.27 - Gráfico da distribuição Quantidade X Duração.

Deve-se ressaltar que a Figura 3.27 contempla somente uma pequena região do gráfico dos eventos ocorridos no mês de setembro, uma vez que a visualização de todos os eventos detectados no período fica prejudicada em razão da ocorrência de eventos de longa duração. 
Os gráficos representados nas Figuras 3.28 e 3.29 mostram as distribuições de probabilidade cumulada das Figuras 3.26 e 3.27. Suas disposições comprovam o que foi dito a respeito da intensidade e duração dos afundamentos. Observa-se na Figura 3.28 que o crescimento da função se intensifica para valores de tensão de maiores intensidades, o que demonstra que a probabilidade de eventos de menor intensidade é maior. Já na Figura 3.29, observa-se um crescimento maior logo no início do gráfico, evidenciando uma maior probabilidade de existirem VMT’s mais curtas.

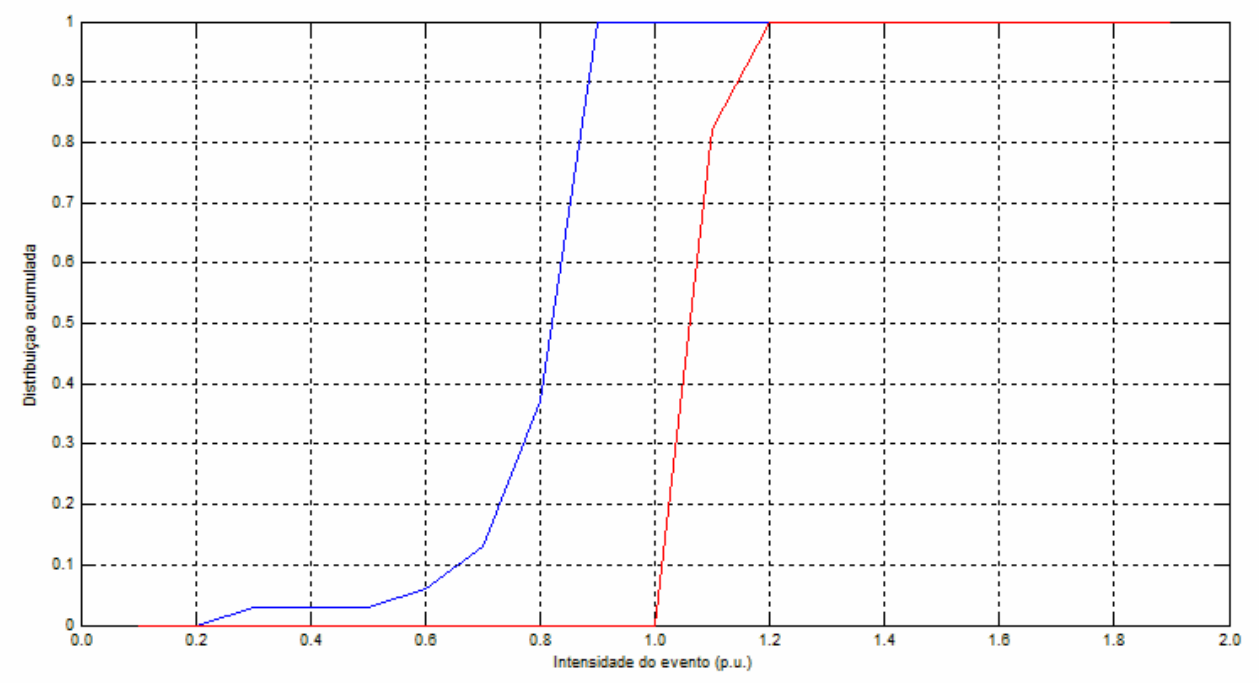

Figura 3.28 - Gráfico da distribuição de probabilidade inversa acumulada por intensidade.

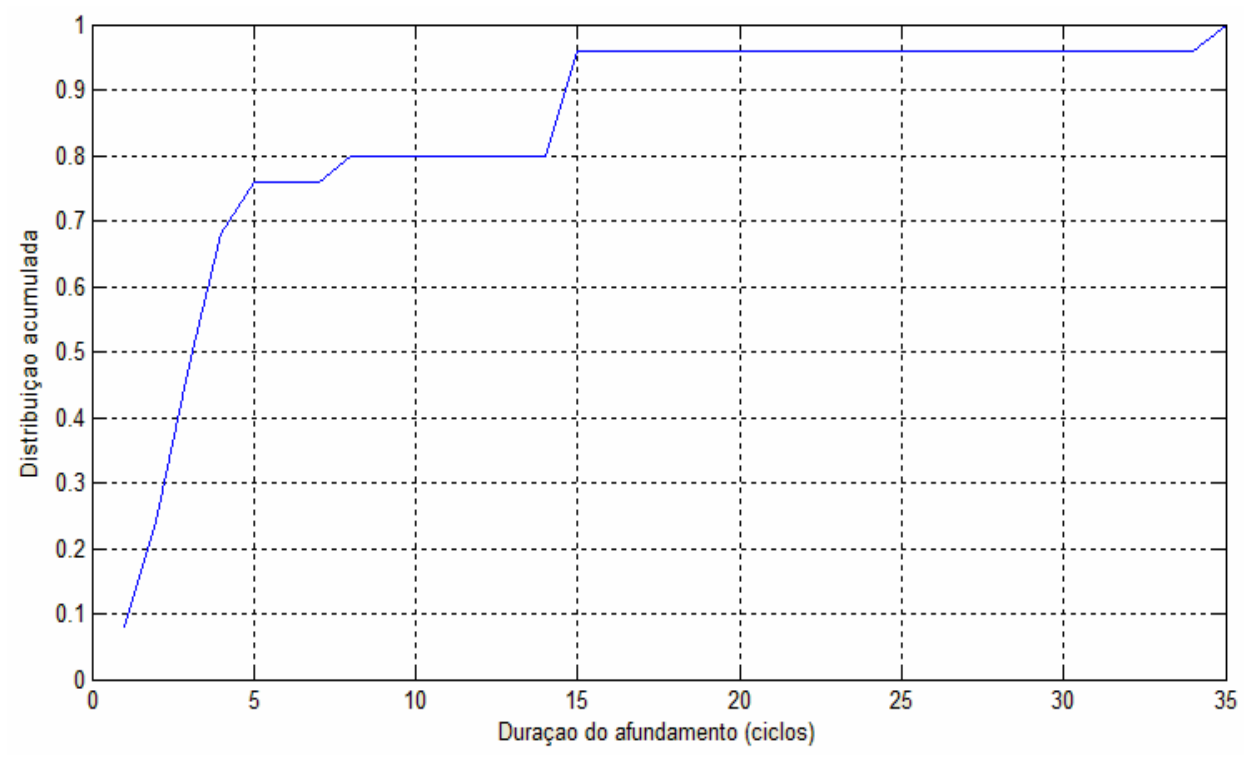

Figura 3.29 - Gráfico da distribuição de probabilidade acumulada por duração. 


\subsubsection{Distribuição dos AFUndamentos POR FASE}

A Figura 3.30 exibe o resultado da seleção do gráfico "Distribuição dos afundamentos e elevações por fase".

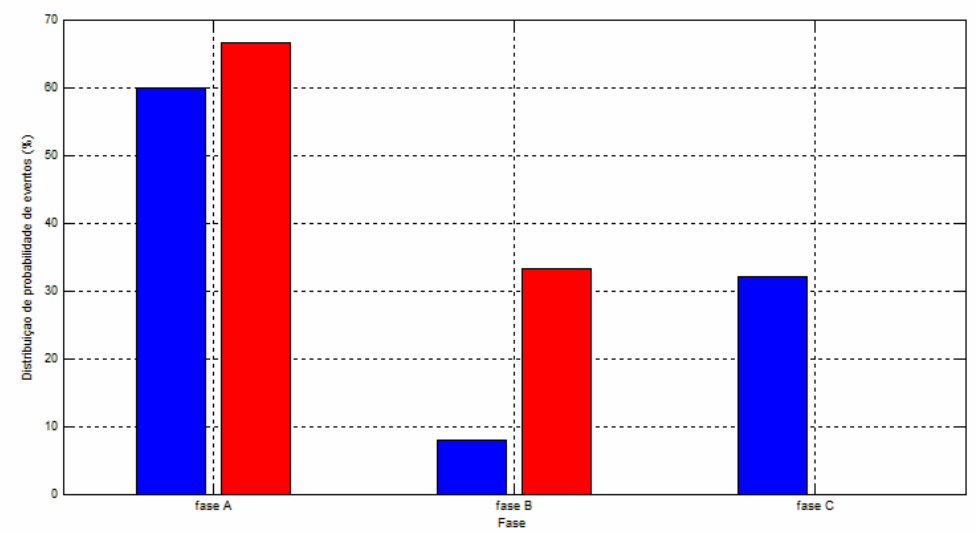

Figura 3.30 - Gráfico da distribuição de probabilidade de ocorrência de afundamentos por fase.

Da Figura 3.30, visualiza-se que a fase A foi a mais prejudicada durante o período de medição. Para exemplificar, a Tabela 3.7 ilustra a quantidade de afundamentos detectados em cada uma das fases durante o mês .

A Tabela 3.7 permite visualizar a ocorrência de 16 afundamentos na fase A, 2 na fase B e 8 na C. Corroborando desta forma com a análise extraída da Figura 3.30.

Tabela 3.7 - Quantidade de afundamentos por fase no mês de setembro na Subestação Miracema.

\begin{tabular}{|c|c|c|}
\hline \multicolumn{3}{|c|}{ Setembro } \\
\hline Fase A & Fase B & Fase C \\
\hline 16 & 2 & 8 \\
\hline
\end{tabular}

\subsection{Módulo de Análise de CuRvas}

Objetiva-se neste módulo efetuar uma análise gráfica dos impactos e causas das VMTs, a partir dos dados oriundos da medição. Para tanto, utilizam-se as curvas descritas no capítulo 3. São elas:

- Curva CBEMA

- Curva ITIC

- Curva de Causas 


\subsubsection{ESTRUTURA Do Módulo De Análise De CuRVAS}

O módulo de análise de curvas, mostrado na Figura 3.31 é acessado por meio do botão “Análise de Curvas” presente na tela de entrada ou a partir do menu "Análises".

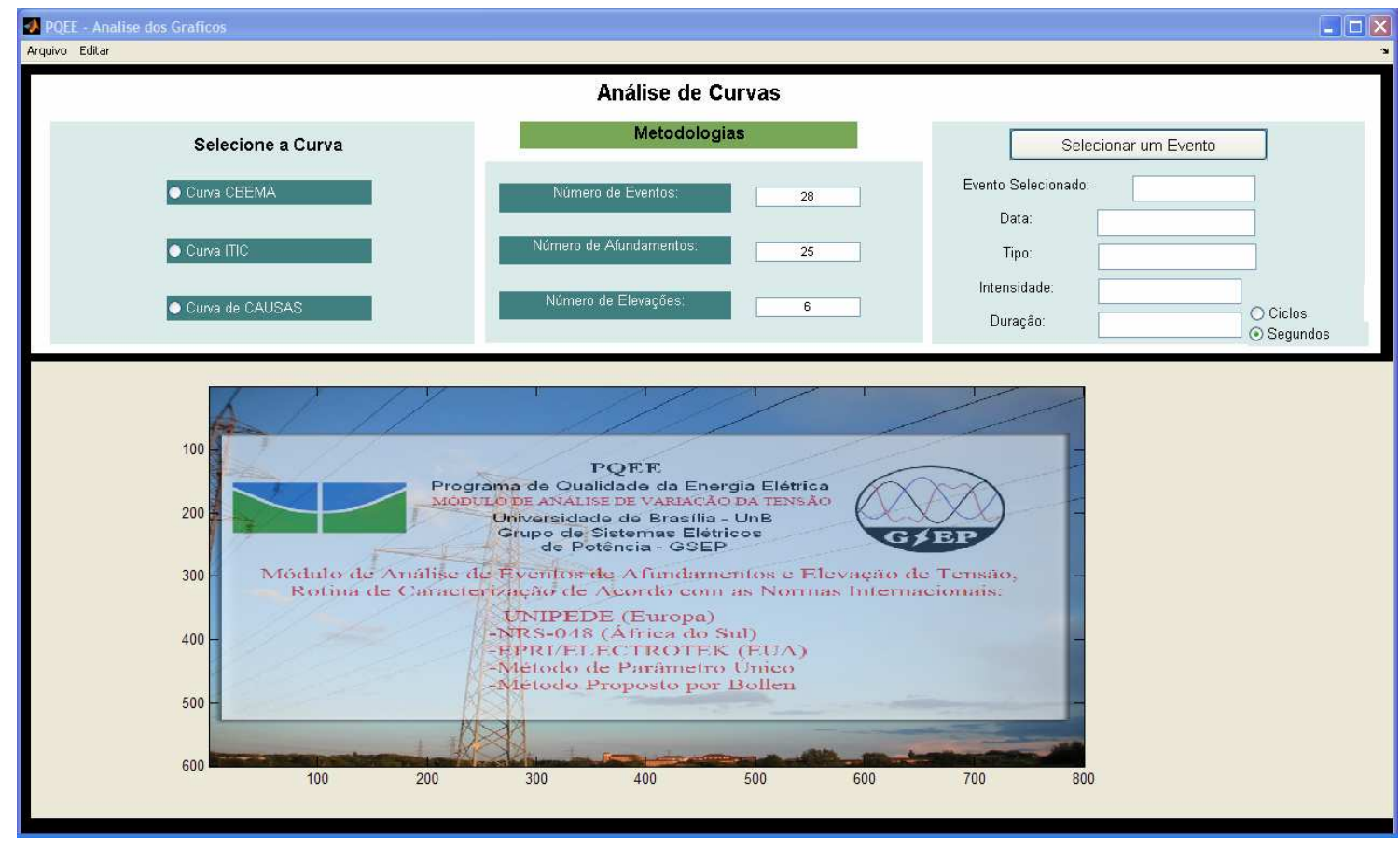

Figura 3.31 - Janela do módulo de análise de curvas.

Para a execução deste módulo é preciso apenas selecionar a curva a ser apreciada. Assim como no módulo de caracterização dos eventos, é possível também obter os parâmetros dos eventos selecionando-se individualmente cada um daqueles que se queira analisar.

\subsubsection{ESTUDO DE CASO DE ANálise DE CURVAS}

Neste tópico serão realizadas as análises das curvas de causas e de efeitos das VMT's disponibilizados neste módulo do programa, para o banco de dados analisado. 


\subsubsection{CURVA DE CBEMA/ ITIC}

As Figuras 3.32 e 3.33 dispõem dos eventos do banco de dados sobre a curva CBEMA e curva ITIC, respectivamente. Observa-se que a grande maioria situou-se na zona em que não traria problemas aos equipamentos eletrônicos, ou seja, na região de imunidade, localizada entre as linhas superior e inferior.

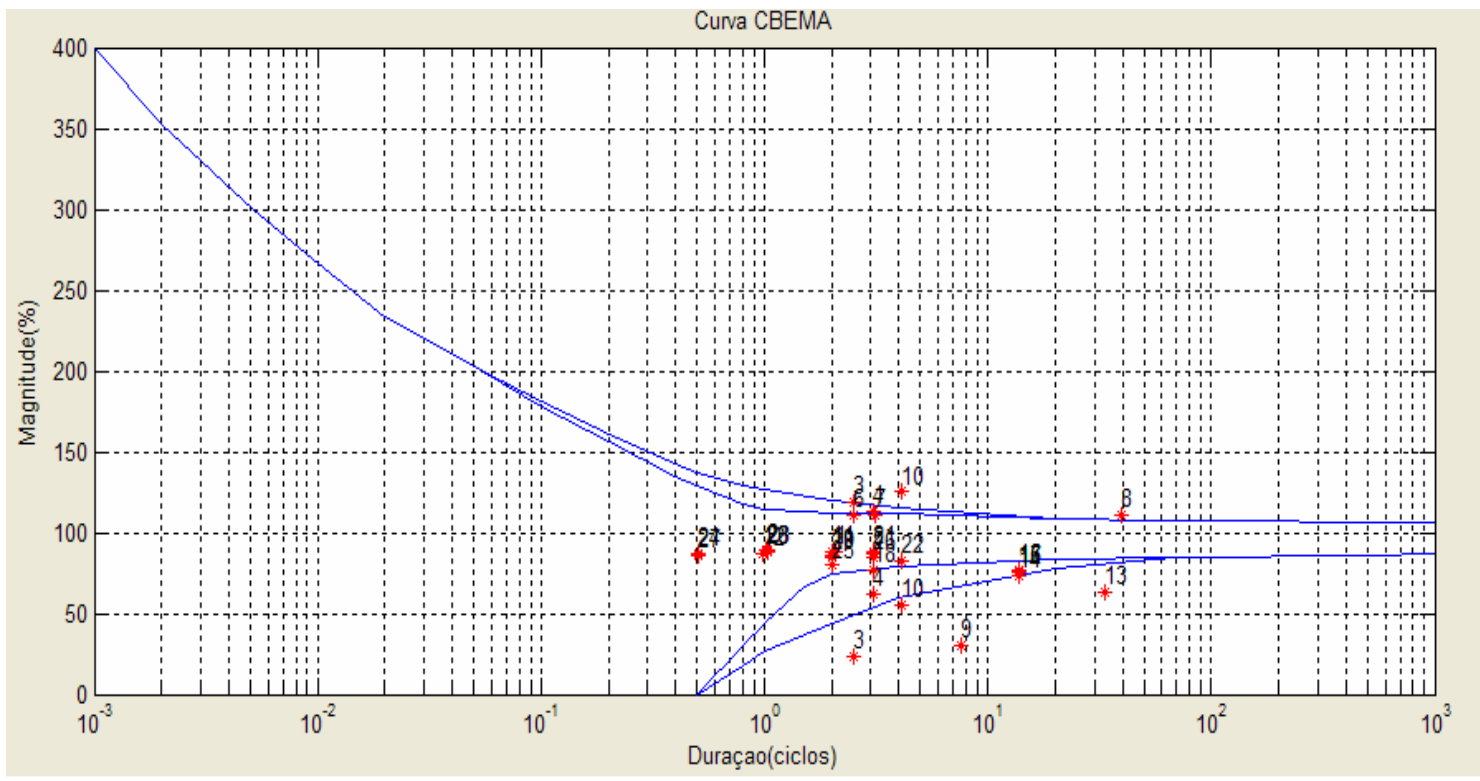

Figura 3.32 - Janela de análise da curva CBEMA.

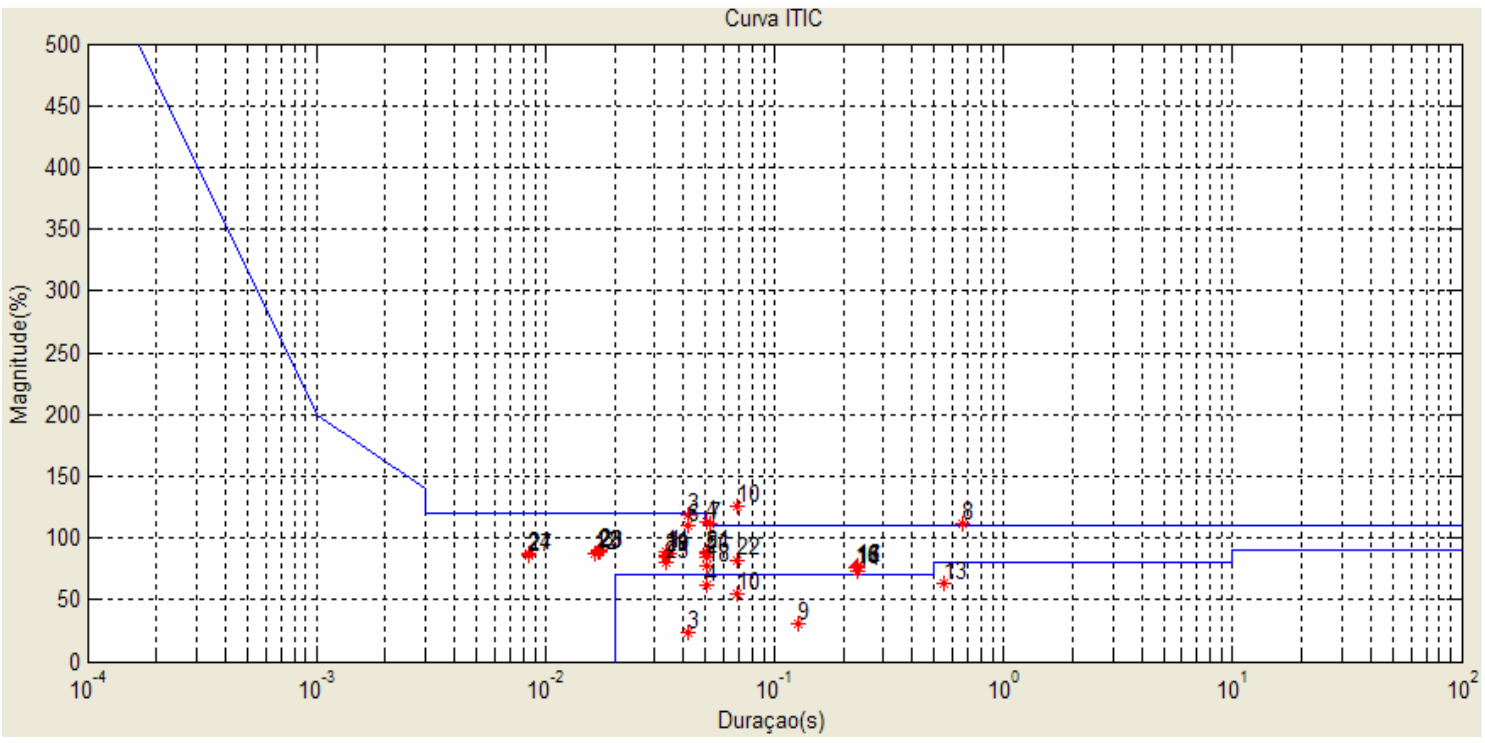

Figura 3.33 - Janela de análise da curva ITIC. 
As Figuras 3.32 e 3.33 revelam que os equipamentos ligados na rede durante a ocorrência dos eventos número 8 e 10 podem ter sofrido danos como, por exemplo, a ruptura da isolação, uma vez que se situam na chamada zona de susceptibilidade. Os afundamentos número 3, 4, 9, 10 e 13, situados na chamada região de sensibilidade, não representariam grande perigo de danos aos equipamentos durante a ocorrência. No entanto, evidencia-se uma grande possibilidade de parada ou mal funcionamento deles no decurso da VMT.

\subsubsection{Curva de CaUsas}

A Figura 3.34 ilustra o gráfico obtido por meio da seleção da opção "Curva de Causas". Esta curva tenta encontrar a possível causa da ocorrência do evento de acordo com suas intensidade e duração. O banco de dados foi o mesmo utilizado no subitem anterior. No entanto, este estudo contempla apenas a análise de afundamentos de tensão.

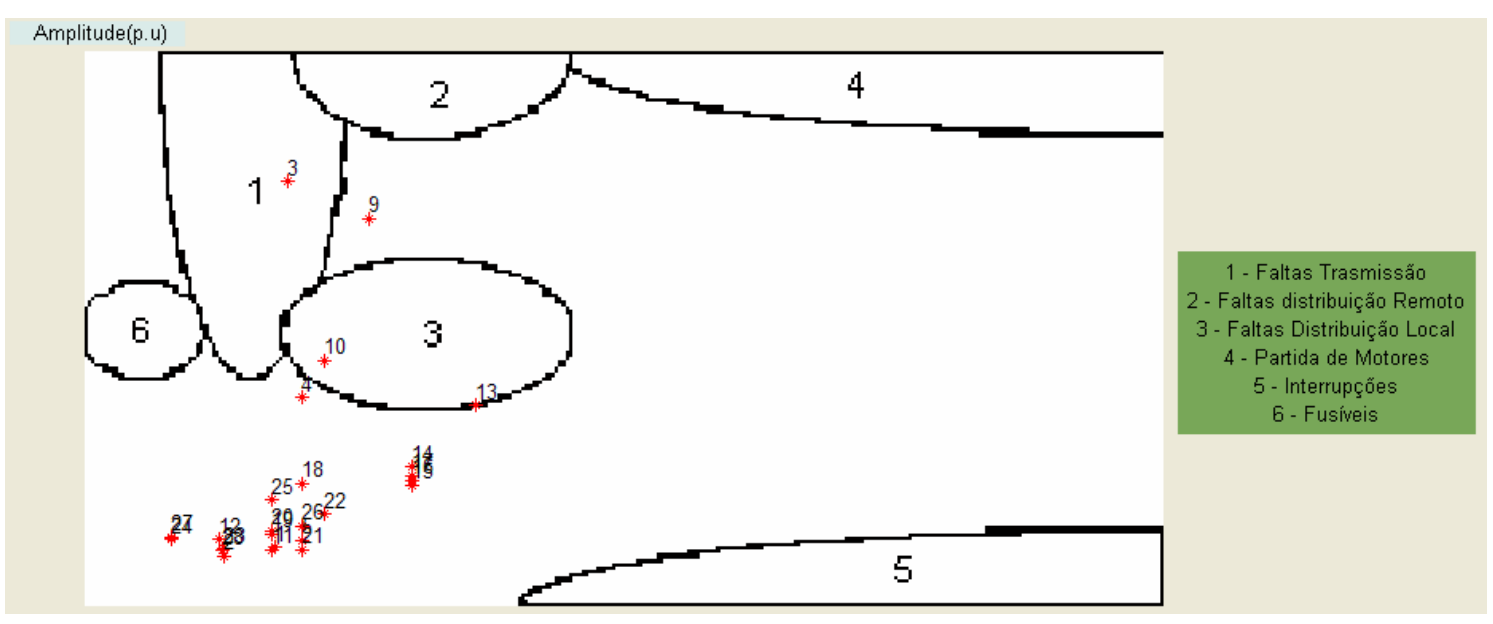

Figura 3.34 - Janela de análise da Curva de Causas.

Visualiza-se na Figura 3.34 que, por não estarem situados dentro do contorno de nenhuma das elipses, para a grande maioria dos afundamentos não foi possível ser associada uma causa pela simples análise de suas intensidade e duração. Para estes casos, somente um estudo mais pontual e preciso pode estimar sua causa. Contudo é possível estimar o motivo de três eventos. O evento número 3, de intensidade 0.23 p.u (tensão remanescente) e duração 2.50 ciclos, localizado na região 1 , tem como provável causa alguma falta no sistema de 
transmissão. Os eventos 10 e 13 foram englobados como resultado de falta no sistema de distribuição local.

\subsection{MÓdULO DE CLASSIFICAÇÃO DOS EVENTOS}

Neste item será apresentado o módulo de classificação dos eventos. Esta ferramenta permite enquadrar cada um dos eventos em faixas pré-estabelecidas por normas internacionais, possibilitando ao usuário obter os padrões de ocorrência das variações momentâneas de tensão. O programa dispõe das seguintes metodologias de classificação: IEEE 1159, NRS 048 e IEC (UNIPEDE).

\subsubsection{ESTRUTURA DO MÓdULO DE CLASSIFICAÇÃo DOS EVENTOS}

Após carregar os dados, esta etapa de análise pode ser acessada pelo botão "Classificação dos Eventos", na tela do módulo de entrada, ou a partir do menu superior “Análises", abrindo-se a janela mostrada na Figura 3.35. Acima, à esquerda, ficam disponíveis as metodologias de classificação: IEC (UNIPEDE), IEEE - 1159 e NRS - 048. As quantidades dos eventos presentes no banco de dados carregado são mostradas no quadro à direita.

Selecionada a classificação desejada, as Tabelas com as quantidades de eventos para cada faixa são calculadas automaticamente pelo software.

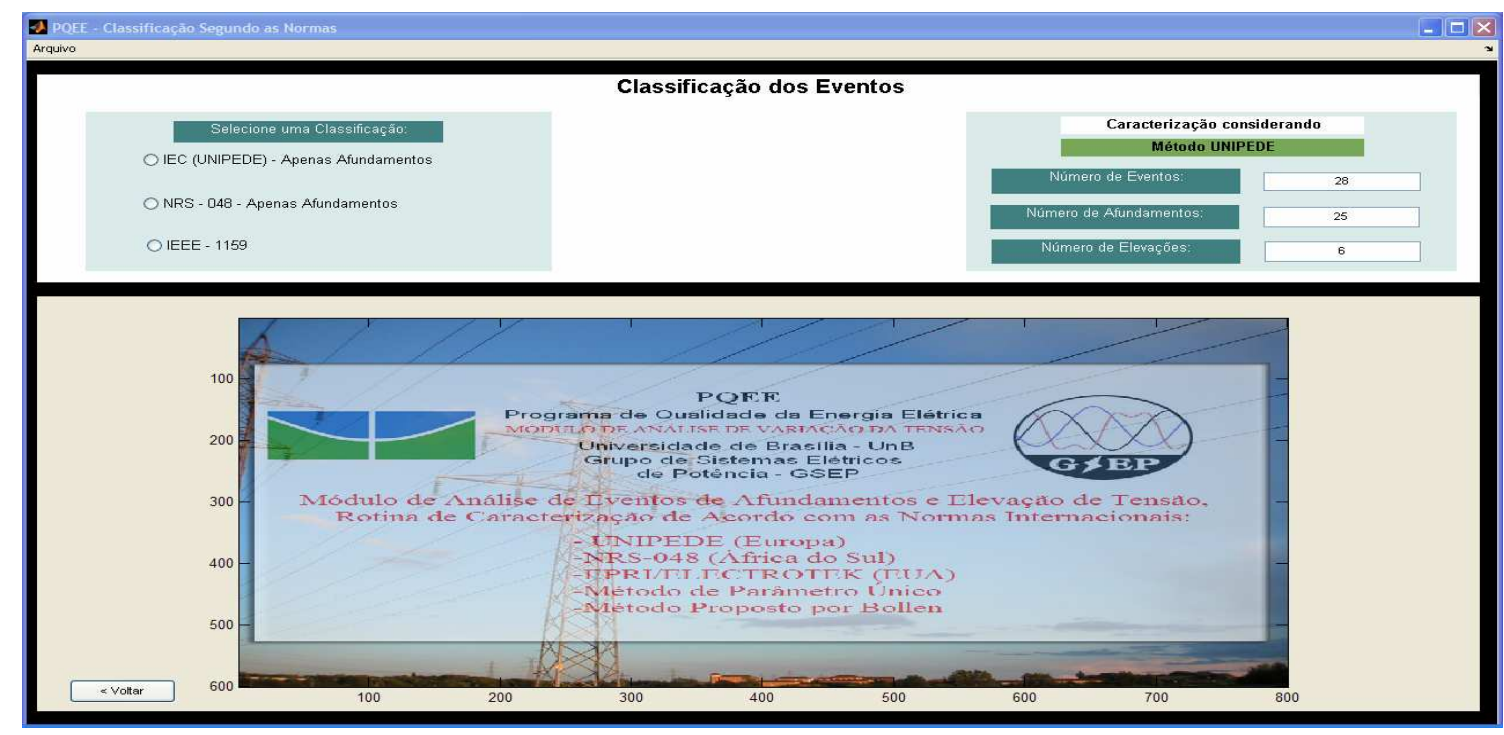

Figura 3.35 - Janela do módulo de classificação dos eventos. 


\subsubsection{ESTUdO DE CASO DA CLASSIFICAÇÃ D OS EVENTOS}

Com o objetivo de ilustrar a utilidade do módulo, será feita a classificação dos dados usados nas etapas anteriores.

\subsubsection{METODOLOGIA UNIPEDE ( IEC 61000-2-8)}

Conforme visto no capítulo 3, a metodologia UNIPEDE é válida apenas para afundamentos de tensão. Ela os separa em 28 faixas possíveis de acordo com a intensidade e duração. A Figura 3.36 ilustra a classificação através desta norma.

\begin{tabular}{|c|c|c|c|c|c|c|c|}
\hline \multicolumn{8}{|c|}{ Metodologia IEC (UNIPEDE) } \\
\hline $\begin{array}{c}\text { Intensidadel } \\
\text { Duraçao }\end{array}$ & $0,5-1$ ciclo & $1 \mathrm{ciclo}-100 \mathrm{~ms}$ & $100 \mathrm{~ms} \cdot-500 \mathrm{~ms}$ & $500 \mathrm{~ms}-1 \mathrm{~s}$ & $1 s-3 s$ & $3 s-20 s$ & $20 \mathrm{~s}-3 \mathrm{~min}$ \\
\hline $70-90 \%$ & 0 & 1 & 1 & 0 & 0 & 0 & 0 \\
\hline $40-70 \%$ & 0 & 1 & 0 & 0 & 0 & 0 & 0 \\
\hline $1-40 \%$ & 3 & 14 & 4 & 1 & 0 & 0 & 0 \\
\hline$<1 \%$ & 0 & 0 & 0 & 0 & 0 & 0 & 0 \\
\hline
\end{tabular}

Figura 3.36 - Classificação dos Eventos segundo metodologia UNIPEDE (IEC 61000-2-8).

A Figura 3.36 mostra que a grande maioria dos afundamentos ocorreu com intensidade entre $1 \%$ e $40 \%$ da tensão nominal e duração entre 1 ciclo e $100 \mathrm{~ms}$. Selecionando-se o botão “Comparar com Caracterização NRS - 048”, o programa mostra as classificações desta metodologia utilizando-se dos dados caracterizados pela norma NRS - 048. Tal procedimento encontra-se ilustrado na Figura 3.37.

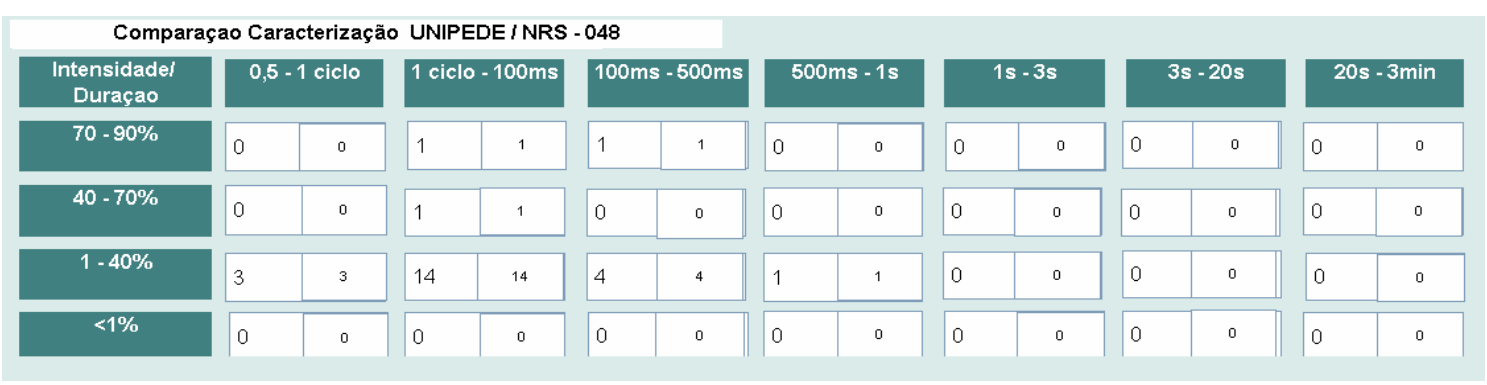

Figura 3.37 - Classificação dos Eventos segundo metodologia UNIPEDE (IEC 61000-2-8) caracterizado pelas norma UNIPEDE e NRS - 048 . 
A Figura 3.37 mostra que não houve mudança de faixa no enquadramento dos afundamentos. As quantidades dos eventos para nos intervalos permaneceram as mesmas. Isso decorre do fato de, neste banco de dados, não haverem grandes diferenças entre os parâmetros encontrados a partir da utilização das duas metodologias.

\subsubsection{METOdologia IEEE - 1159}

É a mais abrangente das metodologias apresentadas neste trabalho. Ordena não apenas afundamentos e elevações como também as interrupções de tensão. A Figura 3.38 exibe esta classificação e ilustra também uma comparação realizada das quantidades de eventos, caracterizados de acordo com a norma NRS - 048.

\begin{tabular}{|c|c|c|c|c|}
\hline Categoria & Duração & Intensidade p.u. & $\begin{array}{l}\text { Qtde de Eventos } \\
\text { UNIPEDE }\end{array}$ & $\begin{array}{l}\text { Qtde de Eventos } \\
\text { NRS - 048 }\end{array}$ \\
\hline \multicolumn{5}{|l|}{ Instantâneo } \\
\hline Afundamento & 0,5 até 30 ciclos & 0,1 até 0,9 & 24 & 24 \\
\hline Elevaçẫo & 0,5 até 30 ciclos & 1,1 até 1,8 & 5 & 6 \\
\hline \multicolumn{5}{|l|}{ Momentâneo } \\
\hline Interrupçăo & 0.5 ciclos até $3 \mathrm{~s}$ & $<0,1$ p.u. & 0 & 0 \\
\hline Afundamento & 30 ciclos até $3 \mathrm{~s}$ & 0,1 até 0,9 & 1 & 1 \\
\hline Elevaçăo & 30 ciclos até $3 \mathrm{~s}$ & 1,1 até 1.8 & 1 & 0 \\
\hline \multicolumn{5}{|l|}{ Temporário } \\
\hline Interrupção & $3 \mathrm{~s}$ até $1 \mathrm{~min}$ & $<0,1 p . u$ & 0 & 0 \\
\hline Afundamento & $3 \mathrm{~s}$ até $1 \mathrm{~min}$ & 0,1 até 0,9 & 0 & 0 \\
\hline Elevaçẫo & $3 \mathrm{~s}$ até $1 \mathrm{~min}$ & 1,1 até 1,8 & 0 & 0 \\
\hline
\end{tabular}

Figura 3.38- Classificação dos Eventos segundo metodologia IEEE - 1159 .

Da Figura 3.38 visualiza-se que do banco de dados examinado não se verificou a ocorrência de interrupções de tensão. A grande maioria dos eventos encontra-se na faixa correspondente aos afundamentos instantâneos, sendo quantificados 24 sags. Quanto às elevações de tensão, nota-se que 5 destas qualificam-se como elevações instantâneas. Na análise comparativa notase que houve uma mudança na classificação de um evento, pois uma elevação deixou de ser enquadrada como momentânea e passou a ser instantânea. Por esta norma ser mais abrangente, ela pode ordenar eventos de intensidades muito diferentes num mesmo patamar. Sendo assim, a análise apenas desta norma não é suficiente para estudo preciso dos eventos. 


\subsubsection{METOdologia NRS}

A metodologia de classificação NRS - 048, assim como a UNIPEDE, só especifica faixas para afundamentos de tensão. Esta norma traz como contribuição a classificação numa mesma região dos afundamentos de pequena amplitude independentemente da sua duração. As demais faixas são bem definidas quanto a seus limites. A Figura 3.39 mostra as quantidades destes eventos, classificados a partir do banco de dados da subestação Miracema. Visualiza-se também na Figura 3.40, a comparação entre as metodologias de caracterização da mesma forma como foi abordada nos itens 3.39 e 3.40 .

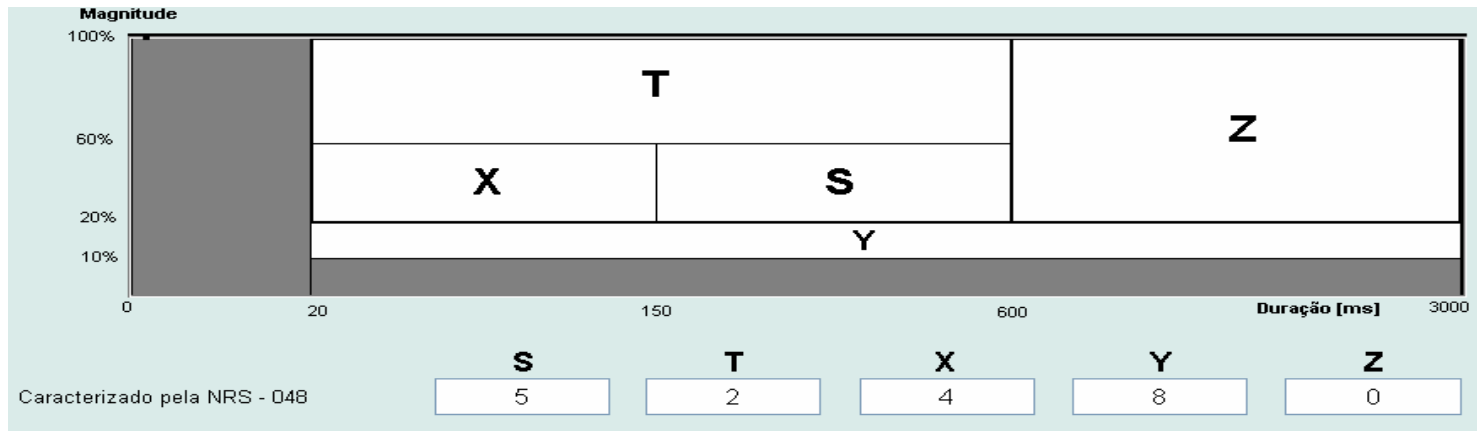

Figura 3.39 - Classificação dos Eventos segundo metodologia NRS - 048.

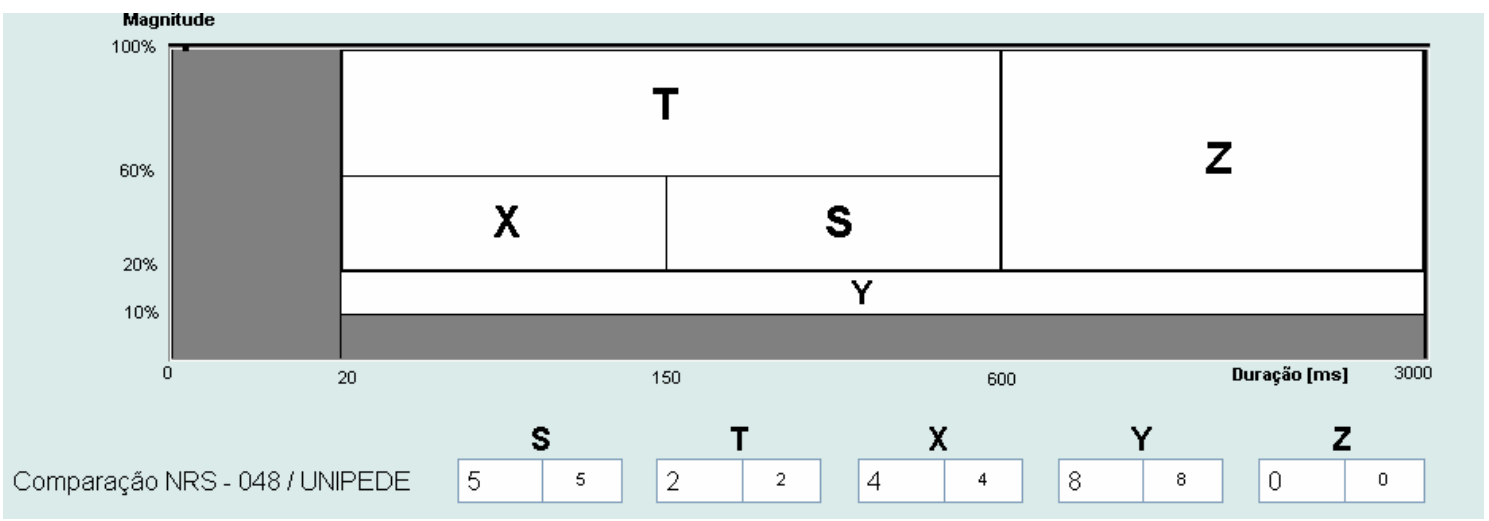

Figura 3.40 - Classificação dos Eventos segundo metodologia NRS - 048/ UNIPEDE.

A Figura 3.39 mostra que os eventos ficaram localizados em sua maioria na região $\mathrm{Y}$, onde se tem menor intensidade e duração entre $20 \mathrm{~ms}$ e $3000 \mathrm{~ms}$, apresentando 8 afundamentos. $\mathrm{Na}$ região Z não foi classificada nenhuma ocorrência. Em relação à comparação entre as caracterizações, não se observa na Figura 3.40 nenhuma mudança de faixa. 


\subsection{CONSIDERA Ç Õ ES FINAIS}

O presente capítulo apresentou a ferramenta computacional para análise de Variações Momentâneas de Tensão, trazendo uma visão geral sobre sua estrutura, bem como sobre o formato do banco de dados a ser utilizado.

Pelas análises realizadas no item de características dos eventos, verificaram-se as diferentes metodologias de caracterização com o uso de exemplos de eventos da SE Miracema. A extração dos parâmetros únicos mostrou-se um método interessante de forma a reduzir o número de parâmetros para caracterizar um único afundamento. A análise comparativa entre as metodologias possibilitou acompanhar as diferenças entre as mesmas, de forma fácil e objetiva.

Relativo ao estudo de casos, pode-se visualizar a caracterização do evento na forma gráfica facilitando seu entendimento, além de ter a disponibilidade de se obter as características referentes a cada evento. Tem-se ainda a possibilidade de, para cada evento, visualizar sua forma de onda e o valor eficaz de tensão. Dessa forma, tal módulo disponibiliza de forma direta e completa informações básicas sobre a caracterização do evento segundo as principais normas internacionais.

No módulo de estatísticas evidenciou-se uma ferramenta de suma importância para uma análise mais direta, quando se quer um panorama sobre o local de medição de forma mais rápida.

A análise de curvas mostrou ser um importante instrumento gráfico para investigação dos efeitos das VMTs sobre equipamentos eletrônicos, bem como as possíveis causas dos afundamentos de tensão. Contudo seu uso presta-se a uma primeira análise, de forma a orientar a continuidade dos estudos em campo para uma diagnose mais precisa.

Por fim, descreveu-se o módulo de classificação dos eventos. Constatou-se que mesmo utilizando-se diferentes métodos, uma das faixas sempre teve a maioria dos eventos em relação às demais. Isso demonstra que mesmo sendo utilizadas metodologias aparentemente diferentes, as três carregam similaridade. 


\section{CAPÍt Ulo 4}

\section{Análise de Parte do Sistema \\ ELETRONORTE}

Neste capítulo, faz-se um estudo conjunto voltado à quantificação e à qualificação das Variações Momentâneas de Tensão nos principais consumidores da Eletronorte. Nesta avaliação, foram utilizados valores oriundos de medições efetuadas nas subestações que alimentam os diversos locais. As análises contemplam os meses de outubro, novembro e dezembro do ano de 2006.

Inicialmente, serão apresentados os dez pontos para que o leitor possa conhecê-los. Em seguida, será elaborada uma análise quantitativa por meio de recursos gráficos e estatísticos onde objetiva-se ilustrar os resultados das análises sobre as Variações Momentâneas de Tensão (VMTs). Para tanto, empregar-se-á o PQEE - Módulo de Variações Momentâneas de Tensão e também o Microsoft Office Excel. Serão postas à apreciação figuras, gráficos de ocorrências, comparações entre os períodos de ocorrência e tabelas com dados estatísticos, que permitem a execução de uma criteriosa pesquisa quanto ao comportamento das VMTs. Em seguida, serão mostradas as análises de curvas onde, a partir dos resultados obtidos, será feita a qualificação dos dados de modo a verificar as causas e seus impactos. Mais adiante serão mostradas as classificações dos eventos pelas metodologias IEEE -1159 e NRS 048. Por fim, será realizada uma análise anual através de uma extrapolação dos bancos de dados onde se pretende especular o comportamento do sistema por um maior período.

\subsection{E S C R I Ç Ã O D OS L OCA IS}

Neste trabalho, serão avaliados os resultados das medições das Variações Momentâneas de Tensão de dez locais, sendo 9 grandes consumidores industriais (Figura 4.1) e 1 linha de intercâmbio entre submercados (Figura 4.2). Os dados aqui apresentados são oriundos da seção de medição e comercialização da companhia Centrais Elétricas do Norte do Brasil SA. (ELETRONORTE), que utilizam medidores do tipo ION 8500, fabricados pela Power 
Measurement. A seguir será realizada uma descrição individual das localidades selecionadas para o estudo.

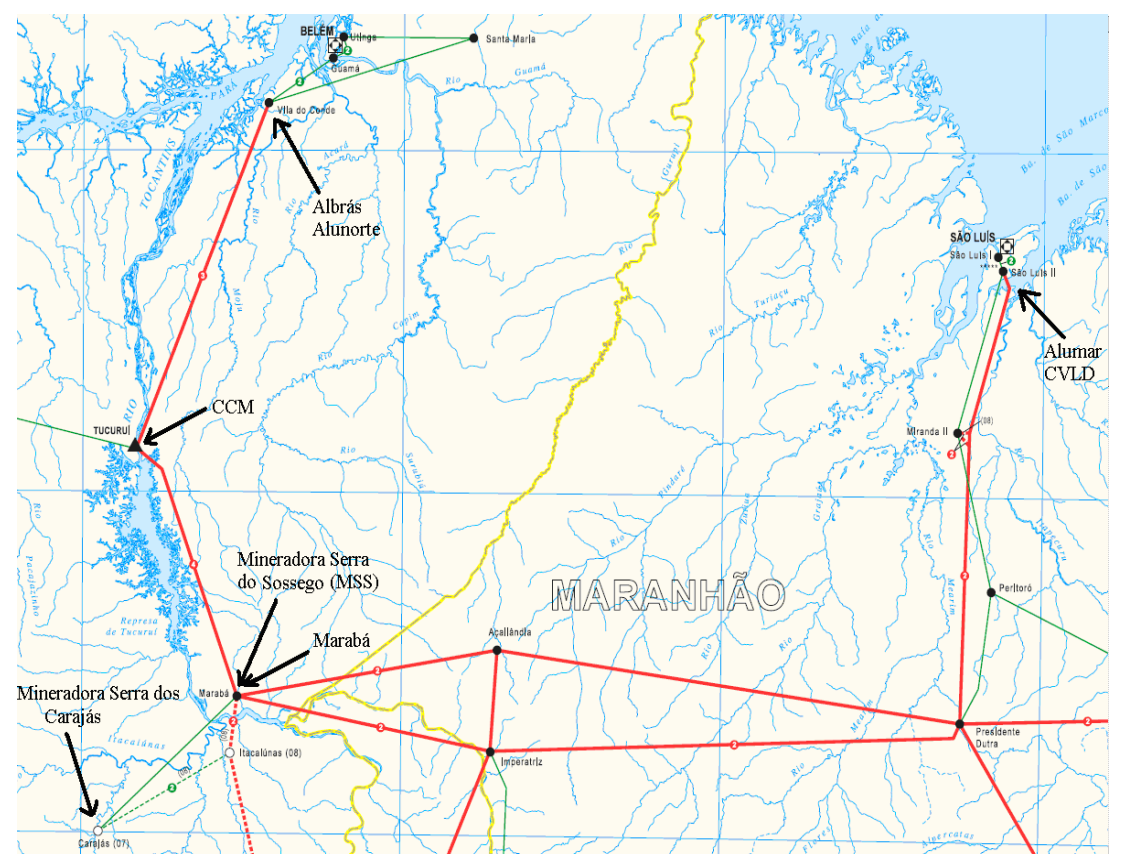

Fonte: ONS (http://www.ons.org.br/conheca_sistema/mapas_sin.aspx). Acesso em: out. 2006.

Figura 4.1 - Grandes consumidores industriais da Eletronorte.

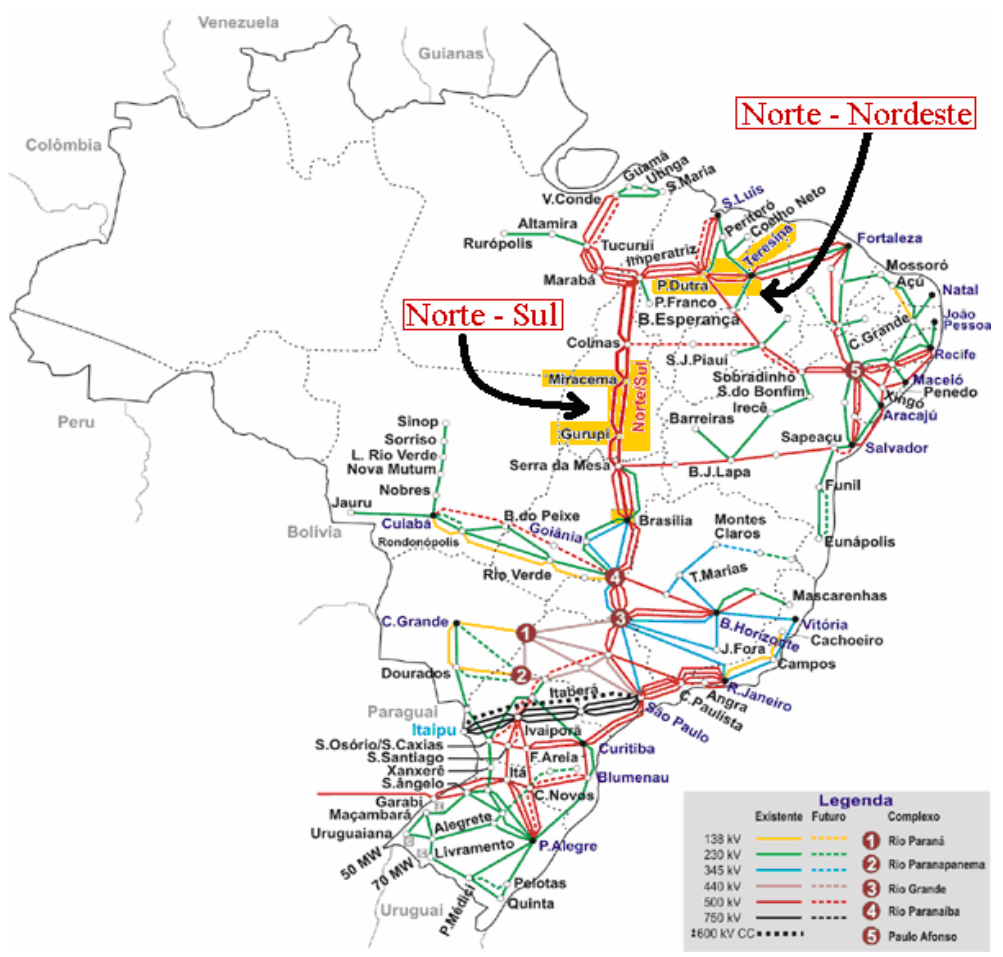

Fonte: ONS (http://www.ons.org.br/conheca_sistema/mapas_sin.aspx). Acesso em: out. 2006.

Figura 4.2 - Linhas de intercâmbios entre submercados da Eletronorte. 


\subsubsection{CONSUMIDORES INDUSTRIAIS}

\section{- Albrás}

A ALBRÁS, Alumínio Brasileiro S.A., é uma indústria de produção de alumínio, cuja demanda atual é cerca de 800 MW, é suprida através de uma subestação própria denominada SE ALBRÁS que, por sua vez, está conectada à Rede Básica na SE Vila do Conde. Tal conexão se dá por meio de uma linha em $230 \mathrm{kV}$, circuito duplo, de comprimento igual a 1,6 $\mathrm{km}$.

\section{- Alunorte}

A ALUNORTE, Alumina do Norte do Brasil S.A., é destinada à produção de alumina. A fábrica é dividida em duas unidades, a Fabril e a Vapor. Atualmente, seu suprimento é oriundo da SE ALBRAS, por meio de linha de transmissão em $230 \mathrm{kV}$, circuito simples, com cerca de $2,5 \mathrm{~km}$ de extensão.

A ALUNORTE Fabril possui uma capacidade instalada de 70MW. Já a ALUNORTE Vapor é composta por três caldeiras de capacidade individual igual a 45 MW. Existe ainda uma central termoelétrica de $25 \mathrm{MW}$, que opera na modalidade de autoprodução local.

\section{- Alumar}

A ALUMAR é uma indústria metalúrgica de produção de alumina e alumínio primário, localizada no município de São Luís, Estado do Maranhão. Com demanda atual de 825 MW, seu suprimento se dá pelo sistema de $230 \mathrm{kV}$ da ELETRONORTE. A carga dessa indústria é composta por retificadores (620 MW), motores assíncronos (45 MW), compressores (15 MW) e outras menores com cerca de 20 MW, constituídas por caldeiras, pré-aquecedores, fornos de indução e motores síncronos. O que resulta em uma demanda total de 825 MW. 


\section{- Camargo Correa Metais (CCM)}

A Camargo Correa metais é uma indústria de Silício metálico, alimentada através da SETucuruí, em 230 kV. Apresenta uma demanda de aproximadamente 73MW.

\section{- Mineradora Serra do Sossego}

Trata-se de uma mina de cobre conectada a Eletronorte através de uma linha de transmissão em 230 kV, oriunda da SE Carajás. Sua capacidade instalada é de 64 MW.

\section{- CVRD São Luís}

Este consumidor divide-se em CVRD-CPPM (Complexo Portuário de Ponta do Madeira) e CVRD-Pelotização. A interligação à Eletronorte se dá através de uma linha de transmissão de $230 \mathrm{kV}$ junto a SE - São Luís II. O Complexo da CVRD engloba as principais atividades do terminal portuário do Estado do Maranhão. Hoje, o Porto se ocupa da logística de exportação de commodities como minério de ferro, manganês, soja, minério semi-beneficiado, além do ferro gusa. A Unidade de Pelotização, recentemente implantada, é uma usina de produção de pelotas voltada aos grandes produtores de aço.

\subsubsection{PONTO DE INTERCÂMBIO}

\section{- Miracema}

Trata-se de um ponto de intercâmbio da rede básica Norte-Sul. Nesse ponto existe uma linha de transmissão de 500 kV que interliga Miracema a Gurupi.

\subsection{A NÁl ISE Q UANTITATIVA}

Esta seção apresentará um estudo quantitativo da ocorrência dos eventos referentes aos dez locais observados. Serão realizadas análises em relação à quantidade de afundamentos e elevações em cada um destes em diferentes períodos do dia, bem como a comparação entre os dias úteis e os finais semana. Mais a frente, serão apreciadas as ocorrências por cada fase do sistema. 


\subsubsection{QUANTIFICAÇÃO DOS EVENTOS}

A Tabela 4.1 apresenta uma visão geral da ocorrência de eventos nos locais em análise durante o período de medição (trimestre):

Tabela 4.1 - Quantificação dos Eventos nos Locais de Medição no período de outubro, novembro e dezembro

\begin{tabular}{|l|c|c|c|}
\cline { 2 - 4 } \multicolumn{1}{c|}{} & \multicolumn{3}{c|}{ Quantificação dos Eventos } \\
\cline { 2 - 4 } \multicolumn{1}{c|}{} & Total de Eventos & Afundamentos & Elevações \\
\hline Miracema & 47 & 47 & 10 \\
\hline Alumar L1 & 73 & 35 & 39 \\
\hline Alumar L2 & 34 & 26 & 8 \\
\hline Albrás L1 & 5 & 5 & 1 \\
\hline Albrás L2 & 6 & 5 & 1 \\
\hline Alunorte & 5 & 5 & 1 \\
\hline Carajás & 32 & 31 & 1 \\
\hline CCM & 14 & 14 & 0 \\
\hline CVLD & 40 & 39 & 1 \\
\hline Tucuruí & 37 & 37 & 1 \\
\hline
\end{tabular}

Em alguns locais nota-se que o número de eventos difere da soma dos afundamentos e elevações. Isto se deve ao fato de certos eventos apresentarem, concomitantemente, uma elevação e um afundamento durante sua ocorrência.

Observa-se da Tabela 4.1 que a subestação Alumar L1 foi o local com maior quantidade de elevações, em conseqüência, o maior total de eventos. No entanto, a maior ocorrência de afundamentos foi na SE Miracema.

Os consumidores Albrás L1, Albrás L2 e Alunorte apresentaram as menores ocorrências de VMTs (Tabela 4.1). Cada um destes locais apresentou 5 subtensões e 1 sobretensão. A subestação de Camargo Correia Metais (CCM) não apresentou nenhuma ocorrência de elevação. Tal fato sugere uma melhor análise no processo de medição adotado para o local.

A Figura 4.3 apresenta um gráfico de barras contendo a quantidade de eventos, afundamentos e elevação para cada um dos dez pontos em análise. 


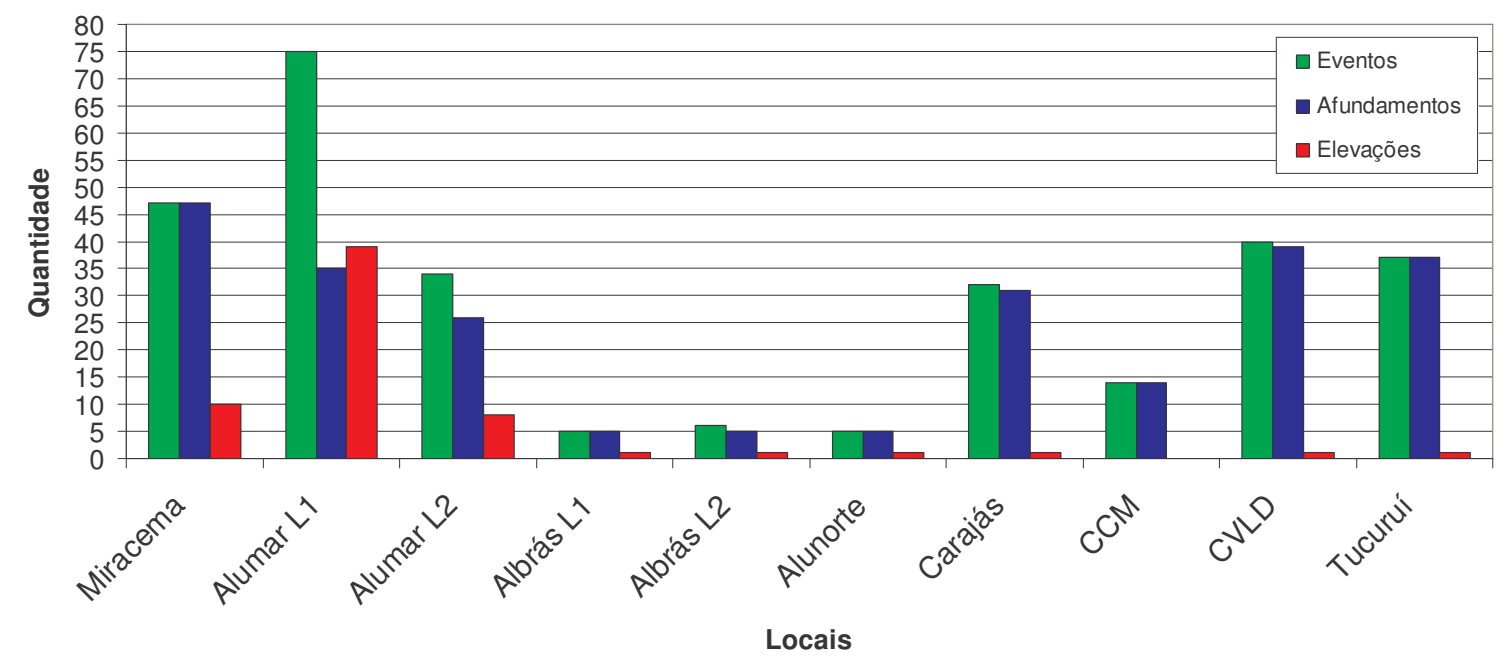

Figura 4.3 - Quantidade de eventos, elevações e afundamentos.

Obteve-se para todo o período de medição nos dez locais analisados um total de 293 eventos, o que representa uma média de 29,3 VMTs por local, e um desvio-padrão de 22,71. Os afundamentos totalizaram 244 ocorrências, um valor médio de 24,4 afundamentos por local com desvio de 15,911. Já as elevações de tensão totalizaram 63 ocorrências, ou seja, 6,3 elevações por local e desvio padrão de 11,9111. O elevado desvio padrão calculado evidencia o comportamento díspar dos dez locais em análise, tal fato é ilustrado pela diferença quantitativa de eventos nos locais Albrás e Alumar L1.

Tabela 4.2 - Participação em Porcentagem

\begin{tabular}{|l|c|c|c|}
\cline { 2 - 4 } \multicolumn{1}{c|}{} & \multicolumn{3}{c|}{ Participação dos Locais (\%) } \\
\cline { 2 - 4 } \multicolumn{1}{c|}{} & Eventos & Afundamentos & Elevações \\
\hline Miracema & 16.04 & 19.26 & 15.87 \\
\hline Alumar L1 & 25.60 & 10.66 & 61.90 \\
\hline Alumar L2 & 11.60 & 2.05 & 12.70 \\
\hline Albrás L1 & 1.71 & 2.05 & 1.59 \\
\hline Albrás L2 & 2.05 & 2.05 & 1.59 \\
\hline Alunorte & 1.71 & 12.70 & 1.59 \\
\hline Carajás & 10.92 & 5.74 & 1.59 \\
\hline CCM & 4.78 & 15.98 & 0.00 \\
\hline CVLD & 13.65 & 15.16 & 1.59 \\
\hline Tucuruí & 12.63 & 3.69 & 1.59 \\
\hline
\end{tabular}


A Tabela 4.2 mostra o percentual da participação de cada local em relação ao total de eventos, afundamentos e elevações. Evidencia-se a grande participação de Alumar L1 em relação ao número de sobretensões no sistema.

\subsubsection{ANÁlise De OCORRÊNCIAS POR PERÍOdOS do DiA}

Neste tópico é realizado um estudo quantitativo do número de ocorrências em quatro períodos do dia, são eles: $0 \mathrm{~h}$ às $6 \mathrm{~h} ; 6 \mathrm{~h}$ às $12 \mathrm{~h} ; 12 \mathrm{~h}$ às $18 \mathrm{~h}$ e $18 \mathrm{~h}$ às $24 \mathrm{~h}$.

A Tabela 4.3 mostra o número de eventos para cada um dos locais estudados e o total de eventos por intervalo do dia.

Tabela 4.3 - Ocorrência de eventos por período do dia

\begin{tabular}{|c|c|c|c|c|}
\cline { 2 - 5 } \multicolumn{1}{c|}{} & \multicolumn{4}{c|}{ Período do Dia } \\
\cline { 2 - 5 } \multicolumn{1}{c|}{} & $\mathbf{0 h}-\mathbf{6 h}$ & $\mathbf{6 h}-\mathbf{1 2} \mathbf{h}$ & $\mathbf{1 2} \mathbf{h}-\mathbf{1 8 h}$ & $\mathbf{1 8 h}-\mathbf{2 4 h}$ \\
\hline Miracema & 13 & 5 & 18 & 11 \\
\hline Alumar L1 & 13 & 20 & 32 & 8 \\
\hline Alumar L2 & 9 & 6 & 17 & 2 \\
\hline Albrás L1 & 0 & 0 & 3 & 2 \\
\hline Albrás L2 & 0 & 0 & 4 & 2 \\
\hline Alunorte & 0 & 0 & 3 & 2 \\
\hline Carajás & 4 & 8 & 17 & 3 \\
\hline CCM & 2 & 0 & 10 & 2 \\
\hline CVLD & 13 & 5 & 16 & 6 \\
\hline Tucuruí & 7 & 12 & 9 & 9 \\
\hline \multicolumn{7}{|c|}{ Total: } & 61 & 56 & 129 & 47 \\
\hline
\end{tabular}

Da Tabela 4.3 nota-se a predominância de ocorrências compreendidas no período de $12 \mathrm{hs}$ às 18hs com 129 eventos nesta faixa, uma participação de 43,97\% do total. Os outros períodos: Oh às $6 \mathrm{hs}, 6 \mathrm{hs}$ às $12 \mathrm{hs}$ e $18 \mathrm{hs}$ às $24 \mathrm{hs}$; apresentaram $20,85 \% ; 19,16 \%$ e $16,02 \%$ do total de eventos, respectivamente. 
Dentro do período compreendido entre $12 \mathrm{~h}$ e 18h, observa-se que Alumar L1 apresenta maior contribuição, um total de 32 eventos. Seguido por Miracema, 18 eventos e Alumar L2 e Carajás com 17 eventos (Tabela 4.3).

A Figura 4.4 apresenta um gráfico de barras com a quantidade de eventos para cada período do dia.

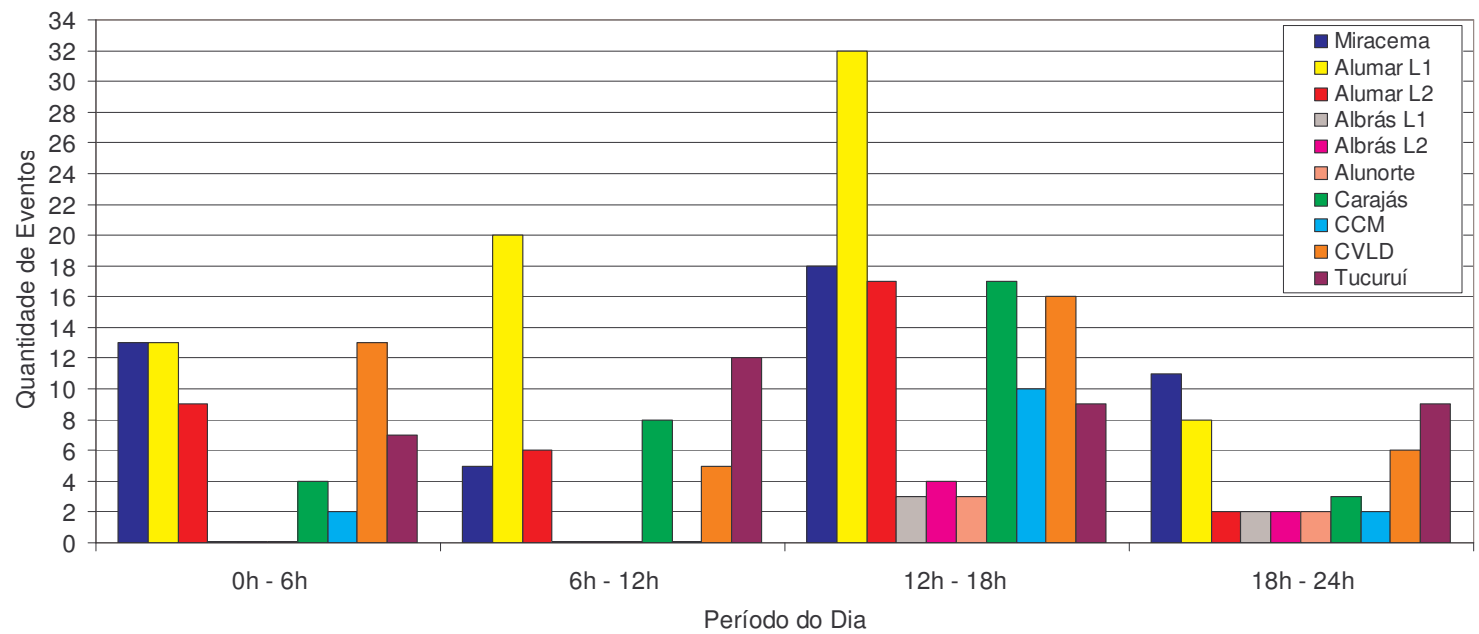

Figura 4.4 - Gráfico da quantidade de eventos versus período do dia.

A partir da Figura 4.4 observa-se a ocorrência de Variações Momentâneas de Tensão em todos os locais observados nos períodos de $12 \mathrm{hs}$ às $18 \mathrm{hs}$ e $18 \mathrm{hs}$ às $24 \mathrm{hs}$. Em Albrás L1, Albrás L2 e Alunorte não houve eventos durante o período da manhã.

O maior número de eventos nos períodos de 6 hs às $12 \mathrm{hs}$, deu-se em Alumar L1. Já entre 18hs e 24hs foi em Miracema (Figura 4.4).

\subsubsection{Análise dos Dias Úteis VERSUS Final de SEMANa}

Esta seção analisa a ocorrência de eventos durante os dois períodos selecionados, de segunda à sexta-feira (dias úteis) e sábado e domingo (final de semana).

Por se tratar de grandes consumidores industriais, sabe-se que eles operam full-time, ou seja, uma produção ininterrupta. Sendo assim, tem-se que a carga nestes locais não sofre grandes alterações quando comparados os períodos de finais de semana e dias da semana. Destarte, 
busca-se com esta análise observar uma proporcionalidade na ocorrência, entre os eventos ocorridos durante os dias úteis e os finais de semana. A proporção encontrada deve ser de aproximadamente $70 \%$ para os dias úteis e $30 \%$ para os finais de semana, relacionados à representatividade do período em estudo e o semanal (7 dias).

As Tabelas 4.4 e 4.5 mostram a ocorrência de eventos, para os dez locais analisados, nos quatro períodos do dia e o total para os dias úteis e fim de semana, respectivamente.

\begin{tabular}{|c|c|c|c|c|c|}
\hline & \multicolumn{5}{|c|}{ Período do Dia em Dias úteis } \\
\hline & $0 h-6 h$ & $6 h-12 h$ & $12 h-18 h$ & $18 h-24 h$ & Total \\
\hline Miracema & 9 & 9 & 9 & 9 & 36 \\
\hline Alumar L1 & 7 & 14 & 24 & 7 & 52 \\
\hline Alumar L2 & 4 & 2 & 12 & 1 & 19 \\
\hline Albrás L1 & 0 & 0 & 3 & 2 & 5 \\
\hline Albrás L2 & 0 & 0 & 3 & 2 & 5 \\
\hline Alunorte & 0 & 0 & 3 & 2 & 5 \\
\hline Carajás & 4 & 3 & 13 & 1 & 21 \\
\hline $\mathrm{CCM}$ & 2 & 0 & 7 & 2 & 11 \\
\hline CVLD & 7 & 4 & 12 & 5 & 28 \\
\hline Tucuruí & 5 & 7 & 8 & 8 & 28 \\
\hline Total: & 38 & 39 & 94 & 39 & 210 \\
\hline
\end{tabular}

Tabela 4.5 - Ocorrência de eventos Final de Semana

\begin{tabular}{|c|c|c|c|c|c|}
\cline { 2 - 6 } \multicolumn{1}{c|}{} & \multicolumn{5}{c|}{ Período do Dia nos finais de semana } \\
\cline { 2 - 6 } \multicolumn{1}{c|}{} & $\mathbf{O h}-\mathbf{6 h}$ & $\mathbf{6 h}-\mathbf{1 2 h}$ & $\mathbf{1 2 h}-\mathbf{1 8 h}$ & $\mathbf{1 8 h} \mathbf{2 4 h}$ & Total \\
\hline Miracema & 4 & 3 & 5 & 0 & 12 \\
\hline Alumar L1 & 6 & 6 & 8 & 1 & 21 \\
\hline Alumar L2 & 5 & 4 & 5 & 1 & 15 \\
\hline Albrás L1 & 0 & 0 & 0 & 0 & 0 \\
\hline Albrás L2 & 0 & 0 & 1 & 0 & 1 \\
\hline Alunorte & 0 & 0 & 0 & 0 & 0 \\
\hline Carajás & 0 & 5 & 4 & 2 & 11 \\
\hline CCM & 0 & 0 & 3 & 0 & 3 \\
\hline CVLD & 6 & 1 & 4 & 1 & 12 \\
\hline Tucuruí & 2 & 5 & 1 & 1 & 9 \\
\hline \multicolumn{7}{|c|}{} \\
\hline \multicolumn{7}{|c|}{ Total: } & 23 & 24 & 31 & 6 & 85 \\
\hline
\end{tabular}


Nota-se a partir das Tabelas 4.4 e 4.5 a ocorrência de 210 eventos durante o período de segunda-feira à sexta-feira e 85 nos finais de semana. Observa-se a prevalência de eventos no período de dias úteis em relação aos finais de semana, em todos os locais analisados. Alumar L1 foi a localidade a apresentar maior quantidade de eventos nos dois intervalos em análise.

A Figura 4.5 mostra a quantidade de eventos ocorridos nos quatro períodos do dia para os dias úteis e fins de semana, respectivamente.

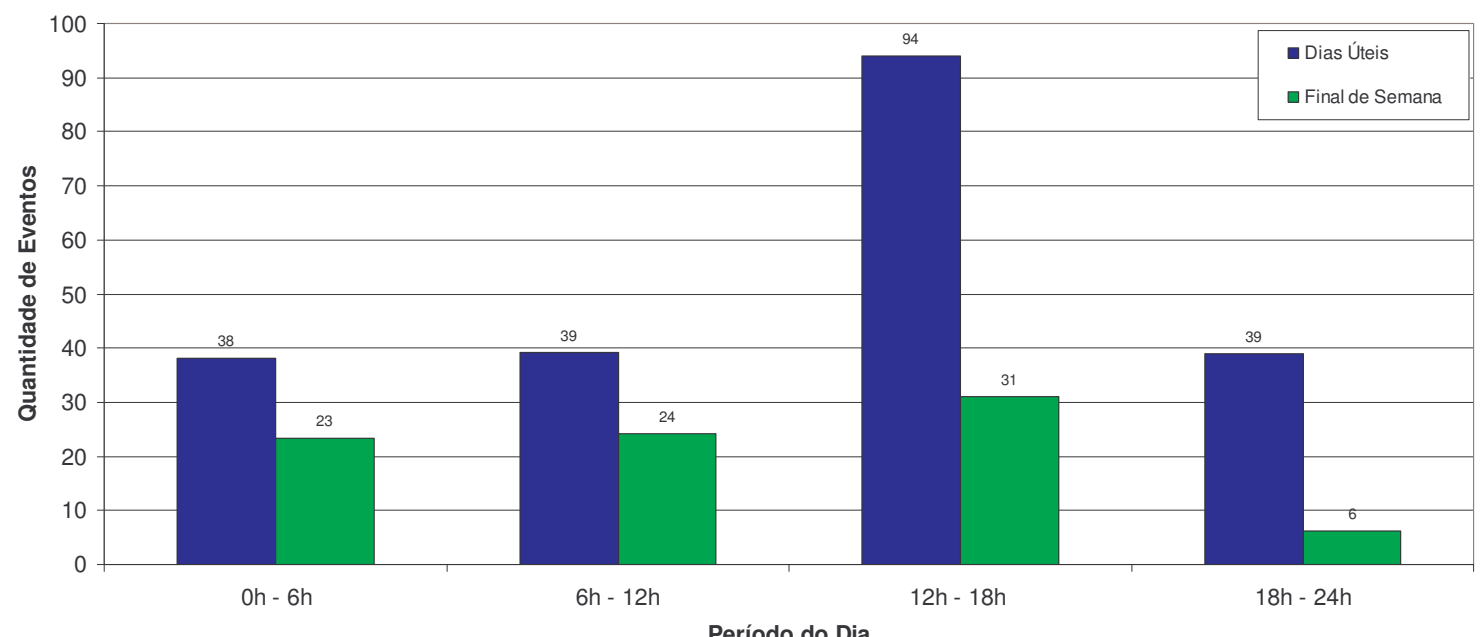

Figura 4.5 - Gráfico da quantidade de eventos versus período da semana.

A participação percentual dos eventos ocorridos nos dois períodos analisados em relação ao total de variações ocorridas em toda a medição, é ilustrada na Tabela 4.6.

Tabela 4.6 - Participação percentual de afundamentos dias úteis versus final de semana.

\begin{tabular}{|c|c|c|}
\cline { 2 - 3 } \multicolumn{1}{c|}{} & Dias Úteis & Final de Semana \\
\hline Miracema & 76.60 & 25.64 \\
\hline Alumar L1 & 71.23 & 28.77 \\
\hline Alumar L2 & 55.88 & 44.12 \\
\hline Albrás L1 & 98.04 & 3.92 \\
\hline Albrás L2 & 81.97 & 18.85 \\
\hline Alunorte & 98.04 & 3.92 \\
\hline Carajás & 65.63 & 34.53 \\
\hline CCM & 78.29 & 22.42 \\
\hline CVLD & 70.00 & 30.00 \\
\hline Tucuruí & 75.68 & 24.32 \\
\hline
\end{tabular}


Por meio dos percentuais acima, observa-se que sete dos consumidores (Miracema, Alumar L1, Albrás L2, Carajás, CCM, CVLD e Tucurui) apresentaram uma proporção das ocorrências entre dias de semana e finais de semana coerente com o esperado. Em Alumar L2, Albras L1 e Alunorte não se tém uma distribuição uniforme, haja vista o baixo número de eventos. Para estes últimos, mostra-se necessário um maior período de medição.

\subsubsection{AnÁlise entre Fases}

Nesta seção, objetiva-se observar o comportamento das VMTs em relação às três fases do sistema. Este tipo de análise possibilita ao concessionário, ou mesmo ao consumidor livre, visualizar a fase mais sujeita a faltas. Consequentemente, estes dados tornam-se relevantes para a tomada de decisões quanto aos investimentos na manutenção da rede. A Tabela 4.7 mostra a ocorrência de afundamentos de tensão nas fases A, B e C.

Tabela 4.7 - Quantidade ocorrência de afundamentos nas três fases.

\begin{tabular}{|c|c|c|c|}
\hline \multicolumn{3}{|c|}{ Afundamentos } & \multicolumn{1}{|c|}{ Fase C } \\
\hline Locais \Fase & Fase A & Fase B & 12 \\
\hline Miracema & 13 & 22 & 6 \\
\hline Alumar L1 & 21 & 8 & 6 \\
\hline Alumar L2 & 18 & 2 & 0 \\
\hline Albrás L1 & 3 & 2 & 0 \\
\hline Albrás L2 & 4 & 1 & 0 \\
\hline Alunorte & 3 & 2 & 11 \\
\hline Carajás & 8 & 12 & 3 \\
\hline CCM & 10 & 1 & 9 \\
\hline CVLD & 18 & 12 & 9 \\
\hline Tucuruí & 7 & 21 & \\
\hline Total & 105 & 83 & 56 \\
\hline Média Aritimética & 10.500 & 8.300 & 5.600 \\
\hline Desvio Padrão & 6.687 & 8.179 & 4.648 \\
\hline
\end{tabular}

Nota-se, a partir da Tabela 4.7, uma maior ocorrência de afundamentos na fase A do sistema, com 105 VMTs. Este valor representa 43,03\% do total destes eventos no período. As fases B e $\mathrm{C}$ apresentam 83 e 56 afundamentos, respectivamente. O que resulta em um valor médio por local por fase de 10,5 subtensões para a fase A, 8,3 para a fase B e 5,6 para a fase C. 
A Figura 4.6 mostra a participação percentual de cada fase para todo o sistema.

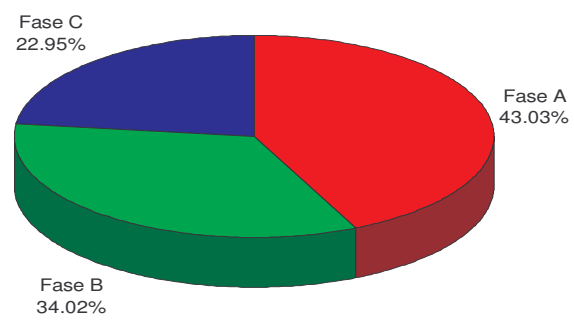

Figura 4.6 - Percentual de afundamentos por fase.

A Tabela 4.8 mostra a participação percentual das fases para cada um dos locais analisados.

Tabela 4.8 - Percentual de afundamentos nas três fases por local.

\begin{tabular}{|c|c|c|c|}
\hline \multicolumn{4}{|c|}{ Afundamentos } \\
\hline Locais \Fase & Fase A & Fase B & Fase C \\
\hline Miracema & 27.66 & 46.81 & 25.53 \\
\hline Alumar L1 & 60.00 & 22.86 & 17.14 \\
\hline Alumar L2 & 69.23 & 7.69 & 23.08 \\
\hline Albrás L1 & 60.00 & 40.00 & 0.00 \\
\hline Albrás L2 & 80.00 & 20.00 & 0.00 \\
\hline Alunorte & 60.00 & 40.00 & 0.00 \\
\hline Carajás & 25.81 & 38.71 & 35.48 \\
\hline CCM & 71.43 & 7.14 & 21.43 \\
\hline CVLD & 46.15 & 30.77 & 23.08 \\
\hline Tucuruí & 18.92 & 56.76 & 24.32 \\
\hline
\end{tabular}

Nota-se da Tabela 4.8 que em Carajás a distribuição de afundamentos por fase apresentou-se mais uniforme, com percentuais de participação mais próximos que dos demais locais. Em Albras L1, Albras L2 e Alunorte, em função do reduzido número afundamentos, não se têm dados significativos que possibilitem atribuir coincidência de ocorrência entre as fases.

A Tabela 4.9 apresenta o número de elevações por local e o total apresentado em cada fase, assim como o valor médio de elevações e os respectivos desvios, de forma semelhante ao estudo realizado para os afundamentos de tensão. 
Tabela 4.9 - Quantidade ocorrências de elevações nas três fases.

\begin{tabular}{|c|c|c|c|}
\hline \multicolumn{4}{|c|}{ Elevações } \\
\hline Locais $\backslash$ Fase & Fase A & Fase B & Fase C \\
\hline Miracema & 4 & 5 & 1 \\
\hline Alumar L1 & 1 & 34 & 4 \\
\hline Alumar L2 & 2 & 5 & 1 \\
\hline Albrás L1 & 0 & 1 & 0 \\
\hline Albrás L2 & 0 & 1 & 0 \\
\hline Alunorte & 1 & 0 & 0 \\
\hline Carajás & 1 & 0 & 0 \\
\hline CCM & 0 & 0 & 0 \\
\hline CVLD & 1 & 0 & 0 \\
\hline Tucuruí & 0 & 1 & 0 \\
\hline Total & 10 & 47 & 0.600 \\
\hline Média Aritmética & 1.000 & 4.700 & 1.265 \\
\hline Desvio Padrão & 1.247 & 10.478 & \\
\hline
\end{tabular}

Nota-se a partir da Tabela 4.9 que a fase B é a fase a apresentar a maior ocorrência de elevações, sendo 47 eventos detectados durante o período de medição, correspondente a $74,60 \%$ do total. As fases A e C apresentam 10 e 6 elevações, as quais retratam 15,87\% e $9,52 \%$, respectivamente.

Pode-se também notar da Tabela 4.9 que somente a fase B de Alumar L1 aduze 37 eventos, o que corresponde $72,34 \%$ dos eventos na fase. Tal fato contribui para o grande desvio encontrado 10,47. Este mesmo comportamento observa-se na fase $\mathrm{C}$ onde se obteve quase a totalidade dos eventos em um mesmo local.

A análise de elevações por fase, por local, apresenta-se pouco conclusiva, haja vista a pequena quantidade de eventos medidos nas três fases.

A Figura 4.7 apresenta a participação percentual de cada fase para todo o sistema.

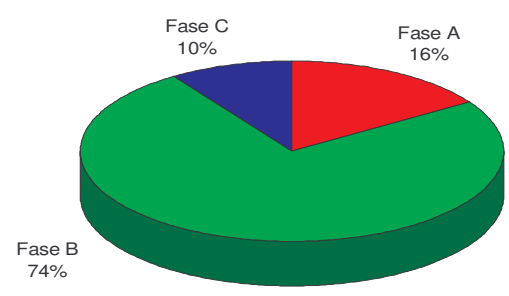

Figura 4.7 - Percentual de elevações por fase. 
A Figura 4.8 mostra um gráfico de barras com os totais dos eventos em cada fase.

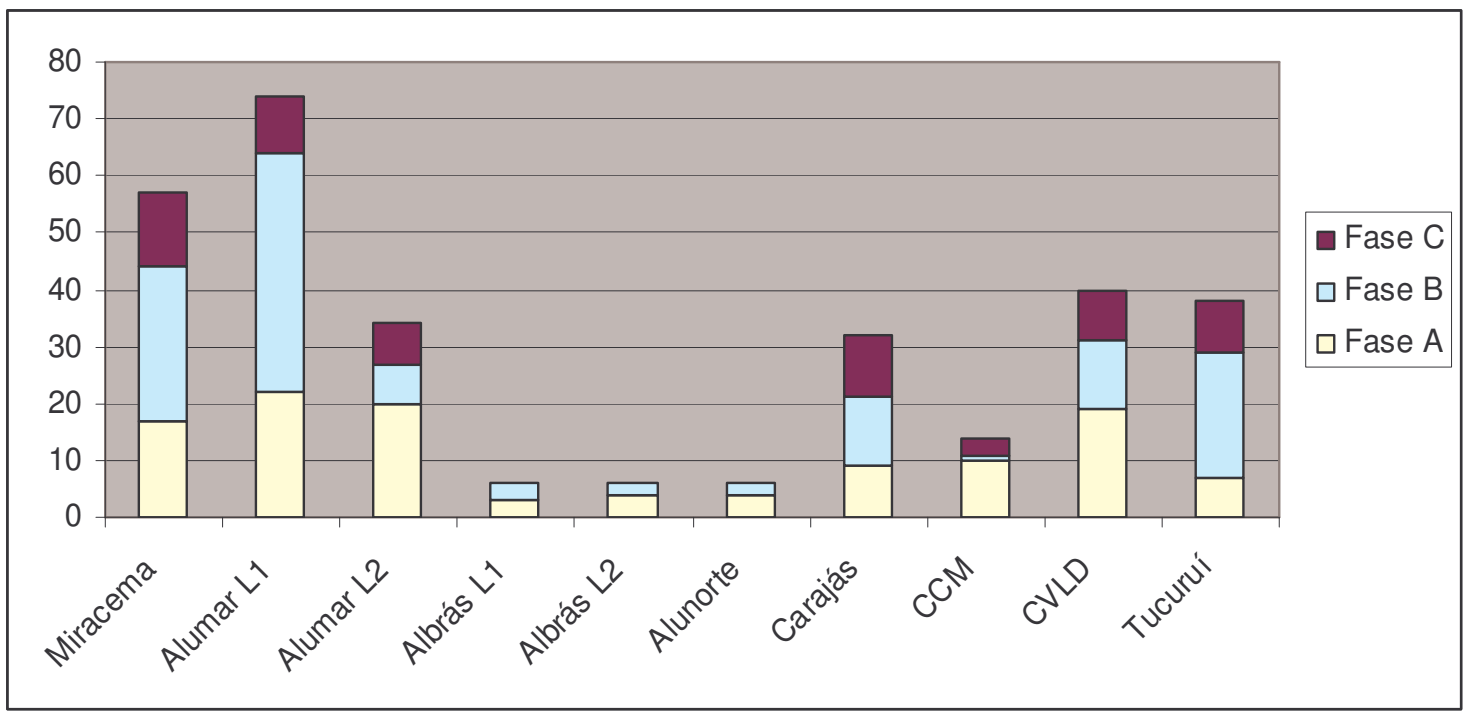

Figura 4.8 - Quantidade de Eventos nas fases A, B e C.

\subsection{CLASSIFICAÇÃ O DOS EVENTOS}

Neste tópico serão mostradas as diversas classificações das Variações Momentâneas de Tensão referentes aos dez locais de medição. Para tanto, será utilizado o submódulo de Classificação da ferramenta computacional PQEE em conjunto com o Microsoft Office Excel. Os dados foram agregados em um período contemplando todo o último trimestre do ano de 2006. Serão apenas apresentadas as metodologias do IEEE-1159 e a NRS-048.

\subsubsection{ClassificaÇÃo SEgUndo A METOdologia IEEE - 1159}

Nas Tabelas 4.10 e 4.11 temos a classificação dos eventos nos principais consumidores da Eletronorte segundo a metodologia IEEE- 1159. 
Tabela 4.10 - Classificação dos eventos em Albras L1 e L2, Alumar L1 e L2 e Alunorte segundo metodologia IEEE - 1159.

\begin{tabular}{|c|c|c|c|c|c|c|c|}
\hline & \multirow{2}{*}{\multicolumn{5}{|c|}{ Quantidade de Eventos }} \\
\hline & & & & & & & \\
\hline Categoria & Duração & Intensidade & $\begin{array}{c}\text { Albras } \\
\text { L1 }\end{array}$ & $\begin{array}{c}\text { Albras } \\
\text { L2 }\end{array}$ & $\begin{array}{c}\text { Alumar } \\
\text { L1 }\end{array}$ & $\begin{array}{c}\text { Alumar } \\
\text { L2 }\end{array}$ & Alunorte \\
\hline $\begin{array}{l}\text { Afundamento } \\
\text { Instantâneo }\end{array}$ & $\begin{array}{c}0,5 \text { a } 30 \\
\text { ciclos }\end{array}$ & 0,1 até 0,9 & 4 & 5 & 32 & 27 & 4 \\
\hline $\begin{array}{c}\text { Elevação } \\
\text { Instantânea }\end{array}$ & $\begin{array}{c}0,5 \text { a } 30 \\
\text { ciclos }\end{array}$ & 1,1 até 1,8 & 0 & 1 & 32 & 12 & 0 \\
\hline $\begin{array}{l}\text { Interrupção } \\
\text { Momentânea }\end{array}$ & $\begin{array}{c}0,5 \text { ciclos a } \\
3 \mathrm{~s}\end{array}$ & $<0,1 \mathrm{pu}$ & 0 & 0 & 0 & 0 & 0 \\
\hline $\begin{array}{l}\text { Afundamento } \\
\text { Momentâneo }\end{array}$ & $\begin{array}{c}30 \text { ciclos a } 3 \\
\mathrm{~s}\end{array}$ & 0,1 até 0,9 & 1 & 0 & 1 & 0 & 1 \\
\hline $\begin{array}{c}\text { Elevação } \\
\text { Momentânea }\end{array}$ & $\begin{array}{c}30 \text { ciclos a } 3 \\
\mathrm{~s}\end{array}$ & 1,1 até 1,8 & 1 & 0 & 4 & 0 & 1 \\
\hline $\begin{array}{l}\text { Interrupção } \\
\text { Temporária }\end{array}$ & $3 s$ a $1 \mathrm{~min}$ & $<0,1 \mathrm{pu}$ & 0 & 0 & 0 & 0 & 0 \\
\hline $\begin{array}{l}\text { Afundamento } \\
\text { Temporário }\end{array}$ & $3 s$ a $1 \mathrm{~min}$ & 0,1 até 0,9 & 0 & 0 & 0 & 1 & 0 \\
\hline $\begin{array}{l}\text { Elevação } \\
\text { Temporária }\end{array}$ & $3 \mathrm{~s}$ a $1 \mathrm{~min}$ & 1,1 até 1,8 & 0 & 0 & 2 & 1 & 0 \\
\hline \multicolumn{3}{|c|}{ Eventos não classificados dentro dos limites } & 0 & 0 & 3 & 2 & 0 \\
\hline
\end{tabular}

Tabela 4.11 - Classificação dos eventos em Carajás, CCM, CVLD, Miracema e Tucurui segundo metodologia IEEE-1159.

\begin{tabular}{|c|c|c|c|c|c|c|c|}
\hline \\
\hline \multirow[b]{2}{*}{ Categoria } & \multirow[b]{2}{*}{ Duração } & \multirow[b]{2}{*}{ Intensidade } & \multicolumn{5}{|c|}{ Quantidade de Eventos } \\
\hline & & & Carajás & CCM & CVLD & Miracema & Tucurui \\
\hline $\begin{array}{l}\text { Afundamento } \\
\text { Instantâneo }\end{array}$ & $\begin{array}{l}0,5 \text { a } 30 \\
\text { ciclos }\end{array}$ & 0,1 até 0,9 & 20 & 12 & 37 & 35 & 27 \\
\hline $\begin{array}{c}\text { Elevação } \\
\text { Instantânea }\end{array}$ & $\begin{array}{l}0,5 \text { a } 30 \\
\text { ciclos }\end{array}$ & 1,1 até 1,8 & 0 & 0 & 0 & 6 & 0 \\
\hline $\begin{array}{l}\text { Interrupção } \\
\text { Momentânea }\end{array}$ & $\begin{array}{c}0,5 \text { ciclos a } 3 \\
\mathrm{~s}\end{array}$ & $<0,1 \mathrm{pu}$ & 0 & 0 & 0 & 0 & 0 \\
\hline $\begin{array}{l}\text { Afundamento } \\
\text { Momentâneo }\end{array}$ & $\begin{array}{c}30 \text { ciclos a } 3 \\
\mathrm{~s}\end{array}$ & 0,1 até 0,9 & 2 & 0 & 1 & 1 & 3 \\
\hline $\begin{array}{c}\text { Elevação } \\
\text { Momentânea }\end{array}$ & $\begin{array}{c}30 \text { ciclos a } 3 \\
\mathrm{~s}\end{array}$ & 1,1 até 1,8 & 0 & 0 & 0 & 1 & 0 \\
\hline $\begin{array}{l}\text { Interrupção } \\
\text { Temporária }\end{array}$ & $3 s$ a $1 \mathrm{~min}$ & $<0,1 \mathrm{pu}$ & 0 & 0 & 0 & 0 & 0 \\
\hline $\begin{array}{c}\text { Afundamento } \\
\text { Temporário }\end{array}$ & $3 s$ a $1 \mathrm{~min}$ & 0,1 até 0,9 & 1 & 2 & 1 & 2 & 6 \\
\hline $\begin{array}{l}\text { Elevação } \\
\text { Temporária }\end{array}$ & $3 \mathrm{~s}$ a $1 \mathrm{~min}$ & 1,1 até 1,8 & 1 & 0 & 0 & 0 & 1 \\
\hline \multicolumn{3}{|c|}{ Eventos não classificados dentro dos limites } & 8 & 0 & 1 & 12 & 1 \\
\hline
\end{tabular}


Observa-se das Tabelas 4.10 e 4.11 que a grande maioria dos eventos foram afundamentos de tensão de curta duração, entre 0,5 e 30 ciclos, sendo, portanto, classificados como afundamentos instantâneos de tensão. Visualiza-se também que não foram observadas interrupções de tensão durante o período de medição. Em relação às elevações de tensão, temse a grande maioria classificada como elevação instantânea. Os consumidores Alumar L1, Alumar L2 e Miracema totalizaram 32, 12 e 6 elevações, respectivamente, nesta faixa.

Ainda das Tabelas 4.10 e 4.11, visualiza-se a ocorrência de 27 eventos que não foram classificados dentro dos limites da norma. Isso decorre, destes eventos apresentarem duração acima de 1 minuto, limite máximo estipulado nesta metodologia.

A Figura 4.9 ilustra a distribuição das Tabelas 4.10 e 4.11 por meio de um gráfico de barras.

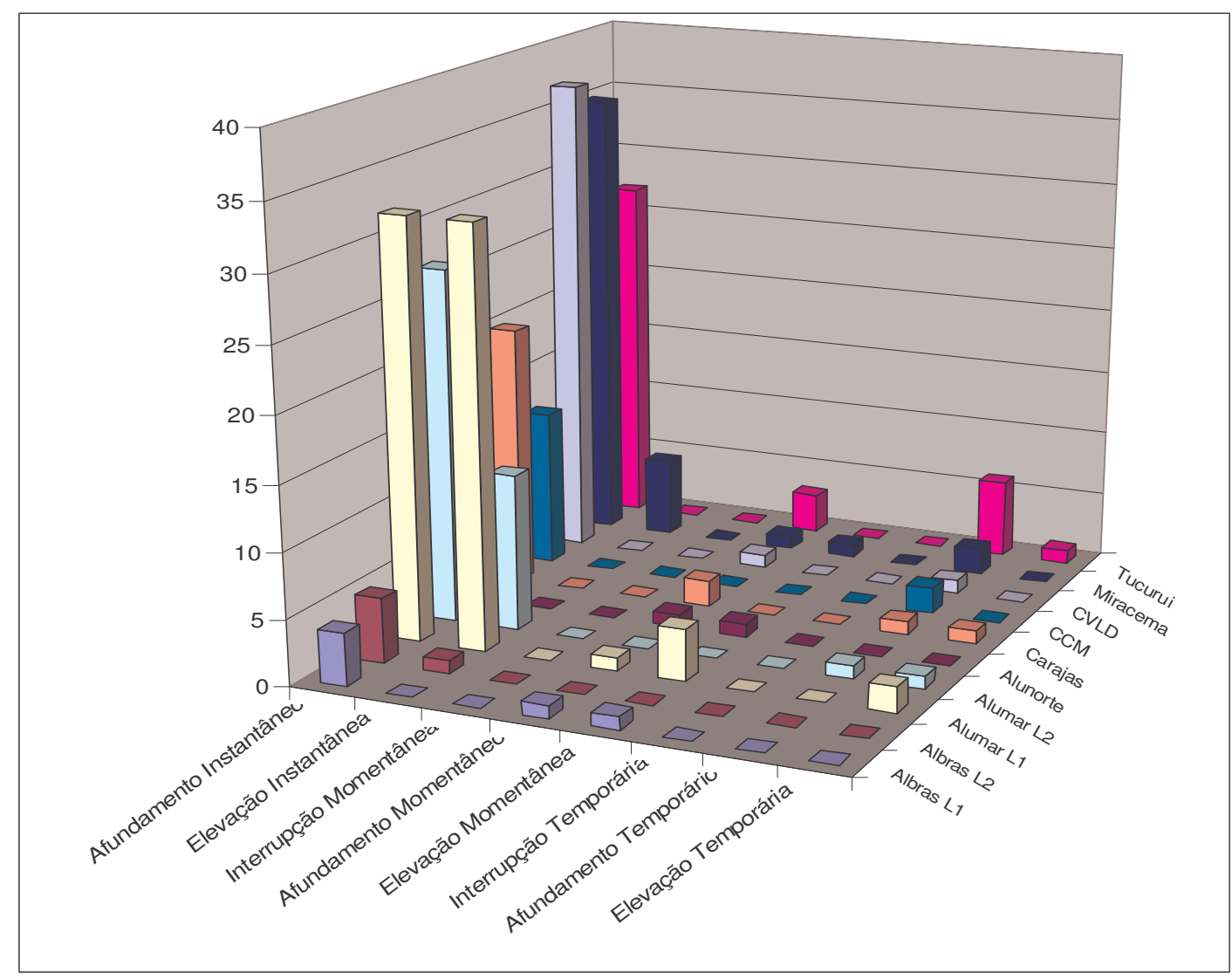

Figura 4.9 - Gráfico com a classificação de dez locais do sistema Eletronorte pela metodologia IEEE-1159 


\subsubsection{ClASSIFICAÇÃO SEGUNDO A METODOLOGIA NRS - 048}

Na Tabela 4.12 temos a classificação dos eventos nos principais consumidores da Eletronorte segundo a metodologia NRS - 048 .

Tabela 4.12 - Classificação dos eventos nos dez locais segundo a metodologia NRS - 048.

\begin{tabular}{|c|c|c|c|c|c|c|}
\hline & $\mathrm{S}$ & $\mathbf{T}$ & $x$ & $\mathbf{Y}$ & $\mathbf{Z}$ & $\begin{array}{c}\text { NÃO } \\
\text { CLASSIFICADO }\end{array}$ \\
\hline Albrás L1 & 0 & 1 & 2 & 1 & 0 & 1 \\
\hline Albrás L2 & 0 & 1 & 2 & 1 & 0 & 2 \\
\hline Alumar L1 & 2 & 0 & 11 & 14 & 0 & 46 \\
\hline Alumar L2 & 1 & 0 & 11 & 11 & 0 & 20 \\
\hline Alunorte & 0 & 1 & 2 & 1 & 0 & 1 \\
\hline Carajas & 0 & 5 & 6 & 13 & 0 & 8 \\
\hline $\mathrm{CCM}$ & 0 & 0 & 1 & 11 & 0 & 2 \\
\hline CVLD & 1 & 0 & 12 & 15 & 0 & 12 \\
\hline Miracema & 1 & 4 & 12 & 9 & 0 & 21 \\
\hline Tucuruí & 0 & 0 & 5 & 13 & 1 & 18 \\
\hline Total & 5 & 12 & 64 & 89 & 1 & 131 \\
\hline
\end{tabular}

Pela análise da Tabela 4.12 visualiza-se que grande parte dos eventos não puderam ser classificados dentro dos limites impostos pela NRS - 048. Isto decorre dos limiares de duração serem muito pequenos, apenas 3 segundos, e além disto a norma não contempla as elevações de tensão. A região $\mathrm{Y}$, que compreende afundamentos com duração entre 20 milisegundos e 3 segundos e intensidade entre $10 \%$ e $20 \%$, foi a que apresentou maior número de eventos, 89 .

Ainda da Tabela 4.12 pode-se notar um grande número de ocorrências na região $\mathrm{X}$, relacionada a defeitos ocorridos no sistema de transmissão, totalizando 64 eventos nos locais analisados. A região $\mathrm{Z}$ teve apenas uma contribuição, oriunda do consumidor Tucuruí.

A Figura 4.10 ilustra a Tabela 4.12 por meio gráfico. 


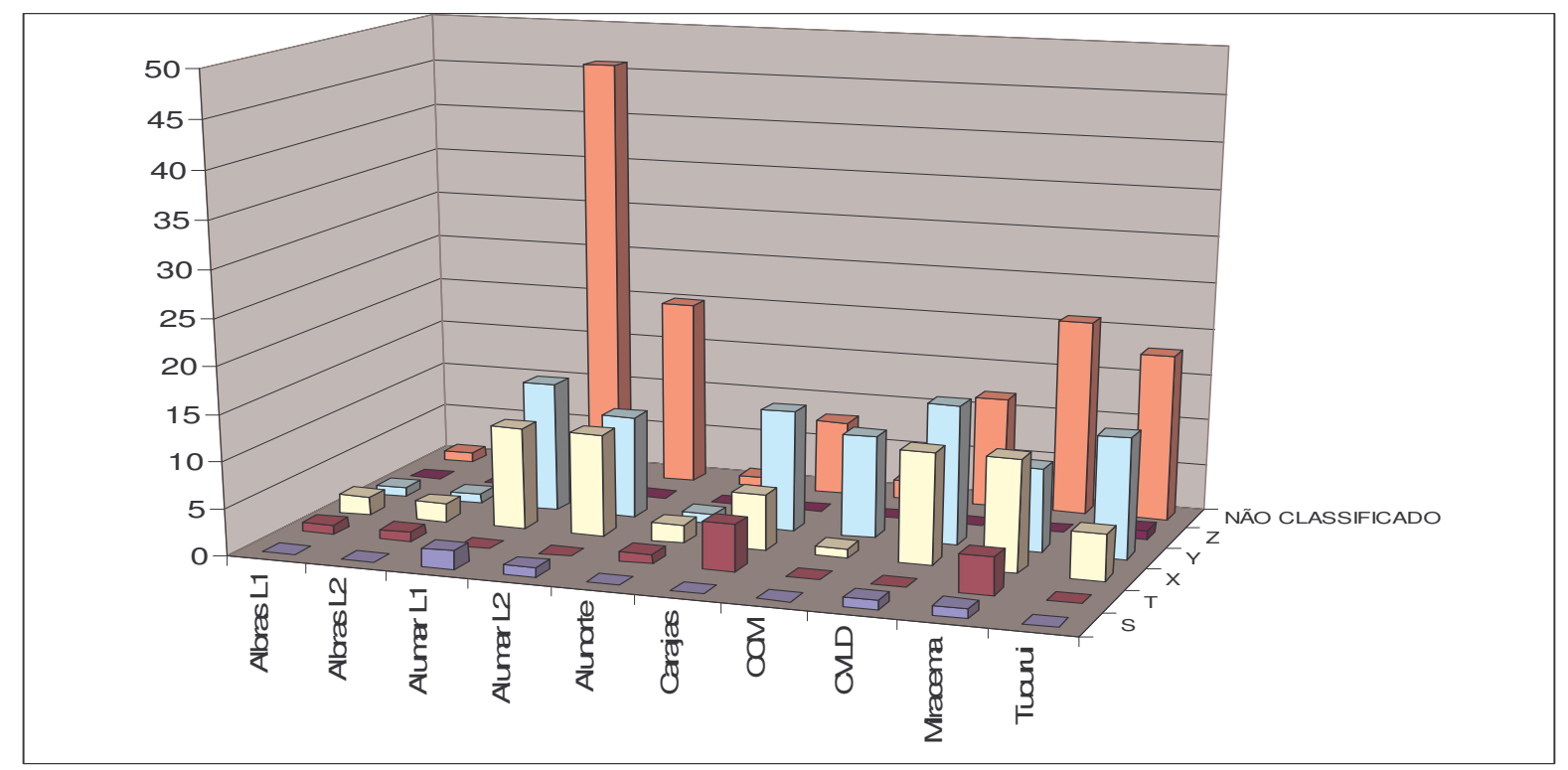

Figura 4.10 - Gráfico com a classificação de dez locais do sistema Eletronorte

\subsection{Análise de Curvas}

Nesta etapa, serão analisadas as curvas ITIC e de Causas para os bancos de dados dos consumidores selecionados do sistema Eletronorte. Para tanto, foi utilizado o módulo "Análise de Curvas" da ferramenta computacional. Para uma melhor visualização das curvas, foram feitas plotagens a partir dos dados agregados, de modo que fosse apresentado para cada local, uma única curva ITIC e de Causas contendo todos os eventos do período de medição.

\subsubsection{CURVA ITIC}

Para evitar uma apresentação exaustiva de figuras, as curvas ITIC dos dez pontos de medição foram colocadas no Anexo I deste trabalho. As Tabelas 4.13 e 4.14 mostram a quantidade de eventos e os valores percentuais por local em cada uma das três regiões da curva, respectivamente. 
Tabela 4.13 - Quadro dos dados obtidos através da análise da curva ITIC dos dez locais em estudo.

\begin{tabular}{|c|c|c|c|c|}
\hline Local & $\begin{array}{c}\text { Total de } \\
\text { eventos }\end{array}$ & Região A & Região B & Região C \\
\hline Miracema & 57 & 21 & 10 & 26 \\
\hline Alumar L1 & 74 & 23 & 19 & 32 \\
\hline Alumar L2 & 43 & 11 & 8 & 24 \\
\hline Albrás L1 & 6 & 1 & 1 & 4 \\
\hline Albrás L2 & 6 & 1 & 1 & 4 \\
\hline Alunorte & 6 & 1 & 1 & 4 \\
\hline Carajás & 32 & 10 & 1 & 21 \\
\hline CCM & 14 & 1 & 0 & 13 \\
\hline CVLD & 40 & 10 & 1 & 29 \\
\hline Tucuruí & 38 & 11 & 1 & $\mathbf{1 8 3}$ \\
\hline Total & $\mathbf{3 1 6}$ & $\mathbf{9 0}$ & $\mathbf{4 3}$ & 26 \\
\hline
\end{tabular}

Tabela 4.14 - Estimativa de ocorrência dos eventos em cada região da curva ITIC.

\begin{tabular}{|l|c|c|c|c|}
\hline \multicolumn{1}{|c|}{ Local } & $\begin{array}{c}\text { Total de } \\
\text { eventos }\end{array}$ & Região A & Região B & Região C \\
\hline Miracema & 57 & $37 \%$ & $18 \%$ & $46 \%$ \\
\hline Alumar L1 & 74 & $34 \%$ & $20 \%$ & $46 \%$ \\
\hline Alumar L2 & 43 & $26 \%$ & $19 \%$ & $56 \%$ \\
\hline Albrás L1 & 6 & $17 \%$ & $17 \%$ & $67 \%$ \\
\hline Albrás L2 & 6 & $17 \%$ & $17 \%$ & $67 \%$ \\
\hline Alunorte & 6 & $17 \%$ & $17 \%$ & $67 \%$ \\
\hline Carajás & 32 & $31 \%$ & $3 \%$ & $66 \%$ \\
\hline CCM & 14 & $7 \%$ & $0 \%$ & $93 \%$ \\
\hline CVLD & 40 & $25 \%$ & $3 \%$ & $73 \%$ \\
\hline Tucuruí & 38 & $29 \%$ & $3 \%$ & $68 \%$ \\
\hline \multicolumn{1}{|c|}{ Total } & $\mathbf{3 1 6}$ & $\mathbf{2 9 \%}$ & $\mathbf{1 2 \%}$ & $\mathbf{5 9 \%}$ \\
\hline
\end{tabular}

Das Tabelas 4.13 e 4.14 observa-se que os consumidores Miracema, Alumar L1 e L2, Albrás L1 e L2 e Alunorte apresentaram em média 18\% dos eventos situados na região B, ou seja na chamada zona de susceptibilidade, o que representa um sério risco de perdas econômicas com a queima de equipamentos ligados nestas redes. 
A Figura 4.11 mostra o percentual de ocorrência dos eventos de acordo com a região que eles ocupam.

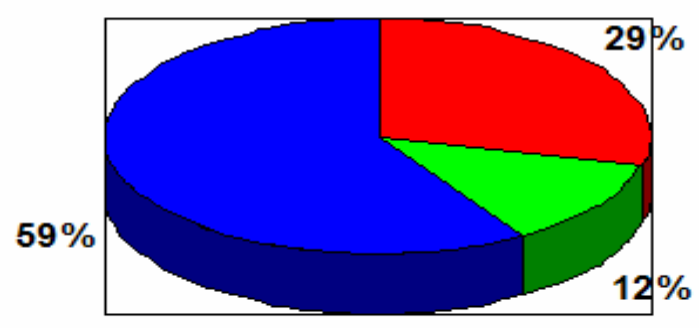

\section{Regiäo A $\square$ Regiäo B Região C}

Figura 4.11 - Percentual de eventos por região da curva ITIC.

A Figura 4.11 revela que os equipamentos ligados na rede durante a ocorrência de $12 \%$ dos eventos, podem ter sofrido danos, como por exemplo, a ruptura da isolação, uma vez que se situam na chamada zona de susceptibilidade. Em 59\% dos eventos não se incorre em grande perigo de danos aos equipamentos, uma vez que esses se encontram situados na chamada região de sensibilidade. No entanto, evidencia-se uma grande possibilidade de parada ou mal funcionamento deles no decurso da VMT. Em $29 \%$ dos casos estão inclusos na região de imunidade, ou seja, a ocorrência de eventos dentro desta área não representarão problemas aos equipamentos.

\subsubsection{Curva de Causas}

Lembra-se que, ao contrário da curva ITIC, que explora possíveis conseqüências das VMTs, a curva de Causas tem o propósito de identificar um possível fator causador para a ocorrência do afundamento momentâneo de tensão. A Tabela 4.15 mostra o percentual de eventos ocorridos em cada região da curva de Causas para os dez locais. 
Tabela 4.15 - Percentual de ocorrência de eventos em cada região da curva de Causas.

\begin{tabular}{|c|c|c|c|c|c|c|c|c|}
\hline Local & $\begin{array}{c}\text { Total de } \\
\text { eventos }\end{array}$ & $\begin{array}{c}\text { Região } \\
\mathbf{1}\end{array}$ & $\begin{array}{c}\text { Região } \\
\mathbf{2}\end{array}$ & $\begin{array}{c}\text { Região } \\
\mathbf{3}\end{array}$ & $\begin{array}{c}\text { Região } \\
\mathbf{4}\end{array}$ & $\begin{array}{c}\text { Região } \\
\mathbf{5}\end{array}$ & $\begin{array}{c}\text { Região } \\
\mathbf{6}\end{array}$ & $\begin{array}{c}\text { Fora das } \\
\text { regiões 1 } \\
\mathbf{3} 6\end{array}$ \\
\hline Miracema & 47 & $6 \%$ & $6 \%$ & $2 \%$ & $6 \%$ & $0 \%$ & $0 \%$ & $80 \%$ \\
\hline $\begin{array}{c}\text { Alumar } \\
\text { L1 }\end{array}$ & 35 & $0 \%$ & $0 \%$ & $11 \%$ & $0 \%$ & $0 \%$ & $0 \%$ & $89 \%$ \\
\hline $\begin{array}{c}\text { Alumar } \\
\text { L2 }\end{array}$ & 30 & $0 \%$ & $0 \%$ & $10 \%$ & $0 \%$ & $0 \%$ & $0 \%$ & $90 \%$ \\
\hline Albrás L1 & 5 & $0 \%$ & $0 \%$ & $0 \%$ & $0 \%$ & $0 \%$ & $0 \%$ & $100 \%$ \\
\hline Albrás L2 & 5 & $0 \%$ & $0 \%$ & $0 \%$ & $0 \%$ & $0 \%$ & $0 \%$ & $100 \%$ \\
\hline Alunorte & 5 & $0 \%$ & $0 \%$ & $0 \%$ & $0 \%$ & $0 \%$ & $0 \%$ & $100 \%$ \\
\hline Carajás & 31 & $13 \%$ & $3 \%$ & $0 \%$ & $3 \%$ & $0 \%$ & $0 \%$ & $81 \%$ \\
\hline CCM & 14 & $0 \%$ & $0 \%$ & $0 \%$ & $0 \%$ & $7 \%$ & $0 \%$ & $93 \%$ \\
\hline CVLD & 39 & $0 \%$ & $0 \%$ & $13 \%$ & $0 \%$ & $0 \%$ & $0 \%$ & $87 \%$ \\
\hline Tucuruí & 37 & $0 \%$ & $0 \%$ & $3 \%$ & $0 \%$ & $3 \%$ & $0 \%$ & $95 \%$ \\
\hline
\end{tabular}

Percebe-se que para a maioria dos afundamentos ocorridos, não há definida, segundo a curva de causas, uma possível causa. Observando-se cada local separadamente, tem-se que a região 1 em Carajás e a região 3 em CVLD são as de maior ocorrência relativa, no qual cada uma tem $13 \%$ dos afundamentos ocorridos no período de medição dos dados. Tais eventos são de prováveis Faltas no Sistema de Transmissão e de prováveis Faltas no Sistema de Distribuição local, respectivamente.

Analisando-se de forma global, tem-se a Figura 4.12, que mostra o valor percentual da quantidade de eventos ocorridos no sistema em cada região da curva de Causas. Essa não apresenta a região da curva em que não se tem uma origem relacionada.
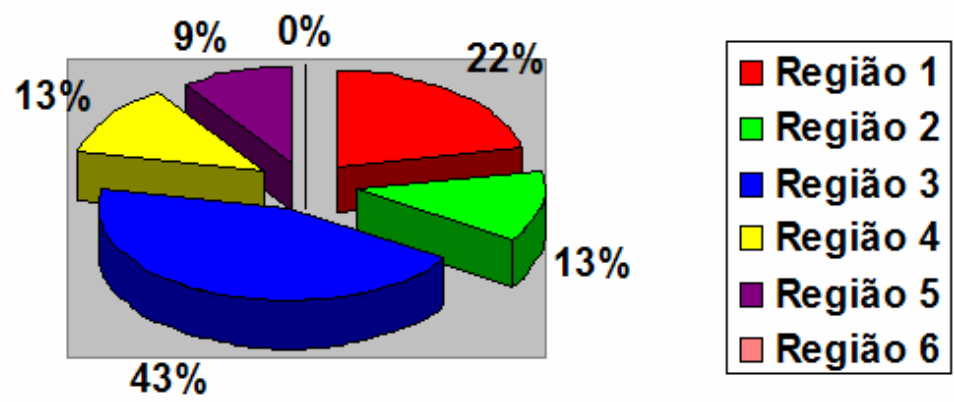

Figura 4.12 - Percentual de eventos nas regiões 1 a 6. 
A região de maior ocorrência é a de número 3, seguida da região 2. Ao levar-se em consideração os eventos que estão fora das seis regiões, têm-se os percentuais mostrados na Figura 4.13.

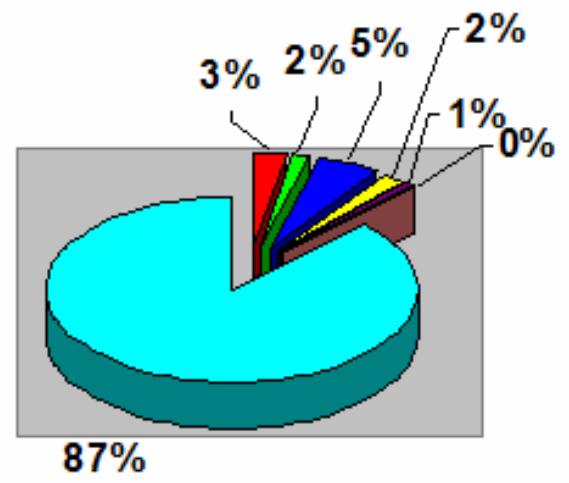

Região 1

Região 2

Região 3

$\square$ Regiäo 4

Regiäo 5

Região 6

Fora das Regióes 1 a 6

Figura 4.13 - Percentual de eventos nas regiões das curvas de Causas.

Infere-se, portanto, que a maior parte dos eventos, $87 \%$, são de causas incertas, não definidas na curva de Causas. Esta proporção sugere que o tratamento das causas dos afundamentos por meio desta curva pode não ser satisfatório para estes dados, sendo, por vezes, necessária a busca de outras formas de estudo das mesmas.

\subsection{ANÁlise ANUAL}

Nesta etapa, tem-se o propósito de apresentar uma análise anual dos eventos. Para tanto, busca-se uma estimativa do número de ocorrências de Variações Momentâneas da Tensão no período de um ano, com base nos dados disponíveis de três meses de medição.

Com esta análise pretende-se verificar se o número de eventos encontrado, no trimestre em análise, está de acordo com os limites estabelecidos por normas como a NRS.

\subsubsection{Metodologia Utilizada para Apresentação Anual dos dados}

O fenômeno de VMT é um processo tipicamente estocástico, ou seja, um fenômeno que varia em algum grau, de forma imprevisível, à medida que o tempo passa. (CLARKE, 1979).

Assim, como as VMTs ocorrem de forma aleatória e em frequiências relativamente baixas, são necessários grandes períodos de medições para se obter dados estocásticos confiáveis. A 
Tabela 4.16 ilustra o resultado de um estudo feito a respeito do tempo necessário para monitoração de afundamentos de tensão. Esta tabela expõe o período de monitoramento necessário em função do número esperado de afundamentos de tensão, assim como o grau de confiança desejado.

Tabela 4.16 - Tabela do período mínimo de monitoração e precisão desejada (KOVAL, 1990).

\begin{tabular}{|c|c|c|}
\hline Freqüência do evento & $\mathbf{5 0} \%$ de precisão & $\mathbf{1 0} \%$ de precisão \\
\hline 1 por dia & 2 semanas & 1 ano \\
\hline 1 por semana & 4 meses & 7 anos \\
\hline 1 por mês & 1 ano & 30 anos \\
\hline 1 por ano & 16 anos & 400 anos \\
\hline
\end{tabular}

Dessa forma, para um evento que ocorra uma vez por dia, seria preciso monitorar um ano para se conseguir uma precisão de $10 \%$. Para a obtenção dos números apresentados à Tabela 4.16, foram utilizadas estatísticas baseadas na distribuição de Poisson (FONSECA, 1999).

Dos dados obtidos nas medições, pode-se ter o total de afundamentos ocorridos em cada período de medição. Este valor pode ser obtido a partir da tela principal da ferramenta computacional após o carregamento dos dados. Calculando-se a média semanal de ocorrência de afundamentos para cada local, tem-se a Tabela 4.17.

Tabela 4.17 - Média semanal de ocorrência dos afundamentos.

\begin{tabular}{|c|c|c|}
\cline { 2 - 3 } \multicolumn{1}{c|}{} & \multicolumn{2}{c|}{ Quantificação dos Eventos } \\
\cline { 2 - 3 } \multicolumn{1}{c|}{} & Afundamentos & Média aproximada de eventos por semana \\
\hline Miracema & 47 & 3,6 \\
\hline Alumar L1 & 35 & 2,7 \\
\hline Alumar L2 & 26 & 2,0 \\
\hline Albrás L1 & 5 & 0,38 \\
\hline Albrás L2 & 5 & 0,38 \\
\hline Alunorte & 5 & 0,38 \\
\hline Carajás & 31 & 2,4 \\
\hline CCM & 14 & 1,07 \\
\hline CVLD & 39 & 3,0 \\
\hline Tucuruí & 37 & 2,8 \\
\hline Marabá & 9 & 0,69 \\
\hline
\end{tabular}


Comparando-se a Tabela 4.17 com a Tabela 4.16, é possível notar que a precisão dos dados estudados com relação à frequiência dos eventos é baixa. Portanto, para uma estimativa anual mais precisa, é necessário ou um maior intervalo de medição ou a utilização de métodos computacionais para simulação de VMTs. Dessa forma, não é possível a exploração de uma análise anual para o banco de dados em estudo.

\subsection{CONSIDERaÇões Finais}

O presente capítulo apresentou um estudo de dez consumidores do sistema Eletronorte, apresentando análises quantitativas e qualitativas, classificação e análise das curvas e ainda uma simulação do comportamento destes locais para o período de um ano.

As análises quantitativas foram determinantes para a verificação de características dos eventos, tais como as fases mais afetadas pelos eventos além dos períodos de maior ocorrência. Foi observado que a maior ocorrência de eventos foi na fase A durante o período de segunda a sexta-feira, ratificando a proporção esperada, correspondente a diferença entre o número de dias nos dois períodos escolhidos.

As análises por meio das curvas e classificatória possibilitaram a avaliação de impactos causados devido aos eventos e algumas de suas possíveis causas. Consequentemente, pode-se observar uma maior ocorrência de eventos de curta duração e de pequena intensidade, tanto em elevações quanto em afundamentos. Essas evidenciam a baixa severidade dos eventos sobrevindos durante o trimestre, sugerindo assim a não interrupção constante da produção nos pontos de medição.

Não foi possível a exploração de uma análise anual baseado na norma NRS-048 pelo fato do banco de dados ser pouco preciso para tal análise. É necessário ou um maior período de medição ou a obtebção de dados por simulações computacionais.

No próximo capítulo serão realizadas as conclusões finais do presente trabalho. 


\section{Capítulo 5 \\ CON CLUS Ã O}

O presente capítulo expõe as conclusões obtidas ao longo deste trabalho que, além de apresentar uma ferramenta computacional para a caracterização, análise de curvas, fornecimento de dados estatísticos e classificação de afundamentos e elevações de tensão, desenvolveu um estudo aplicado ao sistema Eletronorte, realizando a análise conjunta de onze pontos de medição.

O capítulo 1 contextualizou a questão da qualidade da energia, destacando aspectos que explicitam a necessidade de crescentes estudos sobre o assunto. Verificou-se que devido ao crescente aumento do nível de exigência dos consumidores, o fornecimento de energia dentro dos requisitos de qualidade e continuidade é necessário para o encadeamento dos processos produtivos. Frisou-se que, para as VMTs, a monitoração e medição da qualidade da energia elétrica representam providências essenciais para a identificação precisa destes fenômenos. Mostrou-se também, a importância de mecanismos que auxiliem no tratamento dos dados oriundos de medições, visando fornecer subsídios para a definição de indicadores e índices de referência confiáveis para a continuidade e conformidade da energia suprida pelo sistema.

O capítulo 2 foi dedicado ao estudo das variações momentâneas de tensão, onde foram descritas fundamentações teóricas relevantes para o entendimento deste distúrbio. Evidenciaram-se aspectos práticos do fenômeno, como fontes geradoras e prejuízos causados a equipamentos. Apresentou-se também as metodologias e as principais normas internacionais de caracterização e classificação, normas e legislações nacionais, bem como curvas indicativas das causas e efeitos das VMTs.

O capítulo 3 apresentou a ferramenta computacional de análise das VMTs. Denominado "Programa de Qualidade da Energia Elétrica - Módulo de Variações Momentâneas de Tensão", tal ferramenta se revelou um aplicativo simples e objetivo para a análise das VMTs, permitindo a obtenção de diversos resultados.

Através das análises realizadas com a ferramenta, verificou-se as diferentes metodologias de caracterização com o uso de exemplos de eventos da SE Eletronorte Miracema. 
A extração dos parâmetros únicos mostrou-se um método alternativo de forma a reduzir o número de parâmetros para caracterizar um único afundamento. A análise comparativa entre metodologias possibilitou acompanhar as diferenças entre as mesmas, de forma fácil e objetiva.

No módulo de estatísticas evidenciou-se uma ferramenta de suma importância para uma análise mais direta, quando se quer um panorama sobre o local de medição de forma mais rápida.

Através do módulo de classificação dos eventos, realizou-se um estudo com dados da subestação Eletronorte Miracema. Constatou-se que, mesmo utilizando-se diferentes métodos, uma das faixas sempre teve a maioria dos eventos em relação às demais. Isso demonstra que mesmo sendo utilizadas metodologias aparentemente diferentes, estas carregam similaridade.

A análise de curvas mostrou ser um importante instrumento gráfico para investigação dos efeitos das VMT's sobre equipamentos eletrônicos, bem como as possíveis causas dos afundamentos de tensão. Contudo, seu uso presta-se a uma primeira análise, de forma a orientar a continuidade dos estudos em campo para uma diagnose mais precisa.

No capítulo 4, foi apresentado um estudo de onze consumidores do sistema Eletronorte, contendo análises quantitativas e qualitativas, classificação e análise das curvas para um banco de dados de três meses de medição (outubro, novembro e dezembro do ano de dois mil e seis), e ainda uma perspectiva de comportamento destes locais para o período de um ano.

As análises quantitativas para estes onze locais apresentam uma maior ocorrência de eventos na fase A durante o período de segunda a sexta-feira, no horário entre doze e dezoito horas. A análise classificatória por sua vez, exibiu uma maior ocorrência de eventos de curta duração e de pequena intensidade, tanto em elevações quanto em afundamentos.

A análise por meio das curvas e das classificações evidenciou a ocorrência de afundamentos de baixa severidade e curta duração, o que garante ao sistema um nível de continuidade, evitando-se a interrupção das linhas de produção dos locais analisados.

A perspectiva de ocorrência anual de afundamentos mostrou que, dos onze locais verificados, três estariam acima do número de ocorrência máxima recomendado pela norma NRS. Tal fato 
sugere que o sistema como um todo, mantém certa qualidade no fornecimento de energia elétrica referente às VMT's.

Por meio das análises expostas e a partir da utilização da ferramenta computacional aqui mostrada, tem-se a possibilidade de promover diferentes análises do sistema no que tange fenômenos de VMT's. Evidencia-se ainda que o estudo de diversos locais de medição, por meio desta ferramenta, pode fornecer subsídio para a definição de indicadores e índices de referência cada vez mais confiáveis para a continuidade e conformidade da energia suprida pelo sistema. Dessa forma, este trabalho mostrou possíveis análises através de medições de eventos de VMT's, com o objetivo de se prestar uma contribuição para o melhoramento e fiscalização da qualidade da energia elétrica nos sistemas de consumidores e fornecedores. 


\section{RE F E R Ê N C I AS B I B L I O GRÁ F I C AS}

AFONSO J.L e MARTINS, J.S.. Qualidade da Energia Elétrictrica. Departamento de Electrónica Industrial - Universidade do Minho In: Revista o Electricista n. 9 p66-71, 2004.

AGÊNCIA NACIONAL DE ENERGIA ELÉTRICA - ANEEL. Procedimentos de Distribuição de Energia Elétrica no Sistema Elétrico Nacional - PRODIST - Módulo 08: Qualidade da Energia Elétrica. Documento: PND1A-DE8-0880. Brasília, 2006.

BOLLEN, M.H.J.; Understanding Power Quality Problems: Voltage Sag's and Interruptions. IEEE Press Power Engineering Series, McGraw-Hill, Inc, 1998.

BRONZEADO, H. Qualidade da Energia Elétrica - Conceitos, Problemas e Soluções. Maio. 2000.

BUSSAB, W.O, E MORETTIN, P.A. Estatística Básica . 4ª edição - São Paulo: Atual 1987.

CARVAlHO, J. M. Uma Contribuição à Avaliação do Atendimento a Consumidores de Cargas Sensíveis - Proposta de Novos Indicadores. Tese de Doutorado - Escola Federal de Engenharia de Itajubá, Itajubá, 2000.

CARVAlHO, P. L. Uma Contribuição ao Estudo da Depressão de Tensão. Dissertação de Mestrado - Escola Federal de Engenharia de Itajubá, Itajubá, 1997.

CLARKE, A.B. \& DISNEY, R.L. Probabilidade e Processos Estocásticos. RJ, Livros Técnicos e Científicos, 1979.

DAMASCEnO, F. F., ALMEIDA, W. G. Circuitos Polifásicos. DF, Livro - Fundação de Empreendimentos Científicos e Tecnológicos, FINATEC, 1995.

DELMONT, O. F. Utilização da Transformada Wavelet para Caracterização de Distúrbios na Qualidade da Energia Elétrica. Dissertação de Mestrado - Escola de Engenharia de São Carlos, Universidade de São Paulo, São Carlos, 2003. 
DUGAN, R. C.; MCGRAnAGHAN, M. F.; BEATY, H. W. Electrical Power Systems Quality. McGraw-Hill, New York, E.U.A., 1996.

FERREIRA, A. A. Caracterização e Análise de Variações de Tensão de curta Duração. Dissertação de Mestrado, Universidade Estadual de Campinas, Campinas , 2002.

FONSECA, V. R. C. Cálculo Estocástico do Afundamento de Tensão. Dissertação de Dissertação de Mestrado. Pontifícia Universidade Católica de Minas Gerais, Belo Horizonte, 1999. 119p.

GAMA, P. H. R.; OLIVEIRA, A. Conservação de Energia e sua Relação com a Qualidade da Energia. In: XV SEMINÁRIO NACIONAL DE PRODUÇÃO E TRANSMISSÃO DE ENERGIA ELÉTRICA, Foz do Iguaçu, 1999.

GARCIA, M. P. Uma Contribuição para o Estudo do Desequilíbrio de Tensão nos Sistemas Elétricos de Potência. Projeto Final de Graduação em Engenharia Elétrica, Publicação ENE-1/06, Departamento de Engenharia Elétrica, Universidade de Brasília, Brasília, DF, 198p., 2006.

IEEE. Voltage Sags Indices. Draft 2, working document for IEEE P1564 and CIGRE WG 36-07, December 2000, http://grouper.ieee.org/groups/sag/IEEEP1564_01_15.doc.

KOVAL, D. O., .How Long Should Power System Disturbance Site Monitoring Be to Be Significant?., IEEE Transactions on Industry Applications, v. 26, n. 4, p. 705-710, Jul./Aug, 1990.

LEBORGNE, R.C. Uma Contribuição à Caracterização da Sensibilidade de Processos Industriais Frente a Afundamentos de Tensão, Dissertação de Mestrado, Universidade Federal de Itajubá, MG. , 2003

MARTINS, J. S.; AFONSO, J. L. Qualidade da Energia Elétrica. Revista o Electricista, n. 9 p. 66-71, 2004.

MEHL, E. L. M. Qualidade da Energia Elétrica. Curso de pós-graduação em Engenharia Elétrica - Universidade Federal do Paraná, Curitiba, 2002. 
OLESKOVICZ, M.. Qualidade da Energia Elétrica. Curso, USP, São Paulo, 2004

OLIVEIRA, D.. Análise, Quantificação e Qualificação do Desequilíbrio de Tensão.

Relatório de Projeto Final, Universidade de Brasília, DF, 2001.

OLIVEIRA, J.C.D. A Qualidade da Energia Elétrica, 7 ${ }^{a}$ Semana de Engenharia Elétrica, UnB, Brasília, 2005.

OLIVEIRA, M. A. Qualidade da Energia Elétrica. Departamento de Engenharia Elétrica, Faculdade de Tecnologia - Universidade de Brasília, 2005.

ROLIM, T.S.J. Ferramenta Computacional para Análise de Distorções Harmônicas de Tensão, Projeto Final de Graduação - Faculdade de Tecnologia, Departamento de Engenharia Elétrica, Universidade de Brasília, Brasília, DF, 2006.

SILVA, V.F.. Condicionador de Potencia para Aplicação em inversor de freqüência de media tensão. Dissertação de Doutorado, Escola Politécnica, Universidade de São Paulo, São Paulo, 140 p., 2001 


\section{ANEXO I}
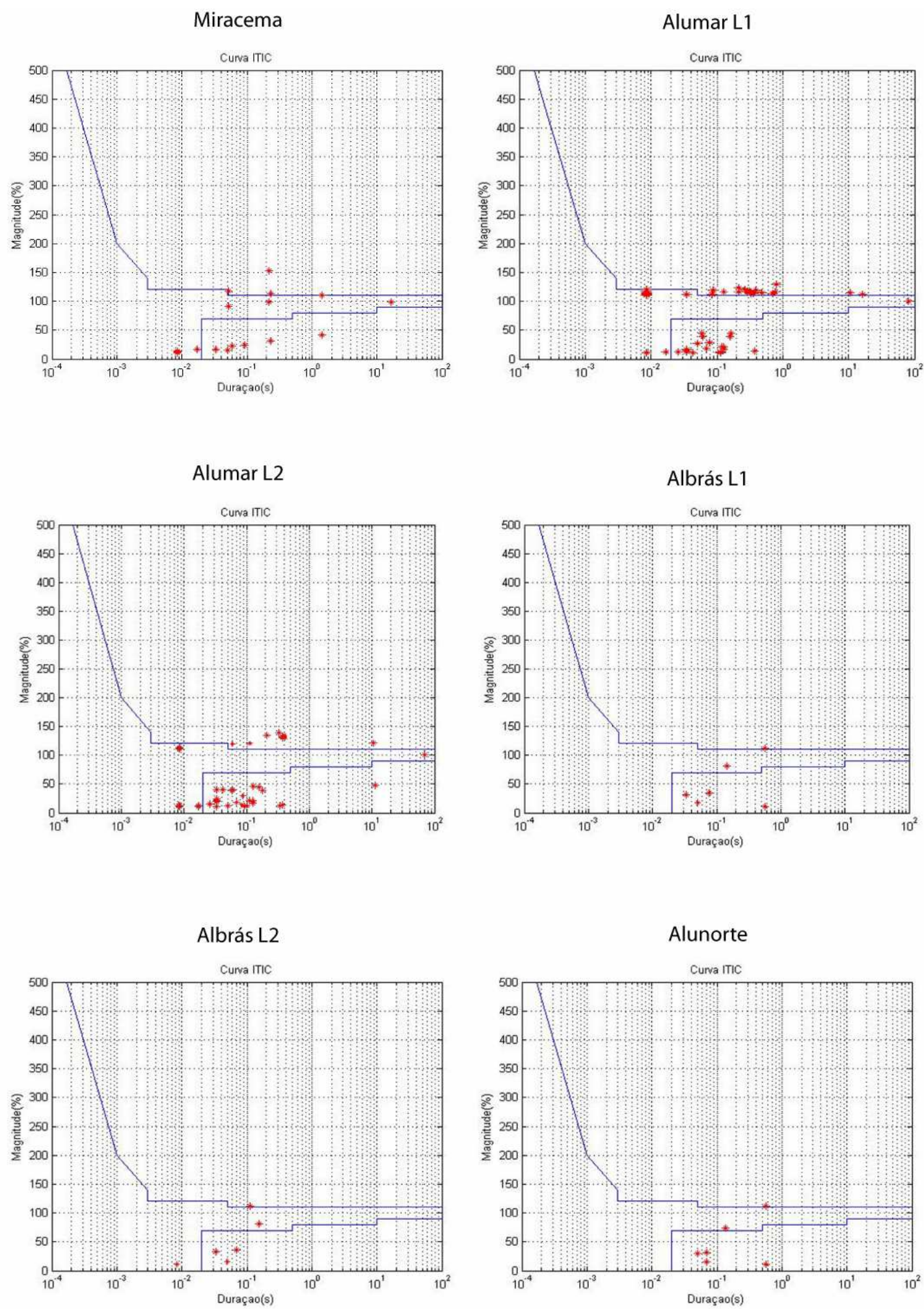

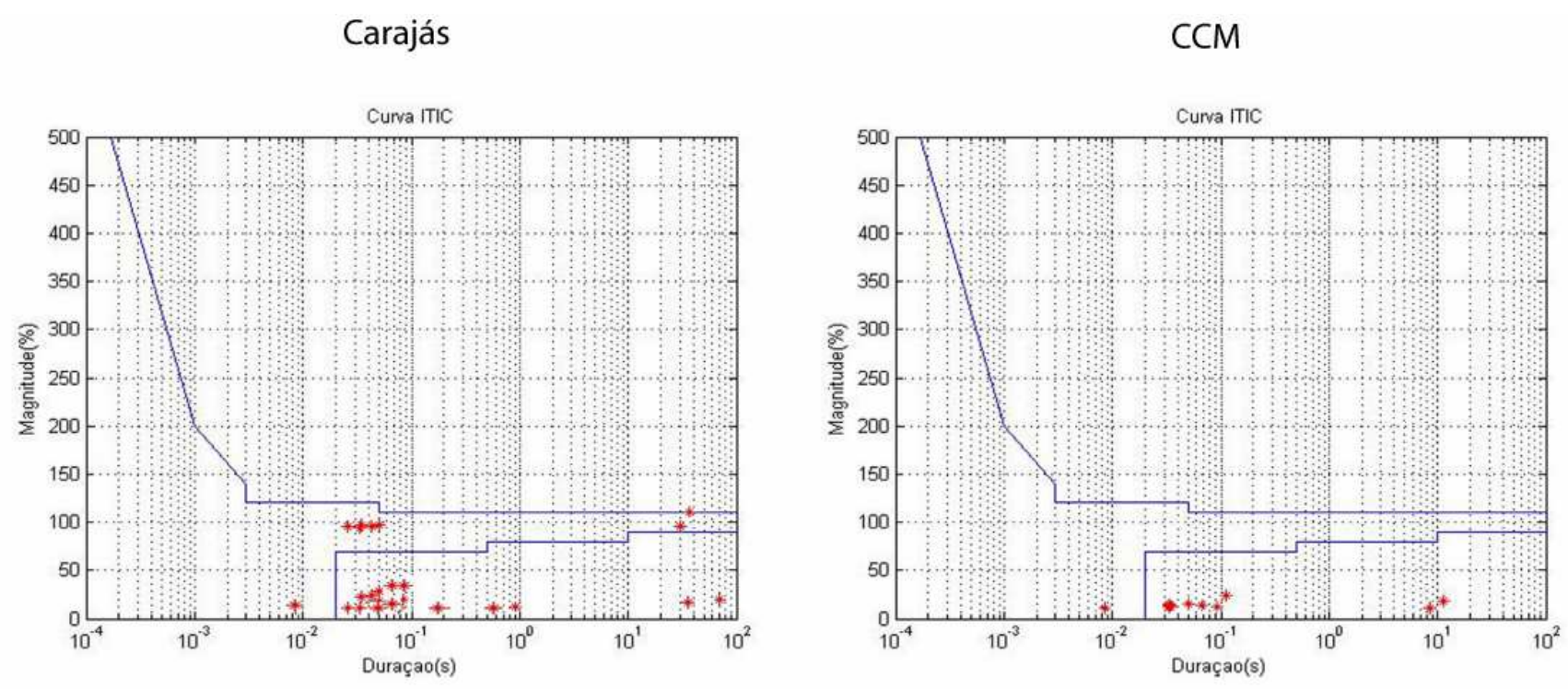

\section{CVLD}
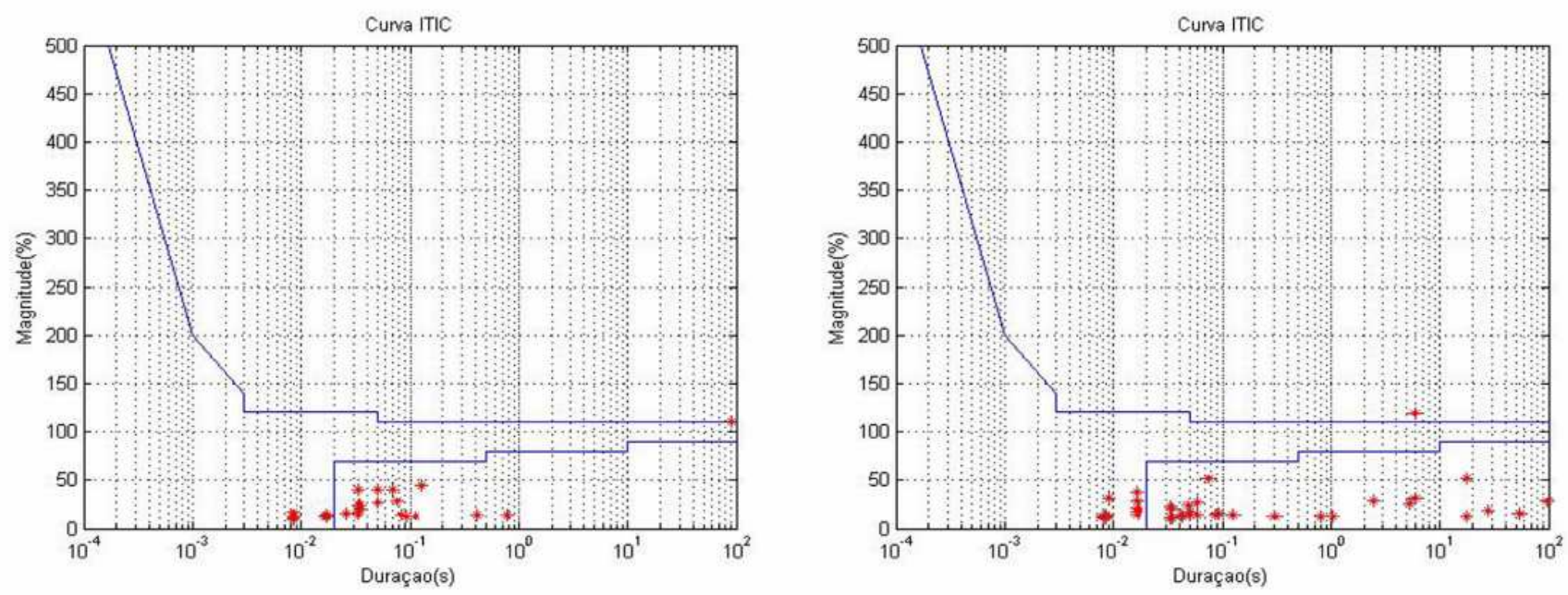

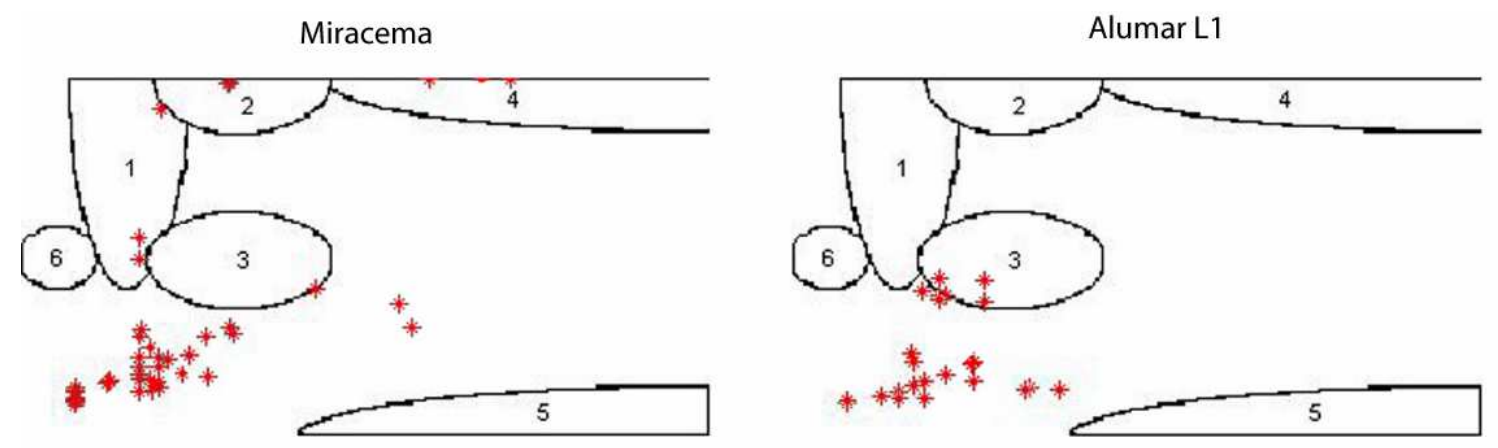

Alumar L2

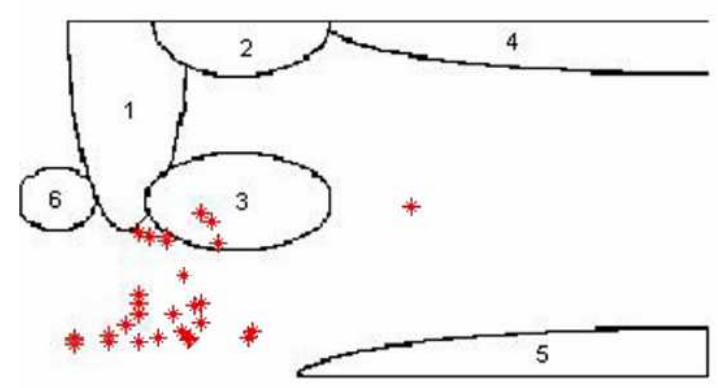

Albrás L1

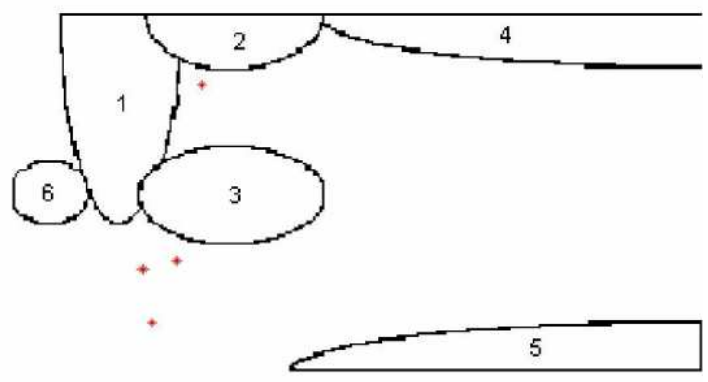

Albrás L2

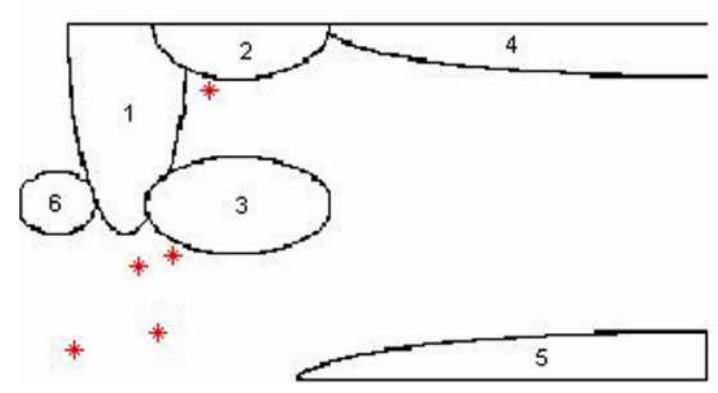

Alunorte

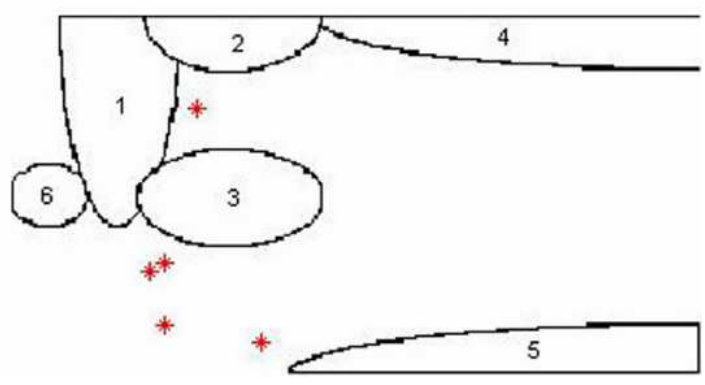



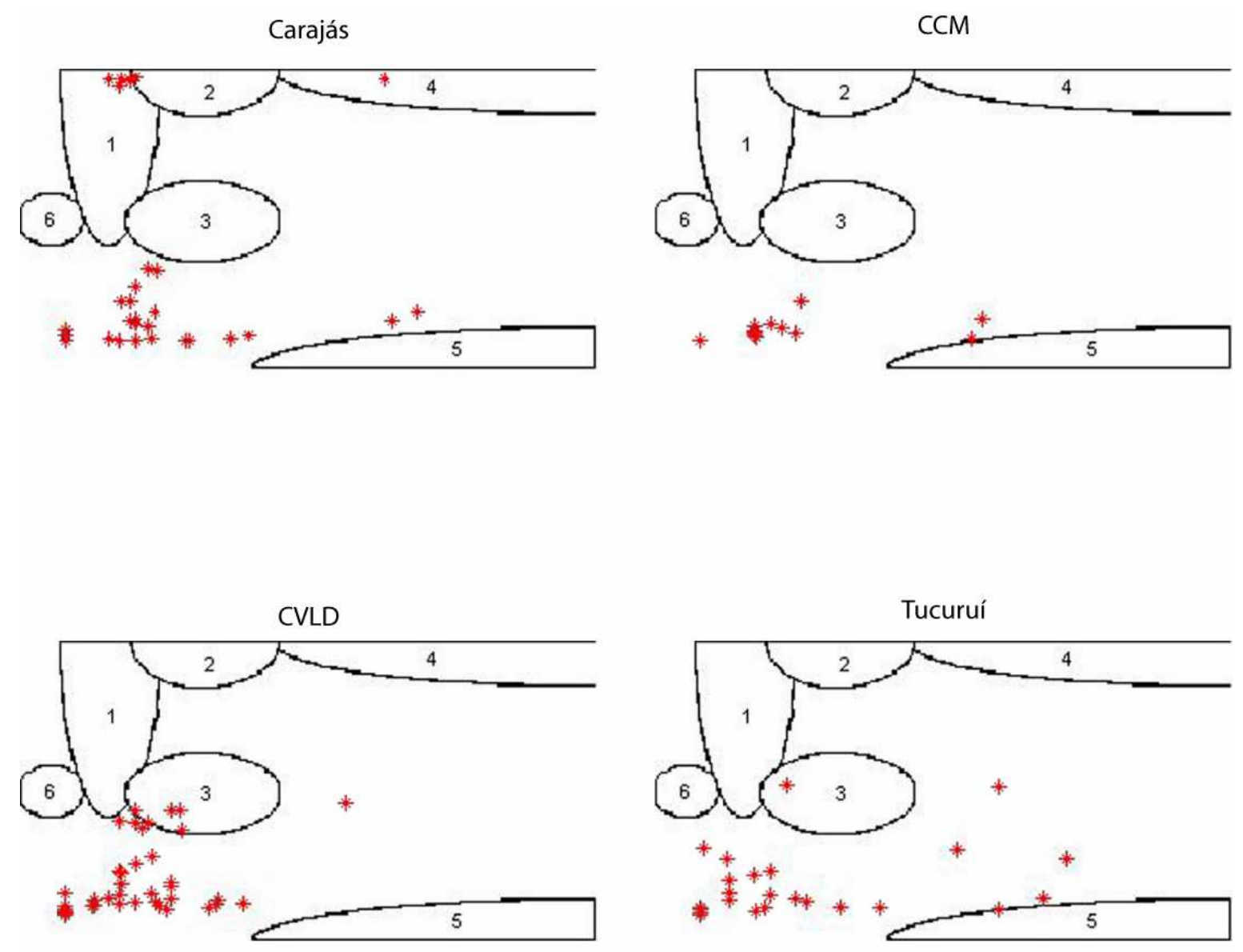